\title{
Liquid-Propellant Rocket Engine Throttling: A Comprehensive Review
}

\author{
Matthew J. Casiano ${ }^{1}$ \\ NASA Marshall Space Flight Center, Huntsville, AL, 35812 \\ James R. Hulka ${ }^{2}$ \\ Jacobs Engineering, ESTS Group, Huntsville, AL, 35812 \\ and \\ Vigor Yang ${ }^{3}$ \\ Georgia Institute of Technology, Atlanta, GA, 30332
}

\begin{abstract}
Liquid-Propellant Rocket Engines (LREs) are capable of on-command variable thrust or thrust modulation, an operability advantage that has been studied intermittently since the late 1930s. Throttleable LREs can be used for planetary entry and descent, space rendezvous, orbital maneuvering including orientation and stabilization in space, and hovering and hazard avoidance during planetary landing. Other applications have included control of aircraft rocket engines, limiting of vehicle acceleration or velocity using retrograde rockets, and ballistic missile defense trajectory control. Throttleable LREs can also continuously follow the most economical thrust curve in a given situation, compared to discrete throttling changes over a few select operating points. The effects of variable thrust on the mechanics and dynamics of an LRE as well as difficulties and issues surrounding the throttling process are important aspects of throttling behavior. This review provides a detailed survey of LRE throttling centered around engines from the United States. Several LRE throttling methods are discussed, including high-pressure-drop systems, dual-injector manifolds, gas injection, multiple chambers, pulse modulation, throat throttling, movable injector components, and hydrodynamically dissipative injectors. Concerns and issues surrounding each method are examined, and the advantages and shortcomings compared.
\end{abstract}

\section{Nomenclature}

$L R E \quad=$ Liquid-Propellant Rocket Engine

\section{Introduction}

I IQUID-Propellant Rocket Engines (LREs) with thrust that can be varied by command have been evaluated since Lthe late 1930s. The Vision for Space Exploration, ${ }^{1}$ outlined in the National Aeronautics and Space Administration Authorization Act of $2005,{ }^{2}$ brought a renewed interest to such throttle capable LREs. The Act established a program to develop sustained human presence on the Moon as a stepping-stone to future exploration of Mars and other remote destinations. ${ }^{2}$ Throttleable LREs will undoubtedly play a significant role in these missions, so understanding the dynamics of throttling LREs as well as the issues of the throttling process will be of critical importance for the success of these missions. This review provides a detailed survey of LRE throttling centered around engines from the United States.

The term 'throttling' is commonly used to describe a varying thrust profile or thrust modulation in an LRE. This nomenclature is used primarily because one of the most common methods of thrust control in an LRE is from regulation of propellant flow rates by control valves. While throttling an LRE is a critical requirement during a

\footnotetext{
${ }^{1}$ Aerospace Engineer, Propulsion Systems Department, Mailstop ER42, Senior Member.

${ }^{2}$ Engineering Specialist, Propulsion Systems Department, Mailstop ER32, Senior Member.

${ }^{3}$ Department Chair, School of Aerospace Engineering, 313 Montgomory Knight Building, Fellow.
} 
lunar descent, there are many other applications for throttleable LREs. A throttleable LRE that continuously follows the most economical thrust curve provides optimum vehicle performance compared to discrete throttling changes over a few percent of the rated power level. The continually changing thrust reduces the amount of propellants required for a mission, thus reducing the mass of the vehicle. Throttleable LREs can also be used for planetary entry and descent, space rendezvous, orbital maneuvering including orientation and stabilization in space, and hovering and hazard avoidance during planetary landing. ${ }^{3-5}$ Other applications include control of aircraft rocket engines, limiting of vehicle acceleration or velocity using retrograde rockets, and ballistic missile defense trajectory control. ${ }^{6}$ An early attempt at estimating throttling requirements for several such missions reported examples such as 10-to-1 throttling for lunar descent, 1.3-to-1 for Venus launch, and up to 100-to-1 for ballistic missiles and orbital rendezvous with generally higher throttling ratios for more precise trajectory control. ${ }^{7,8}$ LREs can be customized for particular flight applications, including a wide range of thrust values, quick restarts, fast pulsing, and quick attitude changes and minor velocity changes. References [3] and [9] describe other benefits of LREs, in general, including that the thrust can be varied on command, which allows further tailoring of the flight application. While thrust profiles of rocket engines with solid propellants have become more flexible, LREs are still much simpler to develop randomly-commanded controllable thrust profiles, since the combustion process is easier to control, stop, and restart.

Throttleable LREs were originally developed during rocket aircraft experiments and research in Germany in the late 1930s headed by Major-General Dr. Walter Dornberger (then Major) and Hellmuth Walter. The first aircraft to incorporate LREs for propulsion during a portion of the flight was the German Heinkel He 112 fighter aircraft in early 1937 at Neuhardenberg airfield, ${ }^{\mathbf{1 0}, 11}$ powered by a version of an A2 (Aggregate 2) rocket motor. This rocket motor, designed by Dr. Wernher von Braun, was fitted to the He 112 aircraft and fueled from nitrogen-pressurized alcohol and liquid oxygen tanks. ${ }^{11}$ As an aside, there are reports and testimonies that describe conflicting dates, places, and events during the mid-to-late 1930s. ${ }^{12-18}$ However, the matters of which aircraft, which engine, and what date for the first rocket powered aircraft flight are corroborated by testimony from Heinkel, Dornberger, and von Braun to have occurred as previously described. ${ }^{11}$ In November of 1937, another Heinkel He 112 aircraft was flown at Neuhardenberg. During a portion of its flight it used a TP-1 (Turbopump-1) rocket engine, designed and built by Hellmuth Walter. An $80 \%$-concentration solution of $\mathrm{H}_{2} \mathrm{O}_{2}\left(20 \%\right.$ concentration $\left.\mathrm{H}_{2} \mathrm{O}\right)$ was forced into the combustion chamber and mixed with a spray catalyst (water solution of sodium or calcium permanganate). A manual pilotoperated stop-cock pneumatically regulated the flow of the $\mathrm{H}_{2} \mathrm{O}_{2}$ solution to the combustion chamber. ${ }^{11}$ The maximum thrust was $220 \mathrm{lbs}$ with an unknown amount of throttling, but this was the first known rocket engine to incorporate manual thrust throttling. ${ }^{17,19}$ Prior to 1937 , LREs were predominantly used by the early pioneers for experimental and meteorological research rockets; these LREs operated at essentially constant thrust. ${ }^{3}$ In April of 1938, the Heinkel He 112 became the first aircraft to be powered by rocket thrust alone through its entire takeoff and flight at Peenemünde West airfield using the throttleable Walter-designed TP-1 engine. ${ }^{11,19}$ The research on throttling engines, after these pioneering works, focused on applicability to missile defense, weapons systems, and then space vehicles. ${ }^{7,8,20}$

There are several methods identified that can control thrust of an LRE. Dressler describes nine methods that have been used in past configurations. ${ }^{19}$ Many of these methods were described conceptually as early as $1950^{\mathbf{2 1}}$ and several others in $1963 .^{7}$ Several had been demonstrated by this time, and are all discussed in this review. Several methods are also discussed in Russian texts with attention to the details of injector element design. The nine methods mentioned in [19] will be discussed in more detail in this paper.

There are only a few physical parameters that can be varied to change the thrust of a single engine, including the propellant types or compositions, the propellant flow rates, the nozzle exit area, and the nozzle throat area. The propellants and nozzle exit area are difficult to control or vary due to physical restrictions, while the nozzle throat area is difficult to vary if the heat fluxes are high. Consequently, varying the propellant flow rates is found to be the simplest recourse to varying thrust. The simple relationship between thrust and propellant flow rates comes from the rocket thrust equation,

$$
F_{T}=\dot{m} \cdot v_{e}+\left(p_{e}-p_{a}\right) \cdot A_{e}
$$

This paper discusses several LRE throttling methods, including high-pressure-drop systems using propellant flow regulation, dual-manifold injectors, gas injection, multiple chambers, pulse modulation, throat throttling, movable injector components, and hydrodynamically dissipative injectors. Several significant projects and studies are discussed. Critical issues such as combustion instability, ${ }^{22}$ performance degradation, and excessive heat transfer 
are examined for each method. Any further concerns and issues surrounding each method are examined, and the advantages and shortcomings of the different methods are compared.

\section{Discussion}

A top level summary of pertinent information from the reviewed projects, research tasks, and investigations are combined in Table I. The following sections review each of the throttling methods.

\section{A. High-Pressure-Drop Injectors}

A typical LRE with a single, fixed-geometry injector can generally be throttled approximately 2 -to-1 or 3-to- 1 .

19 To accommodate deep throttling requirements - often 5-to-1 or more - with a fixed-geometry injector, higherthan-usual injector pressure drops or head losses are necessary to maintain a minimum injector pressure drop at minimum thrust. A satisfactory minimum injector pressure drop is required to ensure adequate resistance for system stability and to ensure sufficient mixing and atomization for good performance. In general, experience and analysis have shown that a nominal injector stiffness $\left(\Delta \mathrm{p}_{\mathrm{inj}} / \mathrm{p}_{\mathrm{c}}\right)$ should be around $15 \%$ to $20 \%$ to avoid combustion instability, but can range from $5 \%$ to $25 \%$ depending on injector type and thermodynamic conditions. ${ }^{\mathbf{1 9}, 23}$

The primary advantage of a fixed-geometry injector is simplicity. Flow of propellants can be regulated by control valves in the propellant lines. Propellants can also be regulated using variable area cavitating venturis. ${ }^{24,25}$ However, since injector stiffness varies linearly with flow rate for liquid propellants, a $5 \%$ minimum $\Delta \mathrm{p}_{\mathrm{inj}} / \mathrm{p}_{\mathrm{c}}$ at $10 \%$ thrust would require $50 \% \Delta \mathrm{p}_{\mathrm{inj}} / \mathrm{p}_{\mathrm{c}}$ at $100 \%$ thrust. Thus the primary disadvantage of a high-pressure-drop injector is a high supply pressure requirement imposed on the pressurization system, tankage, and turbomachinery. ${ }^{19}$

\section{Project Thumper (1948) ${ }^{26}$}

Project Thumper, a program in the United States to develop high-altitude antiaircraft ballistic missile defense against the German V-2 rockets, investigated early rocket engine throttling, including instabilities during throttling operation, throttling engine performance, and the limits of rocket engine throttling. ${ }^{27}$ A low-pressure-drop injector and several iterations of high-pressure-drop showerhead injectors were evaluated. Initial tests with the lowpressure-drop injector developed externally observed oscillations between $10 \mathrm{~Hz}$ and $20 \mathrm{~Hz}$, called motorboating, at low thrust conditions. These oscillations were eliminated with a high-pressure-drop injector, and this injector was speculated to have eliminated liquid oxygen boiling in the manifold, damping pressure perturbations in the chamber by increasing the resistance of the injector, and/or decreasing combustion transients at the injector face. Additionally, erratic irregular fluctuations, called chugging, were encountered during testing below 65 psia chamber pressure. The chugging was described to be like an engine operating intermittently, such as an explosion-cycle thrust chamber, and was attributed to pressure oscillations causing intermittent oxygen vaporization in the injection orifice. A transition between smooth combustion, motorboating, and then chugging was observed as chamber pressure continued to decrease. A high frequency instability between $1100 \mathrm{~Hz}$ and $1500 \mathrm{~Hz}$, called whistling, was present in most of the tests with the high-pressure-drop injector.

The performance over the throttling range generally agreed with theoretical model trends. The characteristic velocity efficiency is shown in Fig. 1. However a significant reduction in performance occurred at less than roughly $30 \%$ chamber pressure. Higher than expected propellant flow was observed to be necessary at low thrust and was explained to be due to poorer combustion at the lower chamber pressures. The various configurations plotted in Fig. 1 examined the effect on nozzle area expansion, chamber length, throat diameter, and injector modifications.

Heat transfer rates remained constant over most of the throttling range down to roughly $59 \%$ chamber pressure. Below this, the heat transfer rate dropped off and was assumed to be due to separating flow in the nozzle. At 56\% chamber pressure using the low-pressure-drop injector and at $87 \%$ chamber pressure using the high-pressure-drop injector, the heat transfer rates increased $2.5 \mathrm{x}$ to $3 \mathrm{x}$ over normal, which was correlated to a $300 \mathrm{~Hz}$ oscillation in the external environment, but it was not understood whether this was a cause or a symptom of the high heat transfer. Below roughly $30 \%$ chamber pressure, fuel coolant was projected to vaporize in the regeneratively cooled engines. To prevent vaporization of the coolant, the engine was required to operate with a low mixture ratio. This helped prevent roughness, burnout, or cessation of operation due to fuel vaporization in the coolant jacket. 
Table I. Summary of Information from Reviewed Projects, Research Tasks, and Investigations

\begin{tabular}{|c|c|c|c|c|c|c|c|c|}
\hline $\begin{array}{l}\text { Throttling } \\
\text { Methodology }\end{array}$ & Program & $\begin{array}{l}\text { Program } \\
\text { Period }\end{array}$ & Organizations & $\begin{array}{c}\text { Engine/ } \\
\text { Rocket } \\
\text { Designations }\end{array}$ & Operating Parameters & Throttling & $\begin{array}{c}\text { Propellant } \\
\text { Combinations/ } \\
\text { Injector Type }\end{array}$ & $\begin{array}{l}\text { Throttling Related } \\
\text { Research Focus }\end{array}$ \\
\hline $\begin{array}{l}\text { High-Pressure- } \\
\text { Drop Injector }\end{array}$ & $\begin{array}{l}\text { Project } \\
\text { Thumper }\end{array}$ & $\begin{array}{l}1948- \\
1949\end{array}$ & $\begin{array}{l}\text { - General Electric } \\
\text { - US Army }\end{array}$ & - Malta Engine & $\begin{array}{l}\text { - } 1000 \text { lbs rated thrust, } \\
315 \text { psia rated } \mathrm{p}_{\mathrm{c}}\end{array}$ & - $10 \%$ to $104 \%$ & $\begin{array}{l}\text { - Ethanol (with } \\
\text { silicone)/ LO } 2 \\
\text { - Malta Low-Pressure- } \\
\text { Drop Injector } \\
\text { - High-Pressure-Drop } \\
\text { Showerhead }\end{array}$ & $\begin{array}{l}\text { - Pursue development of } \\
\text { high-altitude antiaircraft } \\
\text { defense }\end{array}$ \\
\hline $\begin{array}{l}\text { High-Pressure- } \\
\text { Drop Injector }\end{array}$ & $\begin{array}{l}\text { Project MX- } \\
794\end{array}$ & 1950 & $\begin{array}{l}\text { - Willow Run Research } \\
\text { Institute, University } \\
\text { of Michigan } \\
\text { - USAF }\end{array}$ & $\begin{array}{l}\text { - Engine } 0073 \\
\text { - Engine } 0150 \\
\text { - Engine } 0151\end{array}$ & $\begin{array}{l}\text { - } 1000 \mathrm{lbs} \text { rated thrust, } \\
300 \text { psia rated } \mathrm{p}_{\mathrm{c}}, 2.75 \\
\text { MR } \\
\text { - } 200 \mathrm{lbs} \text { rated thrust, } 300 \\
\text { psia rated } \mathrm{p}_{\mathrm{c}}, 2.75 \mathrm{MR}\end{array}$ & $\begin{array}{l}\text { - } 10 \% \text { to } 167 \% \\
\text { - } 33 \% \text { to } 210 \% \\
\text { - } 2.25<\mathrm{MR}<5.0\end{array}$ & $\begin{array}{l}\text { - } 80 \% \text { RFNA and } 20 \% \\
\text { aniline / furfuryl } \\
\text { alcohol } \\
\text { - JP-3 (AN-F-58a) } \\
\text { (with aniline leader) / } \\
\text { RFNA } \\
\text { - Doublet and OFO } \\
\text { triplet } \\
\end{array}$ & $\begin{array}{l}\text { - Obtain performance for } \\
\text { defense systems }\end{array}$ \\
\hline $\begin{array}{l}\text { High-Pressure- } \\
\text { Drop Injector }\end{array}$ & NASA Study & 1964 & $\begin{array}{l}\text { - NASA Lewis } \\
\text { Research Center } \\
\text { - Pratt \& Whitney } \\
\text { Aircraft }\end{array}$ & $\begin{array}{l}\text { - Modified } \\
\text { RL10A-1 }\end{array}$ & $\begin{array}{l}\text { - } 15000 \mathrm{lbs} \text { rated thrust, } \\
300 \text { psia rated } \mathrm{p}_{\mathrm{c}}, 5.0 \\
\text { MR }\end{array}$ & $\begin{array}{l}\text { - } 3.3 \% \text { to } 100 \% \\
\text { - } 2.0<\mathrm{MR}<6.0\end{array}$ & $\begin{array}{l}\text { - } \mathrm{LH}_{2} / \mathrm{LO}_{2} \\
\text { - } \text { Swirl coax - } 20 \% \text { ox } \\
\text { pressure drop } \\
\text { - } \text { Shear coax - } 33 \% \text { ox } \\
\text { pressure drop } \\
\text { - Swirl coax - } 60 \% \text { ox } \\
\text { pressure drop }\end{array}$ & $\begin{array}{l}\text { - Obtain steady-state and } \\
\text { dynamic characteristics } \\
\text { during throttling }\end{array}$ \\
\hline $\begin{array}{l}\text { High-Pressure- } \\
\text { Drop Injector }\end{array}$ & $\begin{array}{l}\text { ARES } \\
\text { Throttling- } \\
\text { Scaling Design } \\
\text { Study } \\
\text { Program* }\end{array}$ & $\begin{array}{l}1967- \\
1969\end{array}$ & $\begin{array}{l}\text { - Aerojet-General Corp. } \\
\text { - Air Force Rocket } \\
\text { Propulsion } \\
\text { Laboratory } \\
\text { - NASA Marshall } \\
\text { Space Flight Center }\end{array}$ & $\begin{array}{l}\text { - ARES } \\
\text { Engine } \\
\text { Design* }\end{array}$ & $\begin{array}{l}25000 \mathrm{lbs}, 100000 \mathrm{lbs} \\
\text { or } 500000 \mathrm{lbs} \text { rated } \\
\text { thrust, } 2800 \text { psia rated } \\
\mathrm{p}_{\mathrm{c}}{ }^{*}\end{array}$ & $\begin{array}{l}\text { - } 10 \text {-to-1* } \\
\text { - } 33 \text {-to-1* }\end{array}$ & $\begin{array}{l}\text { - A-50/ } \mathrm{N}_{2} \mathrm{O}_{4} * \\
\text { - HIPERTHIN platelet* }\end{array}$ & $\begin{array}{l}\text { - Design a throttleable and } \\
\text { restartable engine }\end{array}$ \\
\hline $\begin{array}{l}\text { High-Pressure- } \\
\text { Drop Injector }\end{array}$ & $\begin{array}{l}\text { DC-X and DC- } \\
\text { XA }\end{array}$ & $\begin{array}{l}1991- \\
1995\end{array}$ & $\begin{array}{l}\text { - Pratt \& Whitney } \\
\text { - McDonnell Douglas } \\
\text { - NASA }\end{array}$ & - RL10A-5 & $\begin{array}{l}\text { - } 13500 \text { lbs rated thrust, } \\
485 \text { psia rated } \mathrm{p}_{\mathrm{c}}, 6.0 \\
\text { MR }\end{array}$ & $\begin{array}{l}\text { - } 3.3 \text {-to- } 1 \\
\text { - } 5.0<\mathrm{MR}<6.0\end{array}$ & $\begin{array}{l}\text { - } \mathrm{LH}_{2} / \mathrm{LO}_{2} \\
\text { - } \mathrm{Swirl} \text { coax }\end{array}$ & $\begin{array}{l}\text { - Single-stage to orbit rocket } \\
\text { technology demonstrator }\end{array}$ \\
\hline $\begin{array}{l}\text { High-Pressure- } \\
\text { Drop Injector }\end{array}$ & $\begin{array}{l}\text { Joint } \\
\text { Cooperative } \\
\text { Study }\end{array}$ & 1996 & $\begin{array}{l}\text { - NASA Marshall } \\
\text { Space Flight Center } \\
\text { - Aerojet } \\
\text { - Chemical Automatics } \\
\text { Design Bureau } \\
\text { (CADB) } \\
\end{array}$ & - $\mathrm{RD}-0120$ & $\begin{array}{l}\text { - } 441000 \mathrm{lbs} \text { rated thrust, } \\
3170 \text { psia rated } \mathrm{p}_{\mathrm{c}}, 6.0 \\
\text { MR }\end{array}$ & $\begin{array}{l}\text { - } 25 \% \text { to } 100 \% \\
\text { - } 3.7<\mathrm{MR}<6.4\end{array}$ & $\begin{array}{l}\text { - } \mathrm{LH}_{2} / \mathrm{LO}_{2} \\
\text { - Shear coax }\end{array}$ & $\begin{array}{l}\text { Potential use for the X-33 } \\
\text { demonstrator vehicle } \\
\text { propulsion system }\end{array}$ \\
\hline $\begin{array}{l}\text { High-Pressure- } \\
\text { Drop Injector }\end{array}$ & $\begin{array}{l}\text { Joint } \\
\text { Cooperative } \\
\text { Study }\end{array}$ & 1997 & $\begin{array}{l}\text { - } \text { Boeing Rocketdyne } \\
\text { - NASA Marshall } \\
\text { Space Flight Center }\end{array}$ & - SSME & $\begin{array}{l}\text { - } 470000 \text { lbs rated thrust, } \\
3006 \text { psia rated } \mathrm{p}_{\mathrm{c}}, 6.0 \\
\text { MR }\end{array}$ & $\begin{array}{l}\text { - } 17 \% \text { to } 109 \% \\
\text { - } 5.0<\mathrm{MR}<6.0\end{array}$ & $\begin{array}{l}\text { - } \mathrm{LH}_{2} / \mathrm{LO}_{2} \\
\text { - Swirl coax }\end{array}$ & $\begin{array}{l}\text { Potential use for the X-33 } \\
\text { demonstrator vehicle } \\
\text { propulsion system }\end{array}$ \\
\hline $\begin{array}{l}\text { High-Pressure- } \\
\text { Drop Injector }\end{array}$ & $\begin{array}{l}\text { Common } \\
\text { Extensible } \\
\text { Cryogenic } \\
\text { Engine }\end{array}$ & $\begin{array}{l}2005- \\
\text { current }\end{array}$ & $\begin{array}{l}\text { - Pratt \& Whitney } \\
\text { Rocketdyne } \\
\text { - NASA }\end{array}$ & $\begin{array}{l}\text { - Modified } \\
\text { RL10 }\end{array}$ & $\begin{array}{l}13700 \text { lbs rated thrust, } \\
381 \text { psia rated } \mathrm{p}_{\mathrm{c}}, 5.6 \\
\text { MR }\end{array}$ & $\begin{array}{l}\text { - } 9.5 \% \text { to } 100 \% \\
\text { - } 2.9<\mathrm{MR}<6.0\end{array}$ & $\begin{array}{l}\text { - } \mathrm{LH}_{2} / \mathrm{LO}_{2} \\
\text { - } \mathrm{Swirl} \text { coax }\end{array}$ & $\begin{array}{l}\text { Technology development, } \\
\text { demonstration, risk } \\
\text { reduction, and maturation } \\
\text { of a deep throttling, highly }\end{array}$ \\
\hline
\end{tabular}




\begin{tabular}{|c|c|c|c|c|c|c|c|c|}
\hline & & & & & & & & $\begin{array}{l}\text { reliable, reusable cryogenic } \\
\text { engine }\end{array}$ \\
\hline $\begin{array}{l}\text { Dual-Manifold } \\
\text { Injector }\end{array}$ & $\begin{array}{l}\text { Advanced } \\
\text { Throttling } \\
\text { Concepts } \\
\text { Studies }\end{array}$ & $\begin{array}{l}1963- \\
1966\end{array}$ & $\begin{array}{l}\text { - Pratt \& Whitney } \\
\text { Aircraft } \\
\text { - United Technology } \\
\text { Center } \\
\text { - US Air Force } \\
\end{array}$ & $\begin{array}{l}\text { - Research } \\
\text { Engine }\end{array}$ & $\begin{array}{l}\text { - } 15000 \mathrm{lbs} \text { rated thrust, } \\
300 \text { psia rated } \mathrm{p}_{\mathrm{c}}, 1.7 \\
\mathrm{MR} \\
\text { - } 1000 \mathrm{lbs} \text { rated thrust } \\
\text { - } 8500 \mathrm{lbs} \text { rated thrust } \\
\end{array}$ & $\begin{array}{l}\text { - } 0.8 \% \text { to } 108 \% \\
\text { - } 12.8 \text {-to-1 } \\
\text { - } 29.4 \text {-to-1 }\end{array}$ & $\begin{array}{l}\text { - } \mathrm{A}-50 / \mathrm{N}_{2} \mathrm{O}_{4} \\
\text { - } \mathrm{H}_{2} / \mathrm{F}_{2} \\
\text { - } \mathrm{BA} 1014 / \mathrm{F}_{2} * \\
\text { - Triplet element } \\
\text { - Quadruplet element } \\
\end{array}$ & $\begin{array}{l}\text { Evaluate injector systems } \\
\text { that provide high } \\
\text { combustion performance } \\
\text { during deep throttling }\end{array}$ \\
\hline $\begin{array}{l}\text { Dual-Manifold } \\
\text { Injector }\end{array}$ & $\begin{array}{l}\text { Chamber } \\
\text { Technology for } \\
\text { Space Storable } \\
\text { Propellants } \\
\end{array}$ & $\begin{array}{l}1964- \\
1969\end{array}$ & $\begin{array}{l}\text { - Rocketdyne } \\
\text { - NASA }\end{array}$ & $\begin{array}{l}\text { - Research } \\
\text { Engine }\end{array}$ & $\begin{array}{l}\text { - } 1000 \text { lbs rated thrust, } \\
100 \text { psia rated } \mathrm{p}_{\mathrm{c}}, 2.0 \\
\text { MR }\end{array}$ & - $15 \%$ to $150 \%$ & $\begin{array}{l}\text { - MMH, butene-1, and } \\
\text { diborane / FLOX } \\
\text { - Oxygen difluoride } \\
\text { - Impinging } \\
\end{array}$ & $\begin{array}{l}\text { - Develop design criteria for } \\
\text { selected space storable fuels }\end{array}$ \\
\hline $\begin{array}{l}\text { Dual-Manifold } \\
\text { Injector }\end{array}$ & $\begin{array}{l}\text { Reusable } \\
\text { Rocket Engine } \\
\text { Program }\end{array}$ & $\begin{array}{l}1967- \\
1972\end{array}$ & $\begin{array}{l}\text { - Pratt \& Whitney } \\
\text { Aircraft } \\
\text { - Air Force Rocket } \\
\text { Propulsion } \\
\text { Laboratory } \\
\end{array}$ & $\begin{array}{l}\text { - Advanced } \\
\text { Cryogenic } \\
\text { Engine } \\
\text { - XLR-129-P-1 }\end{array}$ & $\begin{array}{l}\text { - } 250000 \text { lbs rated thrust } \\
\text { - } 2740 \mathrm{psia} \text { main chamber } \\
\text { rated } \mathrm{p}_{\mathrm{c}} \\
\text { - } 4793 \mathrm{psia} \text { preburner } \\
\text { rated } \mathrm{p}_{\mathrm{c}} \\
\end{array}$ & \begin{tabular}{|l} 
- 5 -to- 1 \\
- $5<\mathrm{MR}<7$ \\
main injector \\
- $0.72<\mathrm{MR}<$ \\
1.26 preburner \\
\end{tabular} & $\begin{array}{l}\text { - } \mathrm{LH}_{2} / \mathrm{LO}_{2} \\
\text { - Stacked tangential } \\
\text { inlet }\end{array}$ & $\begin{array}{l}\text { - Demonstrate performance } \\
\text { and mechanical integrity of } \\
\text { rocket engine }\end{array}$ \\
\hline $\begin{array}{l}\text { Dual-Manifold } \\
\text { Injector }\end{array}$ & $\begin{array}{l}\text { Throttleable } \\
\text { Primary } \\
\text { Injector for } \\
\text { Staged } \\
\text { Combustion } \\
\text { Engine } \\
\text { Program } \\
\end{array}$ & $\begin{array}{l}1968- \\
1970\end{array}$ & $\begin{array}{l}\text { - Aerojet-General Corp. } \\
\text { - Air Force Rocket } \\
\text { Propulsion } \\
\text { Laboratory }\end{array}$ & $\begin{array}{l}\text { - MIST } \\
\text { derived }\end{array}$ & - $50000 \mathrm{lbs}$ rated thrust & - $10 \%$ & $\begin{array}{l}\text { - } \mathrm{A}-50 / \mathrm{N}_{2} \mathrm{O}_{4} \\
\text { - } \mathrm{HIPERTHIN} \text { platelet, } \\
\text { impinging oxidizer/ } \\
\text { impinging fuel }\end{array}$ & $\begin{array}{l}\text { - Develop design criteria for } \\
\text { selected space storable fuels }\end{array}$ \\
\hline $\begin{array}{l}\text { Dual-Manifold } \\
\text { Injector }\end{array}$ & $\begin{array}{l}\text { Advanced } \\
\text { Expander Test } \\
\text { Bed Program }\end{array}$ & $\begin{array}{l}1990- \\
1993 \\
1996- \\
1997\end{array}$ & $\begin{array}{l}\text { - Pratt \& Whitney } \\
\text { - NASA }\end{array}$ & $\begin{array}{l}\text { - Expander } \\
\text { cycle engine }\end{array}$ & $\begin{array}{l}\text { - } 20000 \mathrm{lbs} \text { rated thrust } \\
\text { - } 25000 \mathrm{lbs} \text { rated thrust }\end{array}$ & - Proprietary & $\begin{array}{l}\text { - } \mathrm{H}_{2} / \mathrm{LO}_{2} \\
\text { - swirl coax }\end{array}$ & $\begin{array}{l}\text { - Develop and demonstrate an } \\
\text { expander cycle oxygen- } \\
\text { hydrogen engine } \\
\text { technology applicable for } \\
\text { space engines }\end{array}$ \\
\hline Gas Injection & $\begin{array}{l}\text { NACA } \\
\text { Research }\end{array}$ & $\begin{array}{l}1956- \\
1957\end{array}$ & $\begin{array}{l}\text { - NACA Lewis Flight } \\
\text { Propulsion } \\
\text { Laboratory } \\
\end{array}$ & $\begin{array}{l}\text { - Research } \\
\text { Engine }\end{array}$ & $\begin{array}{l}\text { - } 1000 \mathrm{lbs} \text { rated thrust } \\
\text { - Helium gas }\end{array}$ & $\begin{array}{ll}\text { - } 34 \%-89 \% \\
\text { - } 1.3<\mathrm{MR}<2.4 \\
\end{array}$ & $\begin{array}{l}\text { - } \mathrm{NH}_{3} \text { (with lithium)/ } \\
\text { WFNA } \\
\text { - Doublet } \\
\end{array}$ & $\begin{array}{l}\text { - Investigation into gas } \\
\text { injection throttling }\end{array}$ \\
\hline Gas Injection & $\begin{array}{l}\text { Feasibility } \\
\text { Study and } \\
\text { Experimental } \\
\text { Program }\end{array}$ & 1963 & $\begin{array}{l}\text { - United Technology } \\
\text { Center }\end{array}$ & $\begin{array}{l}\text { - Research } \\
\text { Engine }\end{array}$ & $\begin{array}{l}\text { - } 500 \mathrm{lbs} \text { rated thrust, } 300 \\
\text { psia } \mathrm{p}_{\mathrm{c}} \\
\text { - } 500 \mathrm{lbs} \text { rated thrust, } 150 \\
\text { psia } \mathrm{p}_{\mathrm{c}} \\
\text { - Helium gas }\end{array}$ & - $6 \%$ to $223 \%$ & $\begin{array}{l}\text { - } \mathrm{MMH} / \mathrm{MON}-15 \\
\text { - A-50 / } \mathrm{N}_{2} \mathrm{O}_{4} \\
\text { - } \\
\text { Triplet FOF, duo- } \\
\text { doublet FOOF, } \\
\text { showerhead, } 25 \% \\
\text { showerhead / 75\% } \\
\text { duo-doublet } \\
\end{array}$ & $\begin{array}{l}\text { - Investigation into gas } \\
\text { injection throttling using } \\
\text { various injection concepts }\end{array}$ \\
\hline Gas Injection & LMDE Concept & $\begin{array}{l}1963- \\
1965\end{array}$ & - Rocketdyne & - SE-10 & $\begin{array}{l}\text { - } 10500 \text { lbs rated thrust } \\
\text { - Helium gas }\end{array}$ & - 10-to-1 & - A-50 / $\mathrm{N}_{2} \mathrm{O}_{4}$ & $\begin{array}{l}\text { - Competing Apollo lunar } \\
\text { descent engine }\end{array}$ \\
\hline Gas Injection & NASA Study & 1964 & $\begin{array}{l}\text { - NASA Lewis } \\
\text { Research Center } \\
\text { - Pratt \& Whitney } \\
\text { Aircraft }\end{array}$ & - RL10A-1 & $\begin{array}{l}\text { - } 15000 \text { lbs rated thrust, } \\
300 \text { psia rated } \mathrm{p}_{\mathrm{c}}, 5.0 \\
\text { MR } \\
\text { - Helium gas, oxygen gas }\end{array}$ & - 10 -to-1 & $\begin{array}{l}\text { - } \mathrm{LH}_{2} / \mathrm{LO}_{2} \\
\text { - } \text { Swirl coax - } 20 \% \text { ox } \\
\text { pressure drop } \\
\text { - Shear coax - } 33 \% \text { ox } \\
\text { pressure drop } \\
\text { - Swirl coax - } 60 \% \text { ox } \\
\text { pressure drop } \\
\end{array}$ & $\begin{array}{l}\text { - Obtain steady-state and } \\
\text { dynamic characteristics }\end{array}$ \\
\hline Gas Injection & Advanced & 1964 & - Pratt \& Whitney & - Research & - $15000 \mathrm{lbs}$ rated thrust, & - $2 \%$ to $100 \%$ & - A-50 / $\mathrm{N}_{2} \mathrm{O}_{4}$ & - Evaluate injector systems \\
\hline
\end{tabular}




\begin{tabular}{|c|c|c|c|c|c|c|c|c|}
\hline & $\begin{array}{l}\text { Throttling } \\
\text { Concepts Study }\end{array}$ & & $\begin{array}{l}\text { Aircraft } \\
\text { - Air Force }\end{array}$ & Engine & $\begin{array}{l}300 \text { psia rated } \mathrm{p}_{\mathrm{c}}, 1.7 \\
\mathrm{MR} \\
\text { - Cross-injection } \\
\text { combustion gas } \\
\end{array}$ & & & $\begin{array}{l}\text { that provide high } \\
\text { combustion performance } \\
\text { during deep throttling }\end{array}$ \\
\hline Gas Injection & $\begin{array}{l}\text { Throttling } \\
\text { Concept Study }\end{array}$ & 1965 & - Bendix Corporation & $\begin{array}{l}\text { - Research } \\
\text { Engine }\end{array}$ & $\begin{array}{l}\text { - } 14 \mathrm{lbs} \text { rated thrust, } 105 \\
\text { psia rated } \mathrm{p}_{\mathrm{c}} \\
\text { - Nitrogen gas } \\
\end{array}$ & - 35-to-1 & - $\mathrm{A}-50 / \mathrm{N}_{2} \mathrm{O}_{4}$ & $\begin{array}{l}\text { - Evaluate gas injection } \\
\text { technique }\end{array}$ \\
\hline $\begin{array}{l}\text { Multiple } \\
\text { Chambers }\end{array}$ & $\begin{array}{l}\text { Advanced } \\
\text { Thrust } \\
\text { Chamber for } \\
\text { Space } \\
\text { Maneuvering } \\
\text { Propulsion } \\
\text { Program } \\
\end{array}$ & $\begin{array}{l}1965 \\
1967\end{array}$ & $\begin{array}{l}\text { - Rocketdyne } \\
\text { - Air Force Rocket } \\
\text { Propulsion } \\
\text { Laboratory }\end{array}$ & $\begin{array}{l}\text { - Research } \\
\text { Engine }\end{array}$ & $\begin{array}{l}\text { - } 30000 \mathrm{lbs}+3000 \mathrm{lbs} \\
\text { rated thrust } \\
\text { - } 2 \text { chambers }\end{array}$ & - 9-to-1 & - $\mathrm{LH}_{2} / \mathrm{LF}_{2}$ & $\begin{array}{l}\text { - Investigate an advanced } \\
\text { space maneuvering } \\
\text { propulsion system }\end{array}$ \\
\hline $\begin{array}{l}\text { Multiple } \\
\text { Chambers }\end{array}$ & N/A & $\begin{array}{l}1976- \\
1986, \\
1981- \\
1993 \\
\end{array}$ & - Glushko & - RD-170 / & $\begin{array}{l}\text { - } 1777000 \mathrm{lbs} \text { rated thrust } \\
\text { - } 4 \text { chambers }\end{array}$ & - $56 \%$ to $100 \%$ & - $\mathrm{RP}-1 / \mathrm{LO}_{2}$ & $\begin{array}{l}\text { - Russian engine used on } \\
\text { Energia and Zenit vehicles }\end{array}$ \\
\hline $\begin{array}{l}\text { Multiple } \\
\text { Chambers }\end{array}$ & N/A & $\begin{array}{l}1992- \\
1999\end{array}$ & - Glushko & - $\mathrm{RD}-180$ & $\begin{array}{l}\text { - } 933400 \text { lbs rated thrust } \\
\text { - } 2 \text { chambers }\end{array}$ & - $40 \%$ to $100 \%$ & - $\mathrm{RP}-1 / \mathrm{LO}_{2}$ & $\begin{array}{c}\text { - Russian engine used on } \\
\text { Atlas III and Atlas V }\end{array}$ \\
\hline Pulse Modulation & $\begin{array}{l}\text { Lunar Flying } \\
\text { Vehicle Study }\end{array}$ & 1964 & $\begin{array}{l}\text { - Bell Aerospace } \\
\text { Company } \\
\text { - NASA Marshall } \\
\text { Space Flight Center }\end{array}$ & $\begin{array}{l}\text { - Bell model } \\
8414 \\
\text { Throttleable } \\
\text { Maneuvering } \\
\text { Engine }\end{array}$ & $\begin{array}{l}-100 \text { lbs rated thrust, } 80 \\
\text { psia rated } p_{c}\end{array}$ & $\begin{array}{l}\text { - } 1 \% \text { to } 12 \% \text { to } \\
100 \%\end{array}$ & $\begin{array}{l}\text { - A-50/ } \mathrm{N}_{2} \mathrm{O}_{4} \\
\text { - Triplet FOF }\end{array}$ & $\begin{array}{l}\text { - Engine development for use } \\
\text { in Lunar Flying Vehicle } \\
\text { Application }\end{array}$ \\
\hline Throat Throttling & $\begin{array}{l}\text { Reaction } \\
\text { Motors, Inc. } \\
\text { Study } \\
\end{array}$ & 1947 & $\begin{array}{l}\text { - Reaction Motors, Inc. } \\
\text { - Navy }\end{array}$ & $\begin{array}{l}\text { - Research } \\
\text { Engine }\end{array}$ & $\begin{array}{l}\text { - } 2000 \mathrm{lbs} \text { rated thrust, } \\
315 \text { psia rated } \mathrm{p}_{\mathrm{c}}\end{array}$ & $\begin{array}{l}\text { - } 6.25 \text {-to- } 1^{*} \\
\text { - } 60 \%, 75 \% \\
\end{array}$ & - Aniline / acid & $\begin{array}{l}\text { - Design and develop a } \\
\text { variable thrust LRE }\end{array}$ \\
\hline Throat Throttling & $\begin{array}{l}\text { MIT Naval } \\
\text { Supersonic } \\
\text { Laboratory } \\
\text { Study }\end{array}$ & 1961 & $\begin{array}{l}\text { - MIT Naval } \\
\text { Supersonic } \\
\text { Laboratory } \\
\text { - Navy } \\
\end{array}$ & $\begin{array}{l}\text { - Research } \\
\text { Engine }\end{array}$ & $\begin{array}{l}\text { - } 1800 \mathrm{lbs} \text { rated thrust, } \\
300 \text { psia rated } \mathrm{p}_{\mathrm{c}}\end{array}$ & - N/A & - Air & $\begin{array}{l}\text { - Investigate throttling by gas } \\
\text { injection into the nozzle } \\
\text { throat }\end{array}$ \\
\hline $\begin{array}{l}\text { Variable Area } \\
\text { Injector }\end{array}$ & $\begin{array}{l}\text { Variable Thrust } \\
\text { Engine } \\
\text { Development } \\
\text { Program* } \\
\end{array}$ & 1950 & - Reaction Motors, Inc. & $\begin{array}{l}\text { - Research } \\
\text { Engine }\end{array}$ & - 5000 lbs rated thrust* & - 50 -to- $1^{*}$ & $\begin{array}{l}\text { - Hypergolic with } \\
\text { WFNA / WFNA* } \\
\text { - Pintle-type injectors* }\end{array}$ & $\begin{array}{l}\text { - Rocket engine development } \\
\text { to meet the demand for } \\
\text { more flexibility by } \\
\text { continuously variable thrust }\end{array}$ \\
\hline $\begin{array}{l}\text { Variable Area } \\
\text { Injector }\end{array}$ & $\begin{array}{l}\text { Project MX- } \\
794\end{array}$ & 1951 & $\begin{array}{l}\text { - Willow Run Research } \\
\text { Center University of } \\
\text { Michigan } \\
\text { - USAF }\end{array}$ & - Engine 0151 & $\begin{array}{l}\text { - } 200 \mathrm{lbs} \text { rated thrust, } 300 \\
\text { psia rated } \mathrm{p}_{\mathrm{c}}, 2.75 \mathrm{MR} \\
\text { - } 600 \mathrm{lbs} \text { rated thrust, } 300 \\
\text { psia rated } \mathrm{p}_{\mathrm{c}} \\
\text { - } 3000 \mathrm{lbs} \text { rated thrust, } \\
300 \mathrm{psia} \text { rated } \mathrm{p}_{\mathrm{c}}\end{array}$ & $\begin{array}{l}\text { - } 7.5 \% \text { to } 205 \% \\
\text { - } 35 \text {-to-1 } \\
\text { - } 18 \text {-to-1 } \\
\text { - } 6 \text {-to-1 }\end{array}$ & $\begin{array}{l}\text { - } 80 \% \text { aniline and } 20 \% \\
\text { furfuryl / RFNA- } \\
6.5 \% \mathrm{NO}_{2} \\
\text { - } \mathrm{NH}_{3} / \mathrm{RFNA}^{2} 2 \% \\
\mathrm{NO}_{2} \\
\text { - } \mathrm{J}-\mathrm{P} 3 \text { (lead with } \\
\text { furfuryl alcohol) / } \\
\text { WFNA (with max. } \\
2 \% \mathrm{H}_{2} \mathrm{O} \text { ) } \\
\text { - } \mathrm{J}-\mathrm{P} 4 \text { (lead with } \\
\text { furfuryl alcohol) / } \\
\text { WFNA (with max. } \\
2 \% \mathrm{H}_{2} \mathrm{O} \text { ) } \\
\end{array}$ & - Evaluate for missile use \\
\hline
\end{tabular}




\begin{tabular}{|c|c|c|c|c|c|c|c|c|}
\hline & & & & & & & \begin{tabular}{|l|} 
- Swirl, annular orifice, \\
multiport swirl \\
injectors
\end{tabular} & \\
\hline $\begin{array}{l}\text { Variable Area } \\
\text { Injector }\end{array}$ & NACA Study & 1955 & $\begin{array}{l}\text { - NACA Lewis Flight } \\
\text { Propulsion } \\
\text { Laboratory }\end{array}$ & $\begin{array}{l}\text { - Research } \\
\text { Engine }\end{array}$ & $\begin{array}{l}\text { - } 1000 \mathrm{lbs} \text { rated thrust, } \\
300 \text { psia rated } \mathrm{p}_{\mathrm{c}}\end{array}$ & $\begin{array}{l}\text { - } 9.6 \% \text { to } 171 \% \\
\text { - } 8.6 \% \text { to } 159 \%\end{array}$ & \begin{tabular}{|l|} 
- Liquid $\mathrm{NH}_{3}$ (with \\
lithium) / liquid \\
MON-29 \\
- Triplet impinging-jet \\
and swirl cup injector
\end{tabular} & $\begin{array}{l}\text { - Investigate variable thrust } \\
\text { methodology }\end{array}$ \\
\hline $\begin{array}{l}\text { Variable Area } \\
\text { Injector }\end{array}$ & $\begin{array}{l}\text { Lunar Module } \\
\text { Descent Engine } \\
\text { Program }\end{array}$ & $\begin{array}{l}1963- \\
1967\end{array}$ & $\begin{array}{l}\text { - TRW Inc. } \\
\text { - NASA }\end{array}$ & $\begin{array}{l}\text { - Apollo } \\
\text { LMDE }\end{array}$ & $\begin{array}{l}\text { - } 9850 \mathrm{lbs} \text { rated thrust, } \\
106 \mathrm{psia} \text { rated } \mathrm{p}_{\mathrm{c}}\end{array}$ & - $10 \%$ to $100 \%$ & $\begin{array}{l}\text { - } \mathrm{A}-50 / \mathrm{N}_{2} \mathrm{O}_{4} \\
\text { - Pintle injector }\end{array}$ & $\begin{array}{l}\text { - Develop and man-rate an } \\
\text { LMDE }\end{array}$ \\
\hline $\begin{array}{l}\text { Variable Area } \\
\text { Injector }\end{array}$ & $\begin{array}{l}\text { TRW Inc. } \\
\text { Study }\end{array}$ & $\begin{array}{l}1965 \\
1968\end{array}$ & $\begin{array}{l}\text { - TRW Inc. } \\
\text { - NASA }\end{array}$ & - MIRA 150A & $\begin{array}{l}\text { - } 150 \mathrm{lbs} \text { rated thrust, } 108 \\
\text { psia rated } \mathrm{p}_{\mathrm{c}}, 1.59 \mathrm{MR}\end{array}$ & - $18 \%$ to $122 \%$ & \begin{tabular}{|l|} 
- $\mathrm{MMH} / \mathrm{MON}-10$ \\
- $\mathrm{A}-50$ / $\mathrm{N}_{2} \mathrm{O}_{4}$ \\
- Coaxial pintle injector
\end{tabular} & $\begin{array}{l}\text { - Design for use as an attitude } \\
\text { control engine on the } \\
\text { Surveyor spacecraft }\end{array}$ \\
\hline $\begin{array}{l}\text { Variable Area } \\
\text { Injector }\end{array}$ & $\begin{array}{l}\text { Gaseous } \\
\text { Propellant } \\
\text { Throttling } \\
\text { Rocket Engine } \\
\text { Study }\end{array}$ & $\begin{array}{l}1965- \\
1968\end{array}$ & - AFIT & $\begin{array}{l}\text { - Research } \\
\text { Engine }\end{array}$ & $\begin{array}{l}\text { - } 100 \mathrm{lbs} \text { rated thrust, } 350 \\
\text { psia rated } \mathrm{p}_{\mathrm{c}}, 2.0 \mathrm{MR} \\
\text { - } 70 \mathrm{lbs} \text { rated thrust, } 230 \\
\text { psia rated } \mathrm{p}_{\mathrm{c}} \\
\text { - } 75 \mathrm{lbs} \text { rated thrust, } 2.0 \\
\mathrm{MR} \\
\text { - } 76 \mathrm{lbs} \text { rated thrust } \\
\end{array}$ & $\begin{array}{l}\text { - } 4.1-\text {-to-1 } \\
\text { - } 7 \text {-to-1 } \\
\text { - 5-to-1 }\end{array}$ & - $\mathrm{GH}_{2} / \mathrm{GOX}$ & $\begin{array}{l}\text { - Research experiments using } \\
\text { gaseous propellants on } \\
\text { thrust variation }\end{array}$ \\
\hline $\begin{array}{l}\text { Variable Area } \\
\text { Injector }\end{array}$ & LSAM design & $\begin{array}{l}2005- \\
\text { current }\end{array}$ & $\begin{array}{l}\text { - NGST } \\
\text { - NASA }\end{array}$ & - TR202 & $\begin{array}{l}\text { - } 8700 \mathrm{lbs} \text { rated thrust, } \\
700 \text { psia rated } \mathrm{p}_{\mathrm{c}}, 6.0 \\
\mathrm{MR} *\end{array}$ & 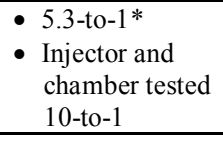 & $\begin{array}{l}\text { - } \mathrm{LH}_{2} / \mathrm{LO}_{2} * \\
\text { - } \mathrm{GH}_{2} / \mathrm{LO}_{2} \text { tested }\end{array}$ & $\begin{array}{l}\text { - Engine design to meet } \\
\text { LSAM requirements }\end{array}$ \\
\hline $\begin{array}{l}\text { Hydrodynamic- } \\
\text { ally Dissipative } \\
\text { Injector }\end{array}$ & $\begin{array}{l}\text { Demonstration } \\
\text { of Throttleable } \\
\mathrm{LOX} / \mathrm{H}_{2} \\
\text { Injection } \\
\text { Concepts }\end{array}$ & 2001 & $\begin{array}{l}\text { - The Pennsylvania } \\
\text { State University } \\
\text { - NASA Marshall } \\
\text { Space Flight Center }\end{array}$ & $\begin{array}{l}\text { - Research } \\
\text { Engine }\end{array}$ & $\begin{array}{l}\text { - } 1000 \text { psia rated } \mathrm{p}_{\mathrm{c}}, 6.0 \\
\mathrm{MR}\end{array}$ & $\begin{array}{l}\text { - } 10 \text {-to- } 1 \\
-4.83<\mathrm{MR} \\
\quad<7.21\end{array}$ & $\begin{array}{l}\text { - } \mathrm{GH}_{2} / \mathrm{LO}_{2} \\
\text { - Russian swirl injector }\end{array}$ & $\begin{array}{l}\text { - Conduct hot-fire } \\
\text { experiments of a designed } \\
\text { swirl injector across the } \\
\text { throttleable range }\end{array}$ \\
\hline
\end{tabular}

*Design Only 


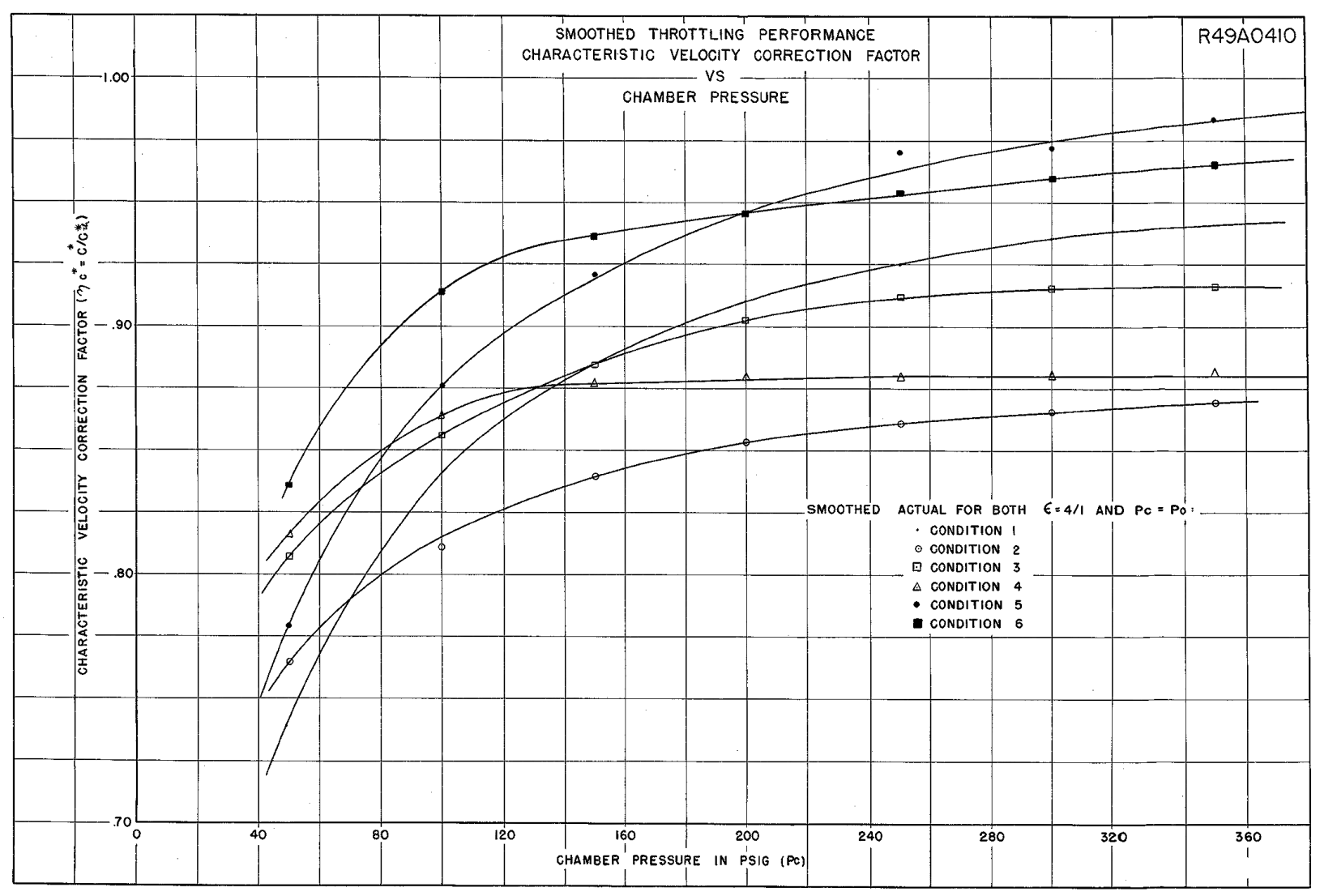

Figure 1. Characteristic Velocity Efficiency from Project Thumper

\section{Project $M X-794(1950)^{21}$}

Under contract to the United States Air Force, the Willow Run Research Center at the University of Michigan obtained rocket engine throttling performance to analyze and design ballistic and airborne defense systems. Several instabilities were encountered during the test program at lower chamber pressures. These were described as whistling, howling, rough burning, and chugging as the thrust was reduced. During whistling and howling, the noise intensity was high enough to shatter glassware, and standing wave patterns were visible in water on the test cell floor. Whistling was likely a high frequency combustion instability. Howling and rough burning were likely low frequency combustion instability, or chug in current nomenclature. Chugging was described as an instability with pulsing combustion, and was likely a low frequency hydraulic instability in the injector. Heat transfer in the engine rose abruptly during the combustion instabilities. Performance was observed to decrease during throttling. Hysteresis was observed when attempting to move in and out of the regions of instability.

One conclusion of this program was that unstable combustion was a serious problem in throttling and could result in erratic operation and destruction of the rocket engine. Other conclusions were that a variable area injector would likely be required to successfully throttle over a range of 5-to-1, and that it would be feasible to use regenerative cooling over the full 10-to-1 throttling range.

Several throttling methodologies were also analyzed in these studies. A table comparing these methods is shown in Fig. 2. Variable area injectors, described in a later section of this paper, were identified to be the most promising throttling method.

\section{NASA Study - Modified RL10A-1 (1964) $)^{28}$}

A modified RL10A-1 engine was used to investigate steady state and dynamic characteristics during throttling from $100 \%$ to $10 \%$ of thrust in an altitude facility at the NASA Lewis Research Center. The modifications to the standard regeneratively cooled and pump-fed RL10A-1 engine included the addition of a turbine bypass valve to vary the amount of flow through the turbine, smaller oxygen injector orifice areas to increase injector pressure drop 
and provide better atomization at low thrust, and a chlorotrifluoraethylene monomer insulation between the oxygen and hydrogen injector manifolds to reduce heat transfer that caused oxygen boiling at low thrust. Analysis indicated that rapid transients from high to low thrust could stall the fuel pump. Emphasis was placed on determining the steady and dynamic characteristics as well as the operational limitations due to interacting engine components.

Three injector configurations were tested, including a shear coax element injector with mid-level oxidizer pressure drop (33\% chamber pressure), and two swirl coax element injectors with low (20\%) and high (60\%) oxidizer pressure drops. All three injector configurations included the injector manifold insulation as well as a transpiration cooled faceplate using approximately $2 \%$ of the total fuel.

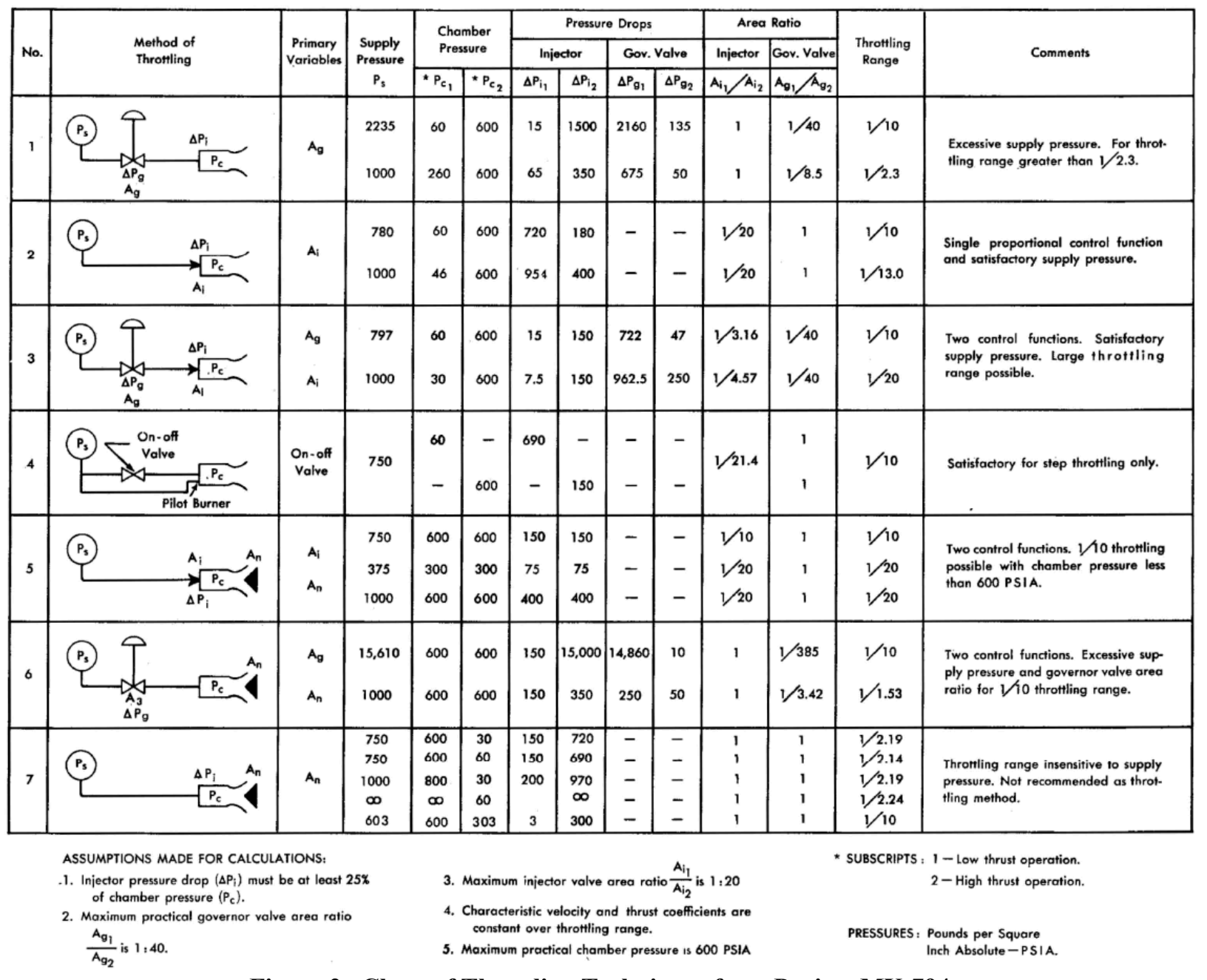

Figure 2. Chart of Throttling Techniques from Project MX-794

Chug at about $170 \mathrm{~Hz}$ was evident at low thrust for all three injectors. However, the onset of chug occurred at lowest chamber pressures with the higher pressure drop injectors, as shown in Fig. 3, although there was a significant influence of mixture ratio between the three injectors. At a mixture ratio of 4.5 , for example, the onset of chug occurred at $32 \%$ thrust for the lowest pressure drop injector, $25 \%$ for the middle-pressure-drop injector, and never occurred for the highest pressure drop injector.

The regions of chug shown in Fig. 3 were defined to be any noticeable periodic oscillation greater than the noise floor. The highest amplitude peak-to-peak oscillations of about $80 \%$ of chamber pressure occurred at the lower thrust - lower mixture ratio region. Figure 3 also shows that two of the injectors became stable again at chamber pressures less than about 40 psia or around $10 \%$ thrust. This restabilization at very low throttling is due to gasification of the oxygen, probably due to heat transfer from the warm hydrogen, at a rate sufficient to increase the oxygen pressure drop. Figure 4 compares oxygen flow rate and pressure drop for the shear coax injector. The deviation from the linear pressure drop relation in the figure indicates a change in oxygen density, and that two- 


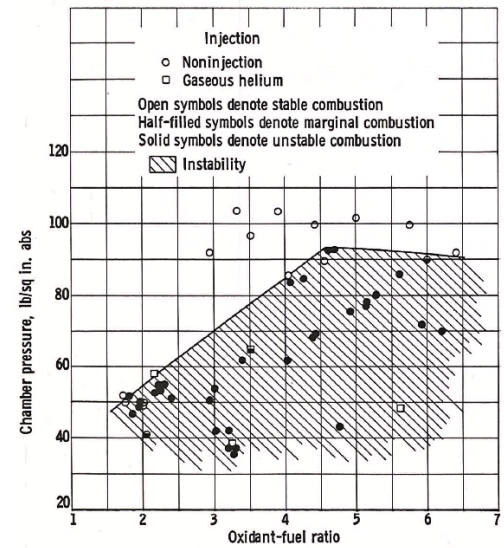

a) Low-Pressure-Drop Injector

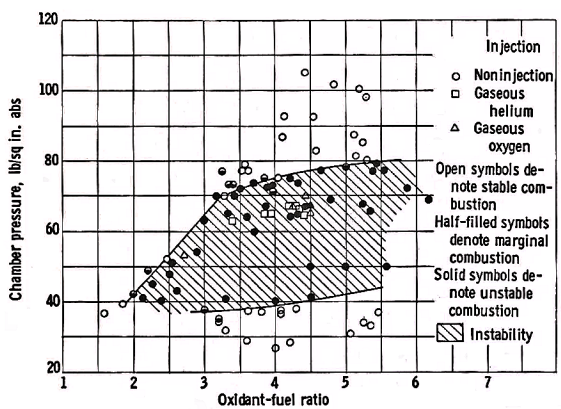

b) Middle-Pressure-Drop Injector

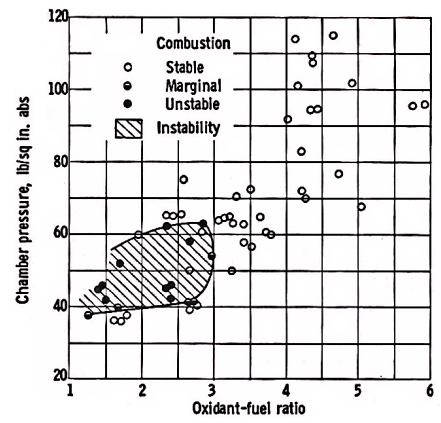

c) High-Pressure-Drop Injector figurations

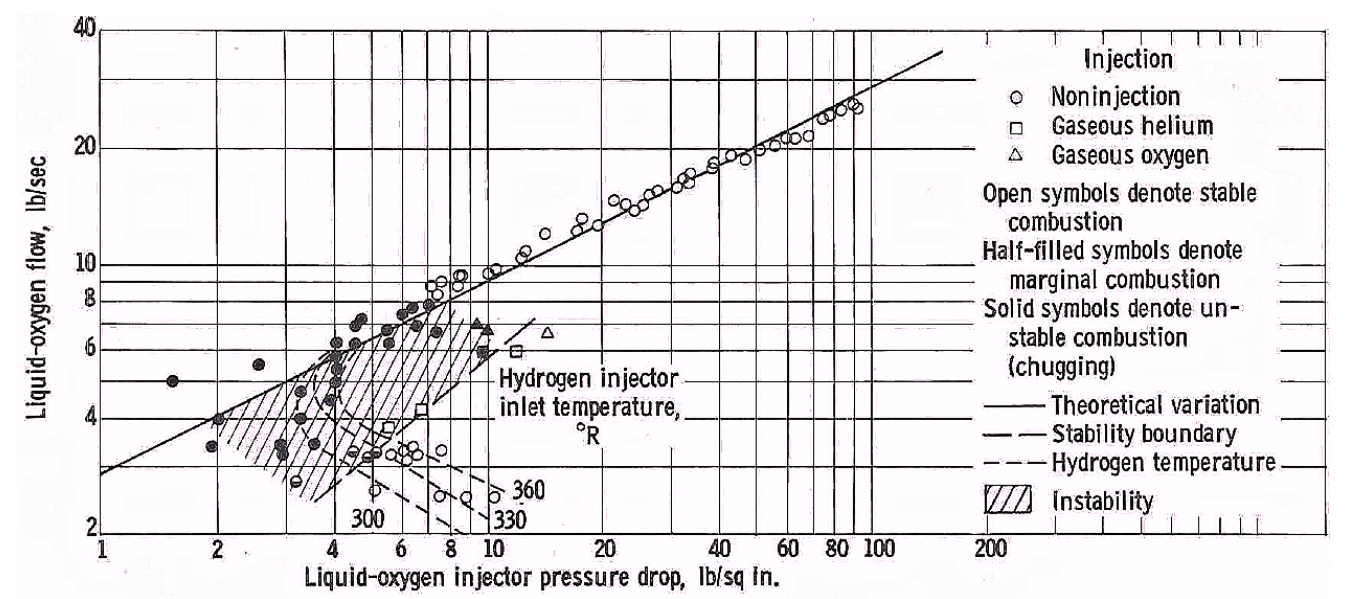

Figure 4. Hydraulic Characteristics while Throttling Liquid Oxygen Shear Coaxial Injector

phase flow begins to move through the oxidizer injector orifices. The amount of deviation is shown in Fig. 4 to be dependent on the temperature of the hydrogen fuel. The added injector resistance (increase in pressure drop) was enough to overcome the negative effects on stability of the increased compliance (more vapor) in the manifold. Several other methods to increase the oxidizer injector pressure drop were also proposed, including further reduction of the oxidizer injector area if pump head rise was available, provide heat transfer to increase the amount of vapor in the manifold, and provide gas injection into the liquid oxidizer manifold.

The engine was also operated in pressurized mode without the pump. Chamber pressures of 10 to 15 psia (about $3 \%$ to $5 \%$ chamber pressure) were explored over mixture ratios from 2 to 6 . The lower limit of 10 psia was due to the inability of the exhaust nozzle to flow full at the available pressure ratio. High temperatures were reached in the jacket outlet temperature at mixture ratios of 5 and higher. A temperature of $700{ }^{\circ} \mathrm{R}$ at a mixture ratio of 5 was determined to be the safe limit since discoloration, metal erosion, and tube burnouts occurred at higher mixture ratios. These tests demonstrated the feasibility to reach $3 \%$ thrust using pressure-fed propellants and inoperative pumps.

Reducing the chamber pressure from $100 \%$ to $33 \%$ reduced the specific impulse by about $3 \%$, but the performance decay was faster below $33 \%$ chamber pressure. This influence was expected since for fixed-orificeinjectors the liquid oxygen pressure drop is reduced with the square of the propellant flow rate, which likely worsened atomization and mixing. Performance was also worsened with the onset of chug, which reduced performance by an additional $8 \%$. The high-pressure-drop swirl coax injector performed the best at low thrust compared to the other two injectors. Both swirl injectors also performed better then the shear element injector.

At a mixture ratio of 5 , chamber coolant jacket outlet temperature increased $100{ }^{\circ} \mathrm{R}$ over the throttling range from $100 \%$ to $25 \%$. The increase in temperature was due to the proportionate decrease in propellant flow rate (and 
coolant flow rate) with pressure. Overall, cooling ability decreased at lower thrusts, however adequate cooling was available over the range tested.

In addition to chug, a flow instability between $1 \mathrm{~Hz}$ and $5 \mathrm{~Hz}$ occurred in the fuel system below chamber pressures of $33 \%$ thrust, or when the coolant jacket pressure reached the hydrogen critical pressure. Regions of mild oscillations and severe oscillations were evident. The mild oscillations were $10 \%$ to $20 \%$ of the fuel weight flow. The severe oscillations at high mixture ratios required engine abort because of overheating of the coolant tubes. Pump boundary conditions and effects were not a cause because of the demonstration of the phenomenon in engine pressurized mode operating without the pump. The speculation was that an unstable liquid-vapor interface was established in the chamber coolant channels. The theory was verified when gas helium or hydrogen was injected upstream of the coolant jacket, which created a finely distributed region of phase transition. Gas weight flows of $20 \%$ of the hydrogen weight flow were needed for stabilization. Another method to avoid the oscillation was to operate at lower mixture ratios.

Dynamic characteristics were investigated during thrust transients. At high deceleration ramp transients, the pump was driven into a stall condition. This high deceleration ramp created a fuel flow excursion from normal flow rates into the stall region. The flow excursion, as simulated with an analytic system model, showed that the accumulator action of the chamber cooling jacket and feed line maintains a high pump discharge pressure while the head-rise potential of the pump decays rapidly during the transient. No operational problems occurred with high acceleration ramp transients.

\section{ARES Throttling - Scaling Design Study Program (1967) $)^{29-32}$}

The Air Force Rocket Propulsion Laboratory at Edwards Air Force Base sponsored development of a throttleable and restartable staged-combustion cycle engine called the Advanced Rocket Engine Storable (ARES) engine at the Aerojet General Corporation. The design goal was 10-to-1 throttling using a HIPERTHIN (HIgh PERformance THrottling INjector) injector ${ }^{33}$ and a transpiration cooled chamber. Although no testing was performed, details of the design changes from a fixed thrust engine to a throttleable version are provided in the documentation along with predictions of stability and performance.

Aerojet Liquid Rocket Company also studied a throttling injector concept applicable to an advanced cryogenic engine and suitable for staged combustion engines. The engine system was to be throttleable over a 33-to-1 thrust range. The unique injector design contained an integral heat exchanger to extend throttling by gasifying the cryogenic propellants prior to injection. The heat exchanger operated by tapping off combustion gases which were directed through a HIPERTHIN injector in a counterflow manner. Predicting the pressure drop aspects of this injection system was difficult because the propellant phase in the injector transitioned from supercritical, to twophase, to gas as the engine throttled down. With gas injection, the injector maintains a constant $\Delta \mathrm{p}_{\mathrm{inj}} / \mathrm{p}_{\mathrm{c}}$ over a wide range of throttling, which is advantageous to an engine system because adequate feed system stiffness can be maintained without using excessive injection pressure drops at full thrust. Testing of the heat exchanger showed nonuniform heat exchange surface in the injector manifold area and insufficient surface area.

\section{5. $D C-X$ and $D C-X A(1991)^{34}$}

The regeneratively cooled expander-cycle RL10A-5 engine, a sea-level throttleable derivative of the RL10 engine family, was developed by Pratt \& Whitney under contract to McDonnell Douglas through a Ballistic Missile Defense Organization funded program, for use on the DC-X (Delta Clipper - Experimental) vehicle, a single-stage to orbit rocket technology demonstrator. Four RL10A-5 engines were installed on the DC-X vehicle. The three major differences of the RL10A-5 engine from the rest of the RL10 engine family were sea level operation, throttle capability from $100 \%$ to $30 \%$ of rated thrust, and reusability. NASA later sponsored a continuation of the program called DC-XA (Delta Clipper - Experimental Advanced), which used the same engines.

Several successful flights of the DC-X and DC-XA included vertical launch, hovering, translating, and vertical landing. One flight reached an altitude of 10,500 ft. On the third flight, two of the engines started slower than the others and resulted in an uneven engine acceleration, but the engines recovered and performed nominally thereafter. The problem was traced back to gaseous helium unwillingly being ingested into the liquid oxygen feed lines, degrading combustion, and lowering thrust. The RL10A-5 demonstrated a 3.3:1 throttling range.

\section{NASA-Aerojet Joint Cooperative Study - RD-0120 (1996) ${ }^{35}$}

Under a joint cooperative agreement with the NASA Marshall Space Flight Center (MSFC), the Aerojet Liquid Rocket Company in 1996 demonstrated off-nominal power operation of the staged combustion cycle RD-0120 
engine for Reusable Launch Vehicle (RLV) evaluations of the X-33 demonstrator vehicle propulsion system. Rated power levels between $25 \%$ and $100 \%$ were examined, including one test simulating an RLV abort scenario with continuous operation at $25 \%$ power level of 480 seconds duration. No combustion instability was observed during any power level. However, following the long duration test at $25 \%$ power level, about $20 \%$ of the nozzle brackets which held the stiffening rings to the nozzle were found to be damaged, attributed to excessive nozzle vibration during separated nozzle flow at the sea level facility. The nozzle was not designed for operation at $25 \%$ power level, and would be easily redesigned to eliminate damage.

\section{NASA-Boeing Rocketdyne Joint Cooperative Study-SSME (1997) ${ }^{36,37}$}

Under a joint cooperative agreement with the NASA MSFC, Boeing Rocketdyne in 1997 demonstrated offnominal power operation of the staged combustion cycle Space Shuttle Main Engine (SSME) for RLV evaluations of the X-33 demonstrator vehicle propulsion system. The SSME does not have a higher-than-usual pressure drop; however it is classified in this section because at low thrust it still maintains a high enough pressure drop to operate sufficiently. Rated power levels of $17 \%, 22 \%, 27 \%, 40 \%, 45 \%$ and $50 \%$ were examined. Normal operation of the SSME ranges from $65 \%$ to $109 \%$ rated power level. Chamber pressure profiles from two tests are shown in Fig. 5. The SSME was recently throttled again in 2008 at the NASA Stennis Space Center.

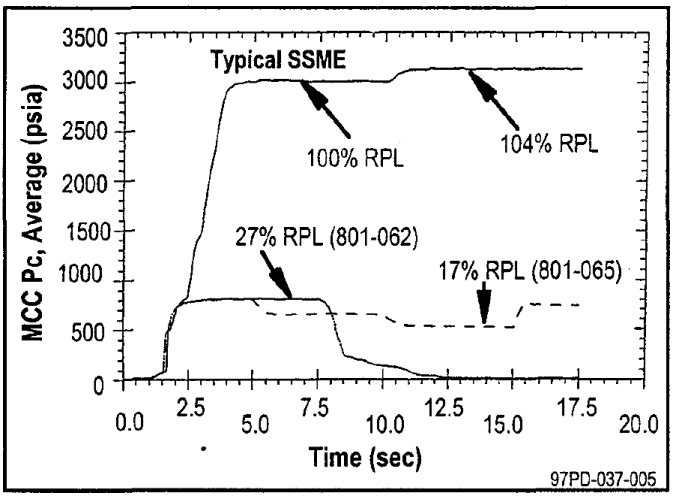

Figure 5. SSME Low Power Level Chamber Pressure

Thrust was predominantly controlled by varying the oxidizer preburner oxidizer valve, and mixture ratio was controlled by varying the fuel preburner oxidizer valve. At low thrust, the chamber coolant valve (CCV) was partially closed more so than normally to help increase turbine inlet temperatures, due to a concern for production of ice in the oxygen preburner. However, higher-than-expected nozzle separation heat loads in combination with the $\mathrm{CCV}$ modification precluded icing concerns. The mixture ratio also was fixed between 3 and 4 to provide a safe margin from the high pressure fuel turbopump boilout point (or stall), which also provided additional cooling of the main combustion chamber at low thrust. The stall point was the most significant issue that drove the operating point balance.

Reduction of the thrust to $17 \%$ (or about 6.4:1 throttling from maximum power level) was achieved by further closing of the fuel preburner oxidizer valve, since the oxidizer preburner oxidizer valve was already at a minimum area. High sample rate instrumentation did not include a chamber pressure measurement; however, there was no evidence of combustion instability in accelerometer measurements. The oxidizer injector pressure drop was so small that the measurements from the test data were not valid, but the pressure drops across the control valves were high and possibly protected against chug. A pump flow test program was recommended to establish safe operating regimes for the pumps at thrusts lower than $17 \%$.

There were many pump-related concerns prior to running the throttling tests, including rotordynamic stability of the turbopumps, running the high pressure turbopumps at shaft critical speeds, the ability of the high pressure fuel turbopump thrust bearing to lift off, the ability of the hydrostatic bearing of the high pressure oxidizer turbopump to run in the stall region, the possibility of the freezing in the high pressure turbopump turbines, the ability to sustain a satisfactory axial thrust balance, the bi-stability of the high pressure oxidizer turbopump boost pump, and the performance of the turbopumps at low flow-to-speed ratios. A slight preburner boost pump bi-stability was observed at $50 \%$ rated power level. 


\section{Deep Throttling Common Extensible Cryogenic Engine (2005) ${ }^{38,39}$}

Pratt \& Whitney Rocketdyne conducted tests of a modified RL10 engine, assembled from a mixture of heritage development hardware and renamed the Common Extensible Cryogenic Engine (CECE) Demonstrator. The engine is for technology development and risk reduction applicable to a deep throttling cryogenic lunar descent engine. Figure 6 shows the engine at multiple power levels during a hot run.

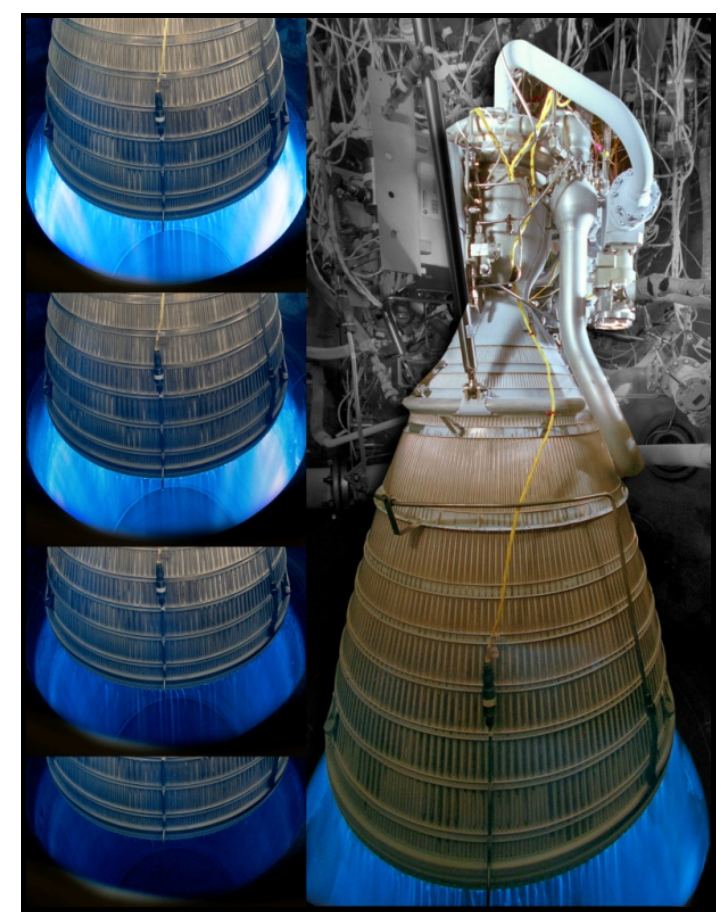

Figure 6. CECE shown at Multiple Power Levels

Two major hardware modifications to the RL10 engine system were made for CECE. First, features of the injector were altered to allow adequate operation over the full throttling regime. This included a reduction in area of the oxidizer flow path and a reduction of the outer row mixture ratio. These changes allowed full operation over the throttling range and improved thermal margin. The fuel-side flow area was similar to a base RL10 engine and needed little modification. The second modification was the selection of a valve suite that provided the necessary system control flexibility. The valve suite used in CECE is discussed in more detail in [38] and [39], however two key additions were the fuel turbine bypass flow to supplement the existing bypass flow route and the addition of the variable area cavitating venturi.

Over the Demo. 1.0, Demo. 1.5, and Demo. 1.6 test series, CECE has accumulated 5032 seconds of total run time while achieving a throttle range in excess of 13-to-1. Figure 7 shows CECE at $30 \%$ power level with ice formation on the nozzle rim due to the cooling and eventual freezing of the steam by the cryogenically cooled nozzle wall. Swirl injector throttling, like the RL10 and CECE throttling configuration, has also been recently studied in [40] including effects of reduced mass flow rate and elevated chamber backpressure. 


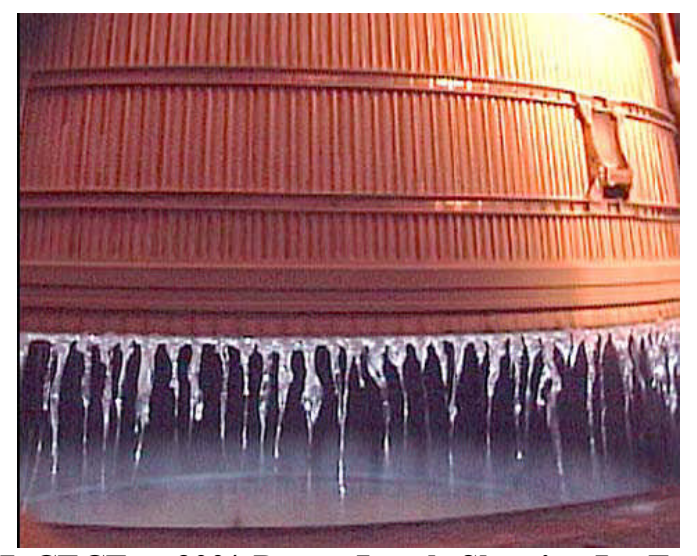

Figure 7. CECE at 30\% Power Levels Showing Ice Formation

Chug oscillations were encountered at low throttle power levels similar to that observed in [28] and [41]. The presence of vapor in the oxidizer manifold and feed system was deduced by extensive stability modeling as responsible for the less than expected margin. An injector revision that incorporated insulation in the LOX manifold was tested in Demo. 1.6 similar to the injector revision in [28]. The insulation provided additional chug margin by effectively decreased the onset of chug to a lower power level. Also, the approach of gaseous helium injection similar to that used in [28] was also examined. The gas injection was successful in eliminating chug oscillations.

\section{B. Dual-Manifold Injectors}

A dual-manifold injector - also called two-stage, dual-element, dual-circuit, or dual-orifice - is an injector designed to maintain satisfactory injector pressure drops at low thrust levels while not requiring the often excessive pressure drops at full thrust compared to the high-pressure-drop injectors described in the previous section. The dual-manifold injector essentially combines two fixed-area injectors into a common structure, with independent feed systems controlling flow to each injector manifold. Deep throttling is achieved by proceeding from two-manifold (primary and secondary) operation at high thrust to single-manifold (primary) operation at low thrust, thus changing the effective injection area. Changing from two-manifold to single-manifold operation is usually as simple as closing a valve. Several constraints must be optimized in the injector design from system requirements, including the pressure drop at the minimum power point, the minimum pressure drop for the secondary manifold, and the maximum injector pressure at full power (maximum thrust). This injection method has been used for fuel injection in turbojet engines, and also by German engineers in the early days of throttling LRE development. ${ }^{19}$

Higher pressure drop across the injector at low thrust is advantageous for both performance and stability, as previously described. Finer atomization of the propellants usually depends on higher injector pressure drop. ${ }^{42}$ The injector stiffness to promote stable combustion is injector dependent, but generally should be at least $15 \%$ to $20 \%$ of the chamber pressure.

Just like with the high-pressure-drop injectors previously described, continuous throttling is provided by control valves in the propellant feed systems. At the operating point where the pressure drop in the secondary manifold reaches its minimum, the control valve feeding the secondary manifold closes, and all the flow transitions to the primary manifold. This abrupt reduction in injection area causes an abrupt increase in injector pressure drop across the primary manifold when flow rate is held constant. The transition historically has ranged between $20 \%$ and $50 \%$ of full flow. Studies have been performed to examine ways of smoothly transitioning by varying flow through both manifolds appropriately.

\section{Advanced Throttling Concepts Study $(1963)^{43-45}$}

An Advanced Throttling Concept Study (1963-1965) was conducted by Pratt \& Whitney Aircraft (P\&WA) and United Technology Center and a parallel High Energy Advanced Throttling Concept Study (1964-1966) was conducted by Pratt \& Whitney Aircraft under two separate Air Force contracts. Prior to these studies, P\&WA sponsored tests of a dual-manifold subscale injector over a 23-to-1 flow range with the same propellants as described in the Advanced Throttling Concept Study. The intent of the Advanced Throttling Concept Study was to evaluate injector systems that provide high combustion performance during deep throttling (specified down to 50-to1). The engine was pressure-fed and used storable propellants. Two injector patterns were examined in this study; the triplet-element injector is shown in Fig. 8. 


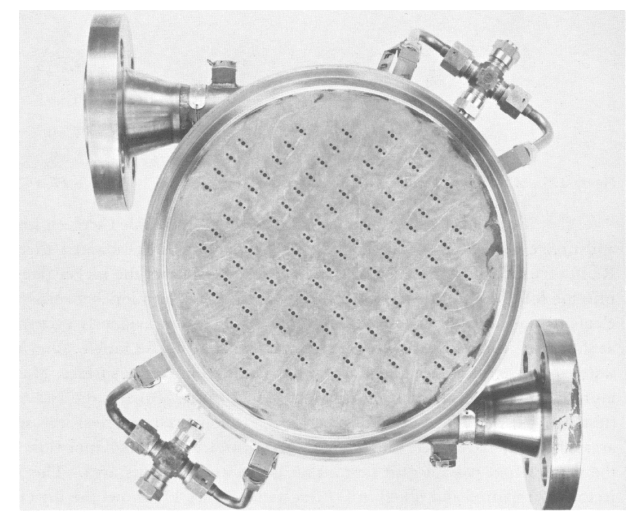

a) Hardware Photo

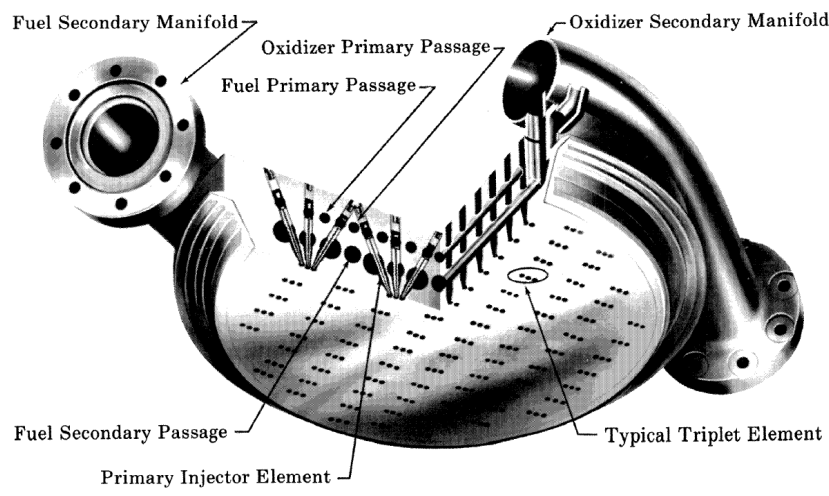

b) Schematic Diagram

Figure 8. Triplet-Element Dual-Manifold Injector

Each individual propellant orifice consisted of a primary flow inner orifice and a secondary flow concentric outer orifice, as illustrated in Fig. 9. A flow divider valve controlled the flow split between the primary and secondary flow paths. High average injection velocities were maintained over a wide thrust range by the controllable flow split and the momentum exchange between the two concentric streams, high enough to obtain good inter-propellant mixing. The primary flow accelerates the low secondary flow (even as low as $2 \%$ thrust) as was demonstrated in water flow experiments. Acoustic liners on the chamber walls were also used to damp high frequency chamber pressure oscillations.

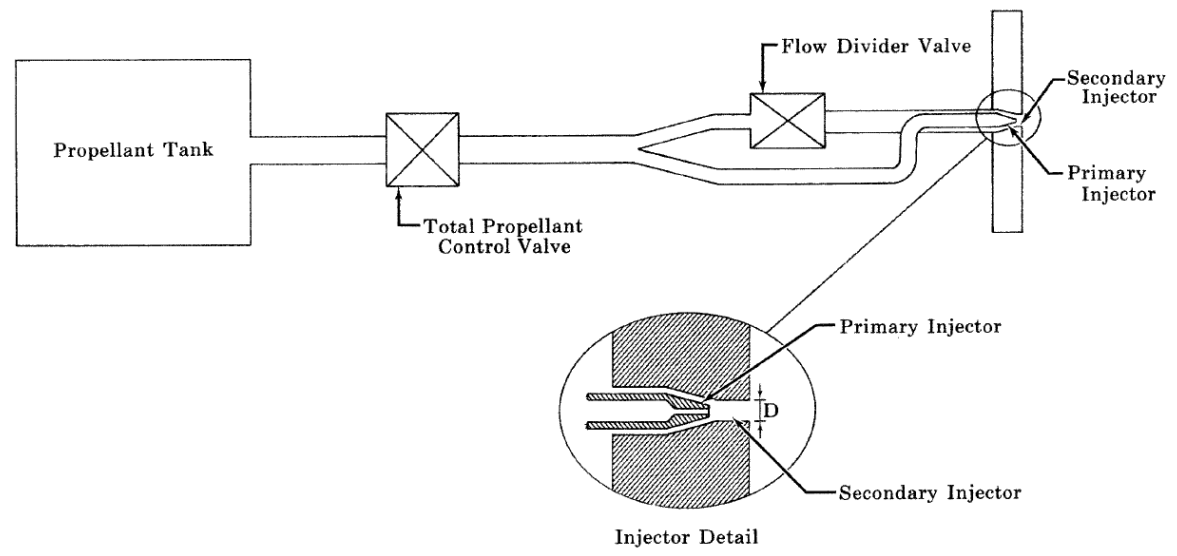

Figure 9. Dual-Manifold Injection Flow System Schematic

System analyses prior to test found that the pressure inside the secondary oxidizer manifold would be below the propellant vapor pressure at low thrust. In the transition thrust range (with two-phase propellant) and pure vapor thrust range at low power levels, there would be significant change in the primary-to-secondary flow split, but only a small effect on total propellant flow, so the presence of vapor in the oxidizer secondary manifold was expected to have a negligible effect on mixture ratio and chamber pressure. A nonlinear dynamic system model also showed no divergent oscillations in the chamber within the entire thrust range and was useful to design optimum propellant supply line geometry. Performance and throttling characteristics of both injectors are limited release data.

The intent of the High Energy Advanced Throttling Concept Study was to evaluate the throttling capability and performance of the dual-orifice injectors using high energy $\mathrm{F}_{2} / \mathrm{H}_{2}$ pump-fed propulsion systems for use in maneuvering satellite applications. Tests were performed with several subscale and full scale injectors with dualmanifold concentric injector orifices and upstream flow control valves as in the Advanced Throttling Concept Study. The subscale injectors were throttled over a 12:1 thrust range. The full scale injectors were throttled over a 29:1 thrust range. Gaseous hydrogen was used as the fuel and thus only the oxidizer dual-manifold was needed. 


\section{Chamber Technology for Space Storable Propellants (1964) ${ }^{46-49}$}

A five year analytical and experimental program called Chamber Technology for Space Storable Propellants investigated dual-manifold injector throttling. The program was to develop design criteria for selected space storable fuels in combination with oxygen difluoride. FLOX ( $70 \%$ fluorine, $30 \%$ oxygen) was experimentally verified as an excellent simulant for oxygen difluoride in terms of performance and heat transfer and was substituted as an oxidizer in most tests because of its lower cost. The injector contained dual manifolds for both fuel and oxidizer. The transition to primary-only flow occurred at $49 \%$ thrust. The engine repeatedly throttled over a 10 -to- 1 range in a variety of duty cycles including demonstration of continuous throttling. The $\mathrm{c}^{*}$ efficiency ranged from $92 \%$ to $98 \%$ over the thrust range.

Two valve flow control schemes, parallel and series as shown in Fig. 10, were investigated. The parallel valve scheme allowed control of the flow to both the primary and secondary manifolds simultaneously. At the transition chamber pressure, the secondary flow was cut off and the single throttle valve fully opened. The difficulty with this simple parallel system was that four valves were needed to operate simultaneously to ensure a smooth thrust change at transition. The series valve scheme provided independent flow control to each manifold propellant line. Throttling began by reducing secondary flow with the primary valve still fully opened. Upon closure of the secondary valve, the primary flow was reduced to continue throttling. The series scheme provided a performance advantage at the mid-thrust range prior to throttling down through the predetermined chamber pressure.

One case of instability occurred with rough combustion at $90 \%$ thrust and $170 \mathrm{~Hz}$ and a peak-to-peak chamber pressure oscillation of $13 \%$. This oscillation was eliminated upon closure of the secondary injector control valve. Release of trapped injector purge gases between the fuel throttle valve and injector likely triggered the instability by passing two-phase flow through the injection orifices. A change to the fuel injector purge pneumatic system was made for subsequent tests and no further instabilities were encountered. Otherwise, all thrust levels demonstrated excellent stability.

Peak performance occurred at secondary flow cut-off when there was a maximum injector pressure drop, or high injection velocity. The performance curve using the series valve configuration is shown in Fig. 11. An empirical correlation was developed that related injector design parameters to the combustion efficiency, based on an empirical expression by Ingebo ${ }^{\mathbf{5 0}}$ that related volume mean droplet diameter, $D_{30}$, to jet diameter $D$ and velocity $V$ for impinging stream injectors. The relationship is Eq. (2),

$$
\eta_{c^{*}}=1-A\left(\sqrt{\frac{D}{V}}\right)^{B}
$$

where $A$ and $B$ were empirical constants whose values changed for different propellant combinations and chamber geometries. The primary and secondary systems can be combined into a mass weighted average $\mathrm{c}^{*}$ efficiency. Additionally, no variation in the Rupe mixing efficiency, $E_{m}{ }^{51}$ was shown over the entire throttle range.

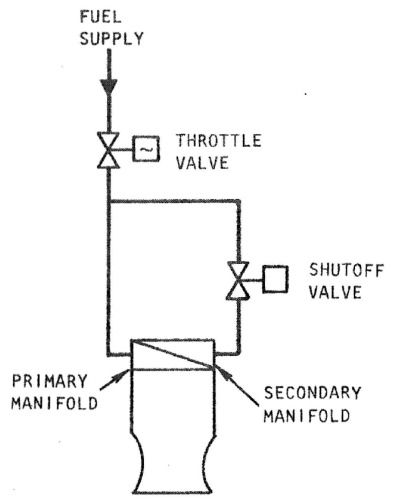

a) Parallel Scheme

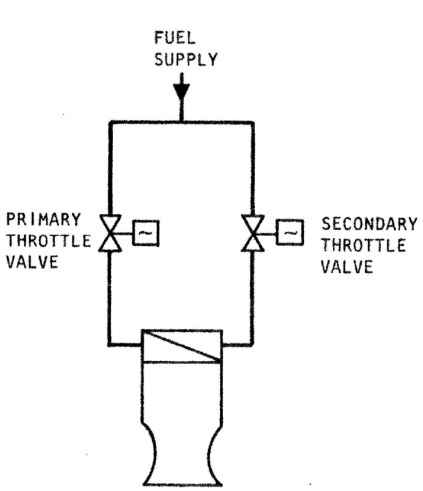

b) Series Scheme 


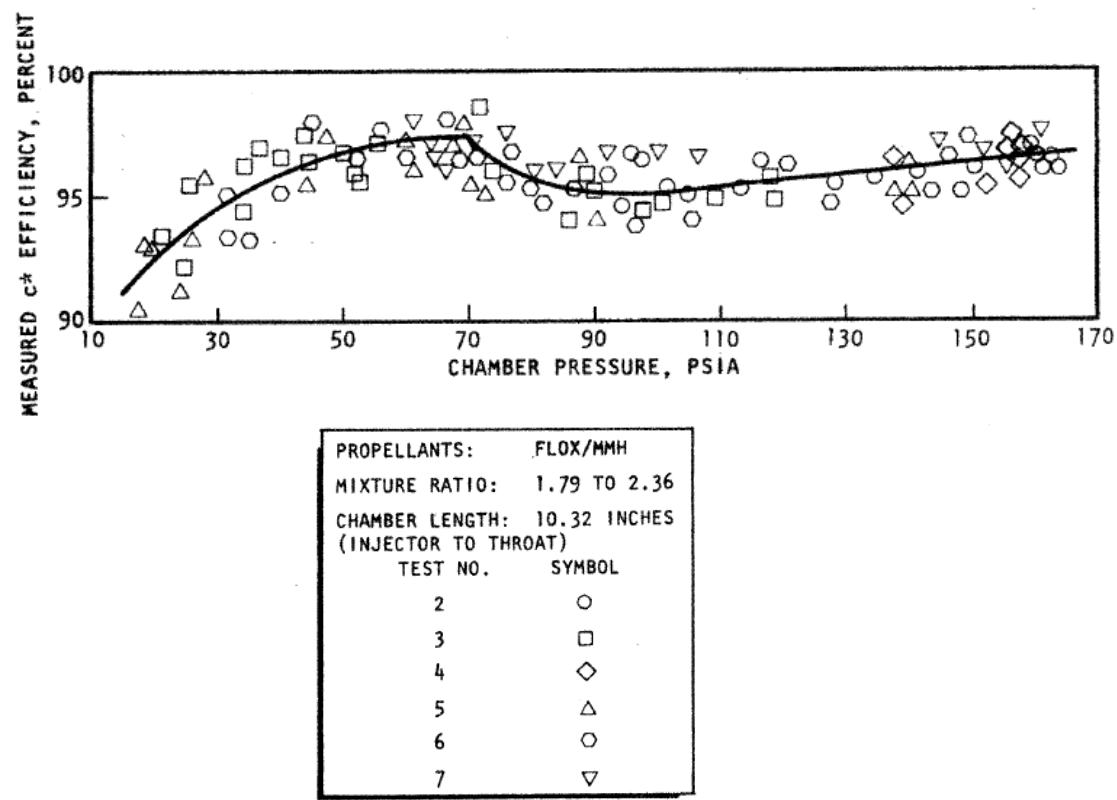

Figure 11. Dual-Manifold Throttling Performance with Series Valve Configuration

The system response in general was good although there was a significant delay when traversing from low thrust to high thrust because of the need to prime the secondary manifold. This would have to be corrected for fast thrust response missions. Continuously flowing fluid through the secondary manifold - either by a bleed flow through the secondary valve or a bleed flow from the primary fluid flow - was proposed to reduce the response during transition.

The throttling heat transfer results suggested the boundary layer in the nozzle region would transition from turbulent to transitional and/or laminar some time during the throttling range.

\section{Reusable Rocket Engine Program (1967) $)^{52-63}$}

Pratt \& Whitney contracted with the U. S. Air Force over several years in the late 1960s and early 1970s to develop a reusable advanced cryogenic staged combustion engine. The initial configuration of this engine was required to throttle 5-to-1 and deliver $96 \%$ theoretical specific impulse at nominal thrust and $94 \%$ during throttling. Consequently the injectors included dual-manifold systems in both oxidizer circuits of the preburner and main injectors, and a variable area system in the fuel circuit of the preburner injector. Both injectors used oxidizer tangential-entry swirl coaxial element designs with dual-inlets, with the main injector including two tangential inlets (also called a "stacked" configuration) and the preburner injector including one tangential inlet and one axial (not self-atomizing) inlet. Testing in component and staged combustion configurations revealed stable operation over the 5-to-1 range as well as dynamic stability demonstrated by combustion chamber pulse guns with up to 80 grains of explosive. However, the use of both dual-manifold oxidizer and variable-geometry fuel systems in the preburner was found to be difficult to control, the variable area fuel circuit experienced mechanical problems, and the hot gas temperature profile variability exceeded requirements. The specific impulse efficiency of the main injector also was about $93 \%$ at $100 \%$ power level, and about $90 \%$ at $20 \%$ power level, which also did not meet requirements. The $\mathrm{c}^{*}$ efficiencies were about $98 \%$ and $96 \%$ at nominal and throttled conditions.

A subsequent phase of this program, with an engine renamed the XLR-129, modified both the preburner and main injector in an attempt to satisfy these requirements, including a modification for $99 \% \mathrm{c}^{*}$ efficiency at rated thrust and $97 \%$ efficiency during throttling. The design for the main injector eliminated the dual-inlet (or "stacked") oxidizer circuit and used one major flow passage. The design for the preburner eliminated the variable area fuel system in favor of a fixed fuel area, but modified the dual-manifold oxidizer circuit from one tangential inlet and one axial inlet to two tangential inlets. This preburner configuration is shown in Fig. 12, and the dual-inlet oxidizer swirl coaxial injector element is shown in Fig. 13. Extensive cold flow testing of dozens of preburner element design configurations was conducted to develop a hydrodynamically stable flow over the 5-to-1 operating range. 


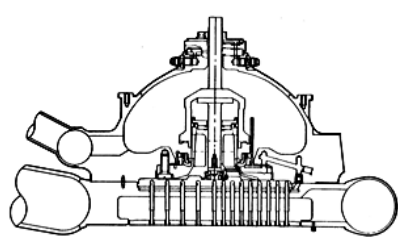

a) Complete Injector

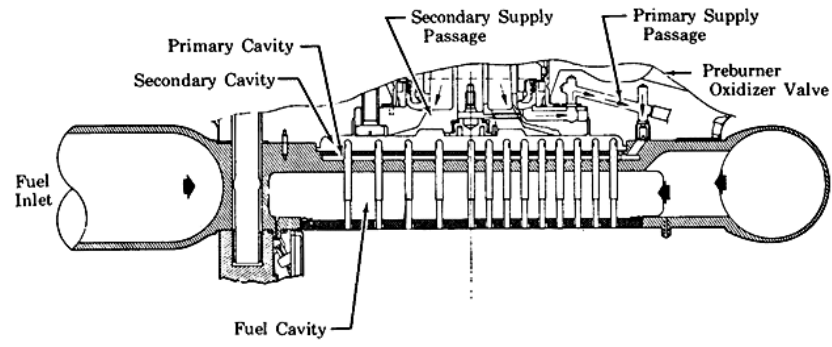

b) Close-up of Oxidizer Dual-Manifold Configuration

Figure 12. XLR-129 Dual-Manifold Preburner Configuration

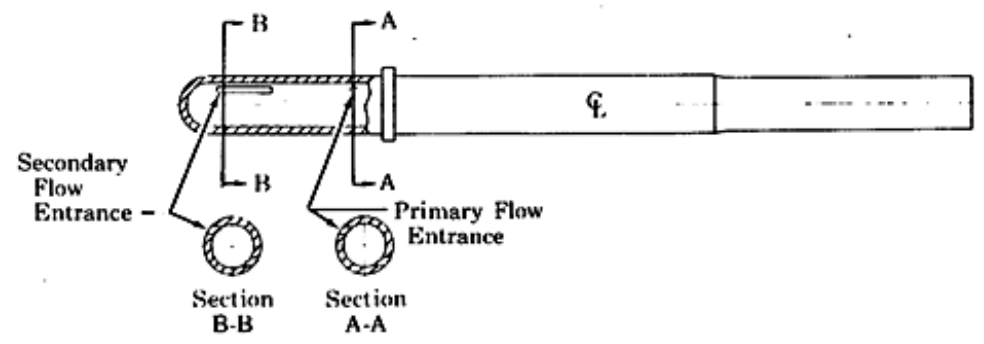

Figure 13. XLR-129 Dual-Inlet Swirl Coax Oxidizer Element

Initial testing of the preburner showed satisfactory hot gas temperature profile variability, but chug was encountered at $20 \%$ power level with amplitudes about $11 \%$ of chamber pressure and frequencies between $75 \mathrm{~Hz}$ and $150 \mathrm{~Hz}$. Development analysis and testing indicated the chug was caused by two factors - low secondary circuit LOX pressure drop and excessive secondary LOX manifold volume. Oxygen flowed through both oxidizer circuits over the entire throttling range, so that at low power levels, pressure drop in the secondary manifold was reduced to a few percent of chamber pressure. The chug was never eliminated even by increasing the primary flow split to $90 \%$ and increasing the mass-weighted percent pressure drop to nearly $60 \%$. Preburner pressure oscillations were postulated to bypass the high-pressure-drop primary flow and drive the system from the secondary flow. This did not happen during the initial phase of the program with a different inlet configuration, even with mass-weighted pressure drops as low as $4 \%$ of chamber pressure. A reduction of the secondary manifold by $20 \%-40 \%$ was predicted to stabilize the system, and during component development a redesigned injector with reduced LOX manifold volumes in both primary and secondary circuits operated without chug at the $20 \%$ power level, although during many tests there was leakage between the primary and secondary circuits.

\section{Throttleable Primary Injector for Staged Combustion Engine Program (1968) ${ }^{64}$}

Aerojet Liquid Rocket Company under contract to the Air Force Rocket Propulsion Laboratory demonstrated a throttleable main injector for a staged-combustion cycle, space engine using storable propellants and a platelet HIPERTHIN injector. ${ }^{33}$ The engine concept was designed to operate over a 10 -to-1 throttling range. Four injector configurations were tested, including three single manifold injectors - showerhead oxidizer/showerhead fuel, showerhead oxidizer/impinging fuel, and impinging oxidizer/impinging fuel - and one dual-manifold injector with impinging oxidizer/impinging fuel. The dual-manifold injector consisted of two fuel manifolds and two oxidizer manifolds with independent platelet circuits for each manifold, as illustrated in Fig. 14.

To achieve the full 10-to-1 throttling range, the main injector included dual manifolds in both fuel and oxidizer circuits, although only a single manifold would be used at low thrust for fuel and oxidizer. The lowest throttling points were stable using single manifolds in both fuel and oxidizer. Chug with peak-to-peak amplitudes $44 \%$ of chamber pressure at $54 \mathrm{~Hz}$ to $115 \mathrm{~Hz}$ occurred when a dual manifold was used with one propellant, although dual manifolds at low thrust was not the normal configuration. Performance was favorable showing as good as or better than the other single manifold designs at the tested mixture ratios, due to the increased atomization of the higher velocity elements producing more momentum exchange at the higher pressure drops. 

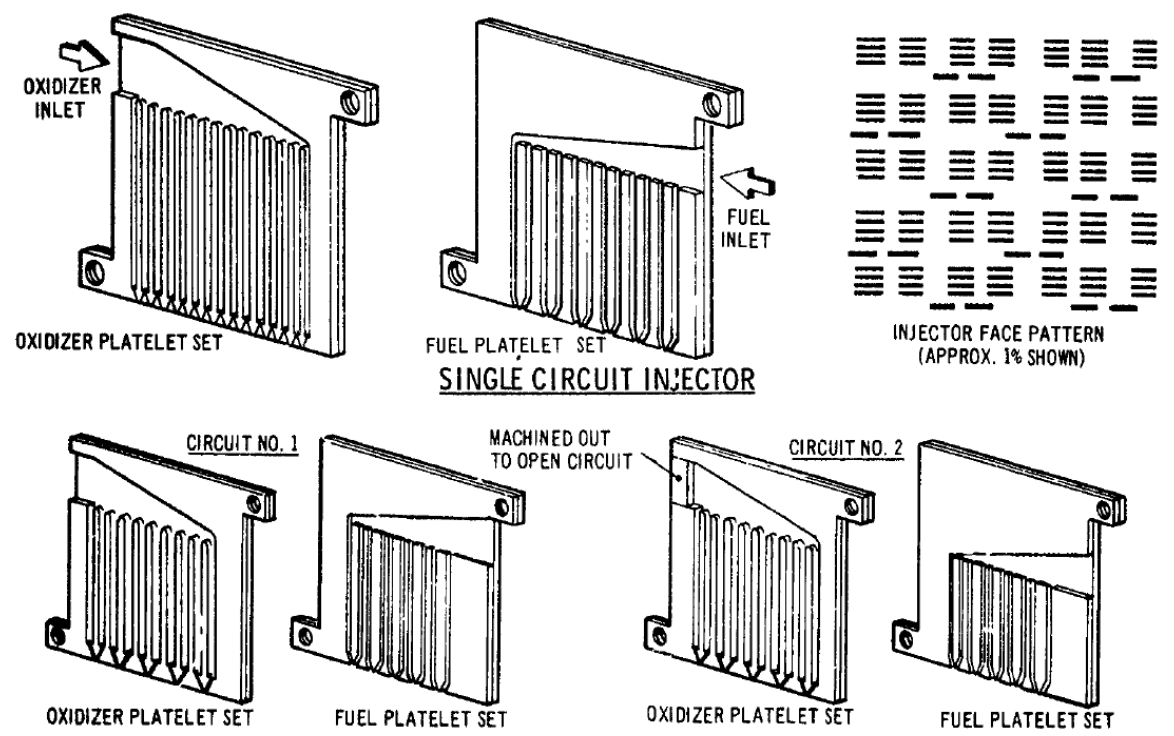

Figure 14. HIPERTHIN Platelet Dual-Manifold Injector Design

\section{Advanced Expander Test Bed Program (1990) ${ }^{65-71}$}

Pratt \& Whitney was contracted by NASA to develop and demonstrate the Advanced Expander Test Bed (AETB), an expander cycle oxygen-hydrogen engine technology applicable for space engines. Among many other features, the AETB was to have a high degree of throttleability with a requirement of 5-to-1 and a goal of 20-to- 1 . Design of the dual-manifold injector had been completed previously in an in-house Pratt \& Whitney Space Engine Component Technology Program. Only the oxygen circuit used a dual manifold; the fuel flowed through a single manifold. The two oxygen streams mixed within the injector element. A lumped parameter electrical circuit analogy analysis of the feed system predicted no chug at 5\%,10\%, and 20\% thrust. Part of the AETB program evolved into a separate technology development NASA Space Act Agreement. This program involved testing a 25 Klbf Thrust Chamber Assembly designed for 20-to-1 throttling capability using the same AETB dual-manifold injector design. Testing took place in 1996 at NASA Marshall Space Flight Center; however the data are currently Pratt \& Whitney Rocketdyne proprietary.

\section{Gas Injection}

Gas injection into the propellants, also referred to as foamed-flow or propellant aeration, is a throttling methodology for LREs that reduces the bulk density of the propellants by introducing a much lower density (sometimes inert) fluid into the propellant flow. The change in flow rate is typically small. For liquid flows at constant flow rate, the pressure drop is inversely proportional to the bulk density. Thus with gas injection at a particular thrust level, the liquid circuit injector pressure drop is increased. The higher pressure drop increases the chug stability margin thrust range and may increase the performance for fixed-geometry injectors. However, Russian experience reports that gas injection can lead to the onset of high frequency pressure fluctuations. ${ }^{4}$

\section{NACA Research (1956) ${ }^{72}$}

A research memorandum published in 1957 by the NACA Lewis Flight Propulsion Laboratory demonstrated rocket thrust variation with foamed storable propellants using helium as the foaming gas. Several qualitative tests of the gas-injection device were made in water. The final helium injector device consisted of a two inch long tube with eleven circles of twenty small holes. Careful calibration of the device was necessary to obtain smooth homogeneous injection and to prevent surges of gas into the liquid. For this system, helium pressure no more than 100 psi greater than the liquid pressure was allowed to obtain smooth helium injection.

A theoretical model was developed that calculated the reduction in liquid flow as a function of gas-to-liquid ratio. The model considered isothermal gas flow under thermal equilibrium and separately, adiabatic flow assuming no energy exchange between the gas and liquid. Less gas injection was shown to be needed at a particular thrust level with a denser liquid propellant flow. Gas injection for thrust variation was shown to be a feasible technique that did not impair combustion efficiency. 
However, several concerns expressed included evaluation of the weight penalty of an additional propellant and its associated hardware, and that discharge coefficients and heat transfer characteristics for a foamed fluid at various conditions would need to be characterized. The importance of keeping the pressure difference between the liquid and gas at a low value was necessary to produce homogenous, uniform, and stable foams. Water flow experiments showed that a large pressure difference created intermittent liquid flows, which could create low frequency combustion instability.

\section{NASA Study - Modified RL10A-1 (1964) 28,41}

During throttling tests of a modified RL10A-1 at the NASA LeRC, described in a previous section, chug occurred at thrust levels higher than expected due to oxygen boiling in the manifold. The sources of the boiling were from increased fuel temperatures in the adjacent manifold along with reduced oxygen saturation temperatures. Videos were taken of the liquid oxygen manifold through a sapphire window. For a particular chug oscillation cycle, oxygen vapor bubbles were observed to form inside the liquid oxygen manifold and then collapse at the same frequency as the chamber oscillations. A sequence of events postulated for this coupled dynamic system was as follows: 1) bubbles began to appear and the liquid oxygen manifold pressure dropped;2) as the size and number of bubbles increased, the bulk density decreased and the injector pressure drop increased; 3) atomization improved and the chamber pressure increased; 4) liquid oxygen flow was reduced and manifold pressure increased; 5) bubbles condensed back into the liquid, which reduced the pressure drop and worsened atomization and lowered chamber pressure; 6) manifold pressure reduced because of an increased liquid oxygen flow, 7) bubbles began to appear again and the cycle is repeated.

To eliminate chug, gaseous oxygen or helium was injected into the liquid oxygen propellant line at the manifold inlet flange to produce a foamed liquid of reduced density. The gas was injected through a vacant instrument port and no attempt was made to distribute the gas or control the bubble size. Video into the manifold showed that the bubbles were too fine to see and appeared as a fog. Helium injection of approximately $0.4 \%$ of the liquid oxygen weight flow, or oxygen injection of $4 \%$ of the liquid oxygen weight flow, eliminated chug over the entire 10-to- 1

throttling range. Differences in required flows were due to the difference in gas volumes as well as condensation of some of the gaseous oxygen.

Gas injection restored the performance lost by the chug. In one case, a $7.5 \%$ increase in $\Delta \mathrm{p}_{\text {inj }} / \mathrm{p}_{\mathrm{c}}$ to a value of $15 \% \Delta \mathrm{p}_{\mathrm{inj}} / \mathrm{p}_{\mathrm{c}}$ eliminated chug at $22 \%$ thrust. The increase in pressure drop to stabilize the combustion with injected gas agreed with the increase in pressure drop required without gas. Helium was also injected into the oxygen manifold at rated thrust levels to see if that improved performance, but only a negligible increase was noted.

\section{Advanced Throttling Concepts Study $(1964)^{43,73}$}

Pratt \& Whitney Aircraft also studied a gas injection technique called cross-injection, in which small amounts of storable fuel were injected into the storable oxidizer propellant line and small amounts of oxidizer were injected into the fuel propellant line, which produced combustion gas in the propellant lines. The propellant line pressures were increased which improved throttling capability.

Two operational modes were considered using a fixed area injector. In the first mode, an appropriate mixture ratio (for the secondary cross injected flow) was determined for a particular thrust that provided a temperature and pressure rise in the propellant line at that thrust level. A significant pressure drop was established across the injector. However, since the secondary line pressure remained constant as the propellant flows increased, the pressure drop increase returned to that of a fixed injector case, so that this mode was only beneficial over a small thrust range.

The second mode requires control of the secondary propellant flow. The secondary mixture ratio was held constant over a thrust range ( $2 \%$ to $\sim 20 \%$ in this case). The disadvantage was that this required a more complicated flow control, but it would maintain high injection pressures and velocities over the range of interest. Figures 15 and 16 show the effect on injection pressure drop considering a small amount of secondary oxidizer flow into the primary fuel line.

The cross-injection technique was hot-fire tested with an injector in the secondary line that provided a $90^{\circ}$ hollow spray pattern in water flow giving fine atomization. Secondary propellant flow mixture ratios were ranged from 0.003 to 0.009 for the fuel-into-oxidizer case and 147 to 525 for the oxidizer-into-fuel case. Repeatable and stable results were demonstrated, with only very small amplitude oscillations evident at $10 \mathrm{~Hz}$ and $170 \mathrm{~Hz}$. 


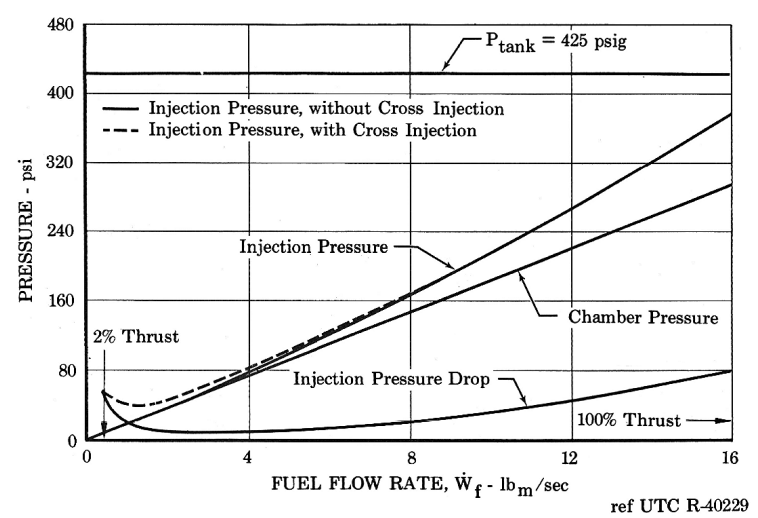

Figure 15. System Pressures versus Fuel Flow Rate with a Constant Secondary Mixture Ratio

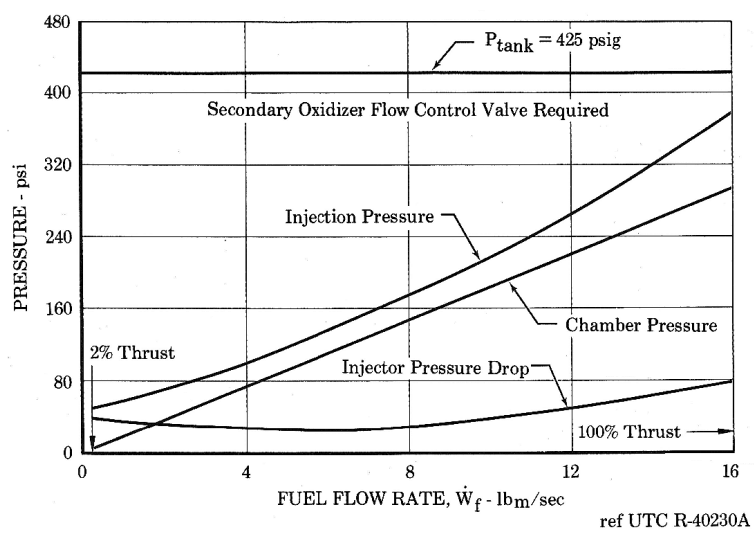

Figure 16. System Pressures versus Fuel Flow Rate with a Constant Secondary Oxidizer Pressure

\section{Throttling Concept Study $(1965)^{74}$}

The Bendix Corporation investigated the gas injection technique using nitrogen gas with a storable propellant injector. A throttle range of 35-to-1 was demonstrated with nitrogen, and a 50-to-1 throttle range was considered possible using helium gas instead of nitrogen. Combustion was stable and efficiency was preserved over the entire throttle range. This concept evolved into the Bimode Bipropellant Attitude Control System which was capable of both pulsing and continuous throttling. Attitude control motors normally use maximum thrust to maneuver the vehicle. However, stabilization, being a much more complex mode, in general would benefit greatly from a varying thrust capability. The Bimode concept keeps the advantage of short duration, maximum amplitude, thrust pulses that result in the maximum unaccelerated coasting time.

\section{Other Engines}

The Rocketdyne SE-10 engine, a competitor to the variable area injector design for the Apollo lunar descent engine, used the helium gas injection at low thrust to enable deep throttling. ${ }^{3,19,75}$ However a $200 \mathrm{~Hz}$ to $500 \mathrm{~Hz}$ chug at low thrust as well as intermittent popping remained present with and without the helium injection. Additional problems with self-induced first tangential modes occurred early in developmental tests, which were solved by implementing a Y-shaped baffle arrangement. ${ }^{76}$

Attitude control thrusters and other very small thrusters (with thrusts of near $1 \mathrm{lb}^{77}$ )use the gas injection technique to not necessarily increase the injector resistance to enable deep throttling, but to alter the total flow rate. This is possible because at low thrust, the flow change due to the inception of gas is not negligible like at high thrust.

\section{Multiple Chambers}

The principle of throttling with multiple chambers is through stopping flow through one or more chambers or varying the thrust of each chamber independently. A deeper throttling can be obtained by independently throttling multiple chambers by a small amount. This concept is primarily used in aerospike engines but has been used in other rocket engine systems as well. Disadvantages include feed system complexity and additional weight, as well as managing propellants and thrust transients during each engine startup or shutdown. ${ }^{19}$

Russian engines often use this feature for reasons other than strictly for throttling. ${ }^{3,78}$ It was experienced that small diameter combustion chambers solved stability problems exhibited in larger diameter chambers. With multiple chambers, each chamber diameter can be reduced. Additionally, smaller parts were easier to manufacture, there was an improved capability to provide thrust vectoring, and the engine overall length was reduced. The 'engine-out' reliability was said to be increased because one or more thrust chambers could be shut off and the total thrust could be maintained by increasing the thrust of the other chambers. Multiple chambers do not provide the optimum engine weight. 


\section{Advanced Thrust Chamber for Space Maneuvering Propulsion Program (1965) ${ }^{79-84}$}

The Air Force Rocket Propulsion Laboratory at Edwards Air Force Base sponsored a Rocketdyne study in 1965 to investigate a space maneuvering propulsion system to be used for satellite intercept or rendezvous. The engine design included multiple concentric regeneratively cooled thrust chambers. Two multiple chamber concepts were combined in one engine study. The first concept was the aerospike engine which could be throttled and contained many small chambers and nozzles. The second concept was to have a standard chamber and bell type nozzle inside of the separate aerospike engine. The outer primary thrust chamber was a toroidal aerospike, divided into segments, producing $30 \mathrm{Klbf}$ thrust, while the secondary inner thrust chamber included a bell nozzle producing $3.3 \mathrm{Klbf}$ thrust.

The development focused on the primary chamber because of the unique toroidal features of the aerospike chamber. It included testing of a full size segment that was $1 / 47^{\text {th }}$ of the toroid circumference. Short duration tests were performed over a chamber pressure range from 300 to 600 psia, and combustion efficiency remained high.

Analysis and design for the follow-up Advanced Maneuvering Propulsion Technology Advanced Development Program was initiated in 1967. The final engine configuration is shown in Fig. 17. Both the $3.3 \mathrm{Klbf}$ chamber and the $30 \mathrm{Klbf}$ chamber would throttle 9-to-1, providing a total effective throttling ratio of approximately 81-to-1. Combustion was stable during hot fire tests of the outer primary chamber segments over a chamber pressure range from 650 psia to 72 psia. Dynamically stable combustion was demonstrated with pulse gun testing. Combustion efficiency ranged from $98 \%$ to $100 \%$ over the entire throttling range of the tested segment.

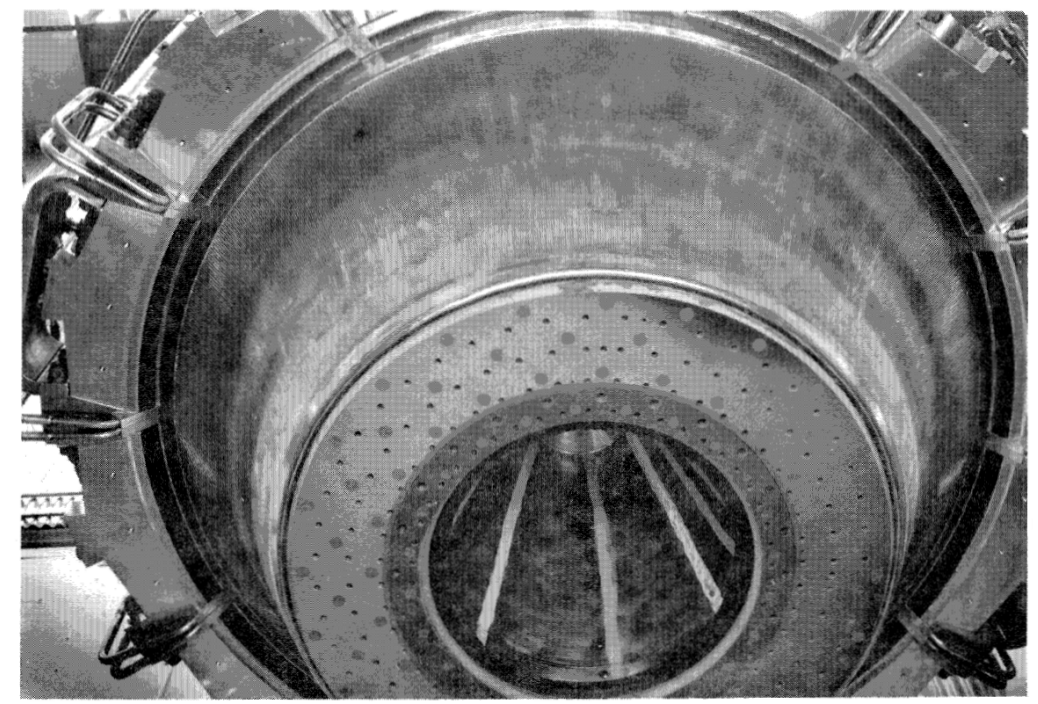

Figure 17. Advanced Maneuvering Propulsion Technology Advanced Development Engine

\section{Other engines}

Many Russian engines have employed multiple chambers, although primarily for combustion stability and manufacturability. ${ }^{35}$ The recent RD-170 and RD-171 engines with four thrust chambers and the RD-180 with two thrust chambers each include one turbopump with each engine system. The RD-170 and RD171 provide 1,777 Klbf vacuum thrust and can throttle to $56 \%$ of maximum thrust, while the RD-180 provides $933.4 \mathrm{Klbf}$ vacuum thrust and can throttle to $40 \%$ thrust.

\section{E. Pulse Modulation}

Pulse modulation, short for Pulse-Width Modulation (PWM), is used predominantly in monopropellant engines. PWM is on-off cycling that provides a quasi-steady state average thrust. PWM in LREs has its roots in pulse jet engines. The German V-1 guided missile developed in Peenemünde contained a pulse jet engine that was flown for military purposes in 1942 and most well known for the London bombing in 1944, and was also known as the "buzz bomb' because of the low frequency sputtering sound caused by set frequency pulses at $100 \mathrm{~Hz}$ and a resonant combustion response at roughly $50 \mathrm{~Hz}$. The air intake shutters closed as the fuel ignited and gas expanded for a short duration. ${ }^{85,86}$ 
Pulse Detonation Engines (PDEs) are a similar recent technology, except that PDEs detonate the fuel and oxidizer mixture while the flow is supersonic. While the PDE combustion process is more efficient than PWM, there have been difficulties converting the energy into efficient thrust.

The primary issues related to PWM are fast response valves and low performance. However, PWM is advantageous when small thrust corrections are needed such as in satellite rendezvous. Throttling with PWM is accomplished with tailoring of the thrust and durations of the pulses. Other disadvantages are shock loading on the vehicle, heat soak in the chamber head end, inefficient use of propellant due to chamber cooling channel and injector dribble volume losses between pulses. ${ }^{19}$ Additionally, the igniting each pulse can be difficult especially for very short pulse widths.

\section{NASA Studies $(1959)^{87,88}$}

A 1959 NASA report examines rendezvous scenarios between two satellites, assuming that one satellite is maneuverable with velocity increments tangential to the orbit. Pulsed thrust was considered for the several maneuvers required for various rendezvous scenarios. The use of fixed-duration thrust pulses, in which pulses provide the necessary total $\Delta \mathrm{V}$ or total amount of thrust necessary to complete a maneuver, was slightly different from the PWM methodology, which uses numerous pulses at a particular frequency and pulse width to provide an average specific impulse and thrust profile. However, the single impulsive thrust maneuver capability was developed initially for use in satellite maneuvering.

In 1961 NASA examined a PWM methodology to evaluate a linear system for applying thrust to a maneuverable vehicle in the terminal phase of a rendezvous. The throttleability limitations of an existing rocket engine are not necessarily a major obstacle to the system design of a maneuverable satellite. However, maneuverable satellites, such as for terminal phase rendezvous systems, would need to employ systems that would average out to be the same thrust as can be performed with a continually variable thrust engine, as illustrated in Fig. 18. The average thrust needed to complete a mission, for example, is shown in the first inset. The second inset gives an effective throttling approach by using pulse modulation of a constant width but with variable thrust. The third inset gives an effective throttling approach by using pulse modulation of variable width but constant thrust. Both methods can be designed to provide the same thrust profile.

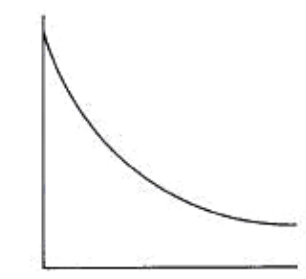

Thrust Program for a System

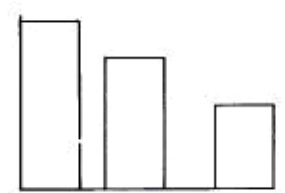

Approximation for which Thrust Interval is Fixed and Thrust is Variable

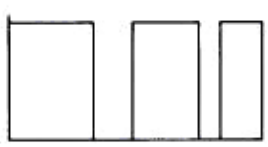

Approximation for which Thrust Magnitude is Fixed, but Duration is Variable

Figure 18. Pulse-Width Modulation Throttling Approaches

\section{Lunar Flying Vehicle Study $(1964)^{89}$}

Bell Aerospace Company began development of a 100-to-1 variable thrust engine in 1964, called the Bell model 8414 Throttleable Maneuvering Engine, for earth orbit, lunar, and planetary spacecraft maneuvering propulsion systems. This engine system combined a continually varying thrust engine and a pulse engine to provide continuous throttling and pulse operation capabilities with maximum performance at highest thrust, where most of the propellant would be consumed. Deep throttling and pulsing performance could be provided without compromising the high thrust performance.

A single fixed-type injector was optimized over the entire thrust range to maintain adequate injection velocities and injector pressure drops for efficient and stable combustion. Gas-injection methods were rejected because of the increased complexity and system weight penalty and dual-manifold and variable area injector methods were also rejected as too complex since most of the time the engine operated at high thrust.

A six-element triplet injector was optimized for performance and pulse response - enough elements for high performance and few enough to minimize manifolding volumes for maximum pulse response and pulse performance. Two independent valves were used, a throttling valve and a bipropellant variable area cavitating venturi with an actuation time of 5 milliseconds attached directly to the manifold. 
Continuous throttle, without pulsing, was achieved down to $12 \%$ of rated thrust. Combustion was controllable, stable, and reproducible. Combustion performance was $94 \%$ at rated thrust with maximum specific impulse at $87 \%$ thrust. Pulse performance was measured from $100 \%$ to $20 \%$ rated thrust using pulse durations of $150 \mathrm{msec}$. Ignition spikes reached a maximum $300 \%$ of the rated pressure.

Figure 19 compares the performance curve for pulsing at a set thrust with continuous throttling of a set thrust and illustrates one of the disadvantages of PWM. There was a major degradation in performance at a specific thrust level due to the short duration time and transient event of the pulse. How much less performance an integrated thrust of the pulse would be compared to a steady state set point of equivalent average thrust was not clear, although it was still expected to be lower due to lower performing conditions during the transient. With even shorter pulses, there is more degradation in performance.

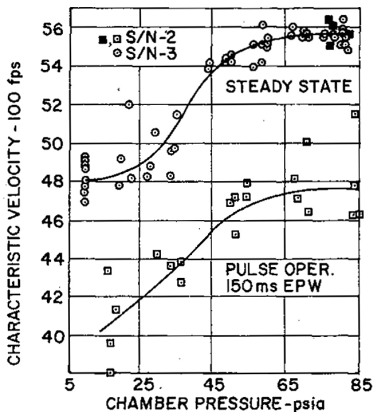

a) Comparison of Steady and Pulsing Performance

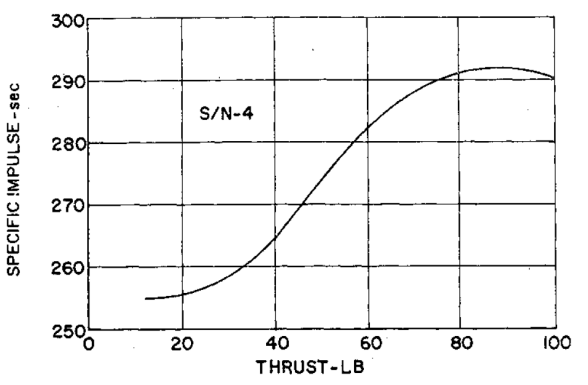

b) Steady Performance

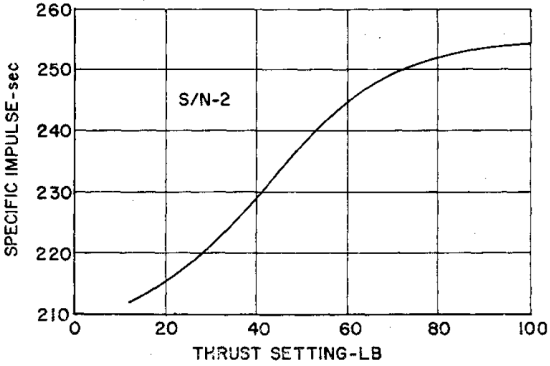

c) Pulsing Performance at 150 msec Pulse-Width

Figure 19. Pulsing Performance Comparisons

The program demonstrated the feasibility of combining single injector throttling with PWM to extend the thrust to deep throttling of 100-to-1. Figure 20 shows the performance over the range of thrust with continuous variable thrust down to $12 \%$ thrust and PWM down to $1 \%$ thrust.

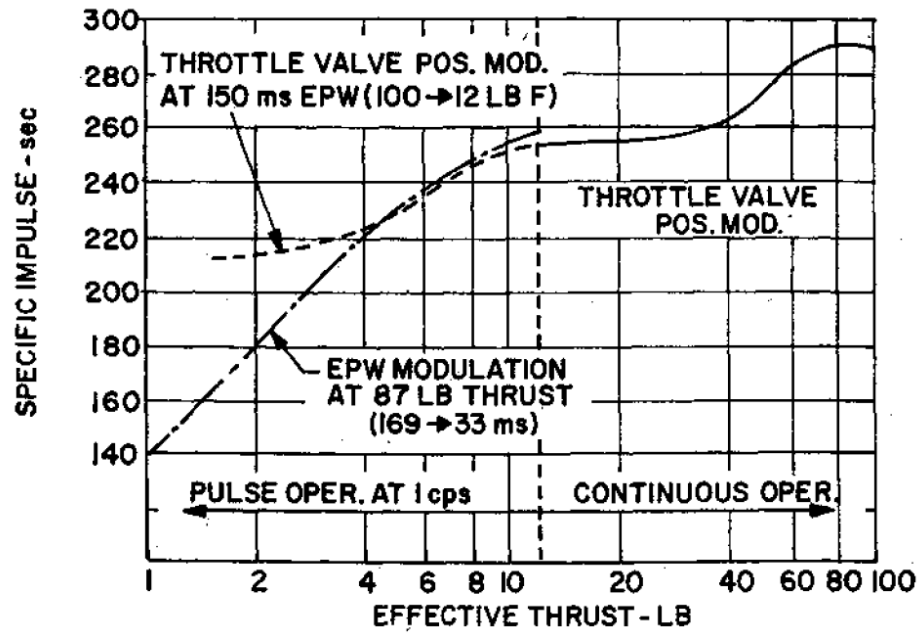

Figure 20. Dual-Mode Throttling Performance

\section{The Bendix Corporation Study $(1965)^{74}$}

The Bendix Corporation reviewed the state-of-the-art techniques of pulsing and variable area throttling in 1965. The pulsing techniques included problems such as low combustion efficiency, high electrical power consumption, low response, materials problems, and unwieldy configurations. Specific impulse was reduced when operating in a regime that required short pulse widths. The repeatability and consistency of engine performance was dictated by the control and minimization of fuel usage by the pulsing accuracy. At that time, varying pulse widths using a single thrust level was not successful and pulsing accuracy was not achieved. 


\section{F. Throat Throttling}

The throat throttling method appears to have been one of the first methods to throttle LREs. Two approaches were defined, including use of a cooled mechanical pintle inserted and retracted through the nozzle throat, and injection of a gas into the throat region. Both methods effectively changed the throat area by providing some blockage into the flow field. Both modes have a net effect on decreasing thrust, since at constant propellant pressures, a throat restriction causes an increase in chamber pressure and hence lower injection pressure drops and reduced propellant flow rates. Because of the high chamber pressures at low thrust, there is an associated maximum theoretical performance at low thrust. The major concerns are excessive vibrations and heat transfer of the pintle. Other issues are that the injector design must provide high injection pressure drops at full flow conditions to maintain minimum pressure drops at low flow rates. Another disadvantage is the high pressure propellant feed system necessary.

\section{Reaction Motors, Inc. Study $(1947)^{90}$}

Reaction Motors, Inc. (RMI) developed a small acid-aniline propellant variable thrust LRE using a throat throttling device called a bulb or restrictor to vary the area of the throat, as shown in Fig. 21. The throat area was varied by inserting and retracting the restrictor, which was internally cooled by fuel through the center shaft and the restrictor bulb since materials that could withstand the temperature were not available to allow an uncooled design. The fuel was then fed into the injector elements. The nozzle and chamber walls were cooled by the oxidizer, which was then also fed into the injector elements.

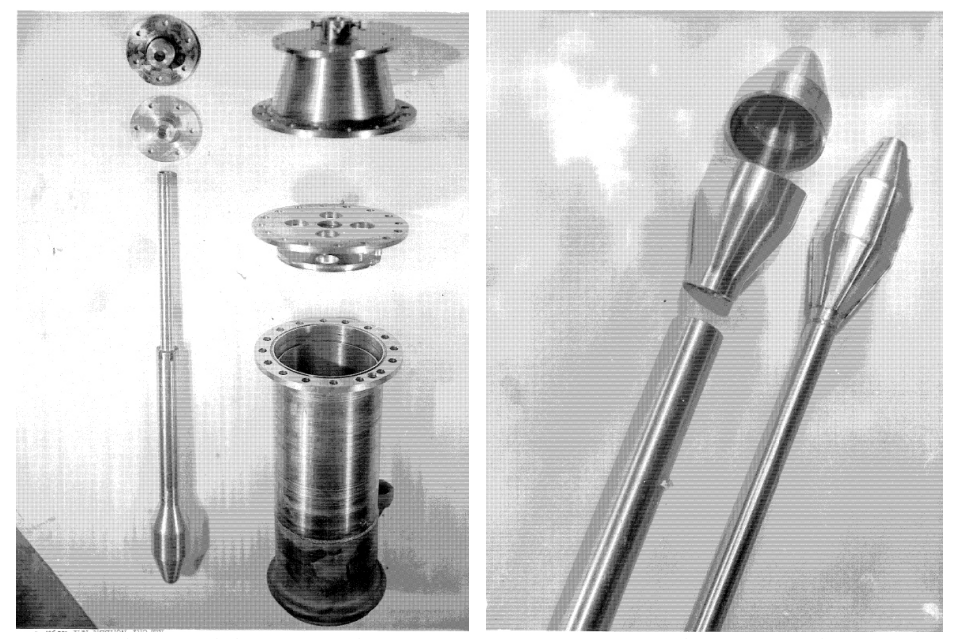

Figure 21. Reaction Motors, Inc. Restrictor Device

With a varying throat area needed for a throttle range of 6.25 -to- 1 , the $\mathrm{L}^{*}$ also varied from 43.5 in. to $272 \mathrm{in}$. A compromise $\mathrm{L}^{*}$ design range was chosen for a single constant volume chamber. Propellant flow rate was also controlled to maintain constant chamber pressure based on the nozzle throat area using a closed loop control system.

The nozzle throat area was originally varied with a restrictor bulb that gave poor expansion ratio characteristics at low thrust, but this was later improved. Large vibrations occurred in one test thought to be due to injector valve flutter. Stiffer propellant valve springs were to be incorporated in future designs. Only a few tests were performed at $60 \%$ and $75 \%$ thrust because of broken lines and severe vibrations. Limited performance information was obtained because of these issues.

\section{Massachusetts Institute of Technology Naval Supersonic Laboratory Study $(1961)^{91}$}

The Office of Naval Research sponsored research in the Naval Supersonic Laboratory (NSL) at Massachusetts Institute of Technology (MIT) for throttling by gas injection into the nozzle throat. A symmetric secondary flow was injected into the nozzle throat to alter the nozzle flow. The total flow ratio - or the ratio of primary flow injected into the chamber plus the secondary flow to the primary flow with no secondary flow - was unity, which indicated that the exhaust velocity did not change with injection rate and the flow behaved as though throttling was accomplished by varying the throat area. Three separate models were developed to analyze this throttling method. The models of Martin ${ }^{2}$ were the first analytical solutions to this flow throttling problem, but disagreed with the NSL 
data. In [91] an improvement to these models was made. The two models based off of Martin's work were the secondary mixing model and the sheet flow model. A newer model, the secondary expansion model, was also developed. Basic assumptions to these models include one-dimensional flow, perfect gas, and isentropic flow. Two-dimensional and three-dimensional airflow investigations validated aspects of all three models. Schlieren photographs showed that all three types of flow occurred.

In addition to these three models, a flow analogy was developed and other pertinent variables investigated. The analogy treated the secondary flow as a blunt body and then combined the two flows with matching boundary conditions. Three variables investigated were temperature, secondary injection gas type, and combustion. There was a significant effect as the secondary fluid stagnation temperature was reduced lower than the primary flow stagnation temperature. Throttling was ineffective for a secondary stagnation temperature 5 times less than the primary stagnation temperature. This effect was also evident in Rocketdyne testing on the $\mathrm{F} 1$ engine and additionally in United Aircraft Corporation (UAC) thrust vectoring experiments. ${ }^{93}$ Rocketdyne showed that a stagnation temperature ratio of 4 did not throttle the primary flow. UAC showed that the effectiveness varied with the square root of the secondary-to-primary stagnation temperature ratio. The high temperature of the secondary working fluid seems to limit the practicality of throat throttling with gas injection.

The type of injection gas also had an effect on throttling behavior. A low specific heat ratio and low molecular rate were desirable properties of the secondary gas because of the low molecular weight and low specific heat ratio of the combustion gas. Helium showed the most potential as a throttling secondary gas because of its low molecular weight.

Other variables examined were injection angle, nozzle throat pressure gradient, and secondary flow injection location. Throttling increased with decreasing injection angle, the angle between the nozzle axis and the injection axis. A reduction in the nozzle throat pressure gradient had a small effect on increasing flow throttling. The location of the secondary flow injection needed to be at the throat because the influence is strongest there to create a choked primary flow.

\section{Other Engines}

A February 1946 Aerojet report (Report No. RTM-20) described the development of a $100 \mathrm{lb}$ thrust nitromethane monopropellant variable thrust engine. A stainless steel pintle was moved into the nozzle throat to vary the thrust 10 -to- 1 . Performance was measured only at $65 \%$ and $100 \%$ thrust. A $1948 \mathrm{M}$.W. Kellogg report (Report No. SPD-156) described and presented a highly complex injector design that showed the throat throttling methodology. The throat was throttled by a pintle and the injector. The injector contained movable concentric injector rings. A 1950 University of Michigan report (Report UMN-71) discussed variable thrust engines using throat throttling, and concluded the method to be not feasible because of low pressure drops at low thrust. The report also stated that combustion instability would be likely with the RFNA and aniline propellants in an engine with a 100 inch $\mathrm{L}^{*}$. The variable $\mathrm{L}^{*}$ was not taken into account. An analytic study of variable thrust LREs was performed by the Army Ballistic Missile Agency on the Redstone Arsenal in Alabama in 1961. ${ }^{94}$ The analysis compared the relative efficiencies between a variable throat area nozzle and a fixed nozzle geometry for storable propellants. The report concluded there would be a $10 \%$ weight savings of propellant due to the performance increase gained with the variable throat area nozzle, which was insignificant to the overall vehicle weight. The underlying assumptions of the configurations and model were not provided.

\section{G. Variable Area Injector}

The variable area injector is often referred to as a pintle injector because the majority of variable area injectors contain a single central pintle feature that is moved to vary the injector orifice area. The maximum thrust occurs when the injection orifices are fully open. As the injection area is reduced using movable injector components, the chamber pressure and thrust are reduced. Pressure drop increases as the engine throttles down because of the decreasing injection area, which results in high injection velocities and good atomization and high combustion efficiency over a wide throttle range. The most familiar variable area injector throttleable engine is certainly the Apollo Lunar Module Descent Engine (LMDE).

The major advantages to this method are its design simplicity, but with some complexity of the actuating and guiding elements. Design requirements are sometimes conflicting, such as different injector pressure drops to obtain throttling chug stability and maximum combustion efficiency. An optimization based on mission requirements provides the tradeoff between performance and throttling capability. Generally there is a need for flow control valves in conjunction with variable area injection for complete mixture ratio and throttling control. Performance efficiency may not be as high as it would be in a multi-element injector. 


\section{Variable Thrust Engine Development Program $(1950)^{95}$}

Reaction Motors, Inc. examined variable thrust pressure-fed engine designs based on injectors previously tested under the U. S. Navy's Bureau of Aeronautics (BuAer) and the U. S. Air Force. Four injector concepts were examined that represented methods to control the relationships of propellant flow rates, injector pressure drops, and chamber pressure. The first injector concept used a single controllable valve that changed the injector annulus area of one propellant. The second injector concept used a single controllable valve for both injector holes. Atomization was promoted by having radially injected propellants impinge on a splash plate. The third injector included valve control of the axial movement of a flow selector piston that covered or uncovered small holes permitting selection of specified flow. The propellant streams impinged on a splash plate prior to injection into the chamber. The fourth injector concept consisted of two poppet valves. The variation of propellant inlet pressure gave a wide flow range for a prespecified smaller range of injector pressure drop, which was accomplished by balancing the pressure drop with poppet spring forces.

\section{Project $M X-794(1951)^{96}$}

As follow-on to the propellant throttling study described in a previous section, two additional progress reports were published by the Willow Run Research Center at the University of Michigan. The second and third progress reports evaluated the variable area throttling methodology.

In the second progress report, an injector was converted into a throttling injector by using a plunger whose movement simultaneously covered or uncovered both propellant ports, thus keeping the mixture ratio constant and the propellant flow rates controlled from a constant supply pressure. Multiple swirl injectors with various size propellant orifices were tested to obtain performance information for a particular injector design configuration. The best performing injector was converted into a variable area injector. Continuous throttling was achieved over a range of 27-to-1. With a constant supply pressure, the pressure drop increased as the engine throttled down, which minimized rough burning at low chamber pressures. The throttleable injector showed lower performance than single thrust injectors tested with various size injection orifices, and the condition worsened as propellant flow decreased. This result was attributed to the result of improper mixing due to the changing of the propellant entry angle. Covering of orifices by the plunger altered the entry angle of the flow so that less mixing was obtained.

In the third progress report, different size injectors, different types of injectors, and different propellants were tested. The same remotely controlled plunger was used to cover and uncover the propellant orifices. Continuous throttling was achieved over a 35-to-1 range for the lower thrust engines and 6-to-1 for the larger thrust engines. Triangular orifices maintained a constant geometric shape, as the plunger covered or uncovered the holes, which provided better flow control at low flow rates, although the holes were difficult to fabricate. The other injectors had circular or rectangular orifices.

High frequency combustion instability was encountered at higher chamber pressures with the low thrust WFNA and jet fuel propellant combination. The instability was eliminated by increasing the chamber contraction ratio from 8-to-1 to 16-to1. The chamber diameter was increased and the chamber length was decreased with a net increase in $\mathrm{L}^{*}$.

For the mid-range thrust development tests, the propellant supply pressure was constant, which allowed the pressure drop to increase with decreasing chamber pressure, and the mixing and spray formation to improve at lower propellant rates. No combustion instabilities were experienced even after reducing the pressure drop by lowering the propellant tank pressures. In one case the plunger seized, which was corrected with an o-ring seal between the plunger and the injector body.

\section{NACA Study $(1955)^{97}$}

An investigation to examine the performance and operating characteristics of two variable area injectors over a wide thrust range was conducted by Tomazic in 1955. The first injector was a triplet impinging-jet injector with six groups of 10 triplet sets; each group was controlled by a pneumatic valve actuator, which varied the number of triplet sets that were open. The second injector was a swirl-cup injector where two fuel entry holes and two oxidizer entry holes injected the propellants in a swirl pattern into a cup. The orifices were arranged alternately 90 degrees apart. A movable piston formed the bottom of the cup and was moved by a pneumatic valve actuator. The piston moved over the entry holes to change the area. Schematics of the two injectors are shown in Figs. 22 and 23. 


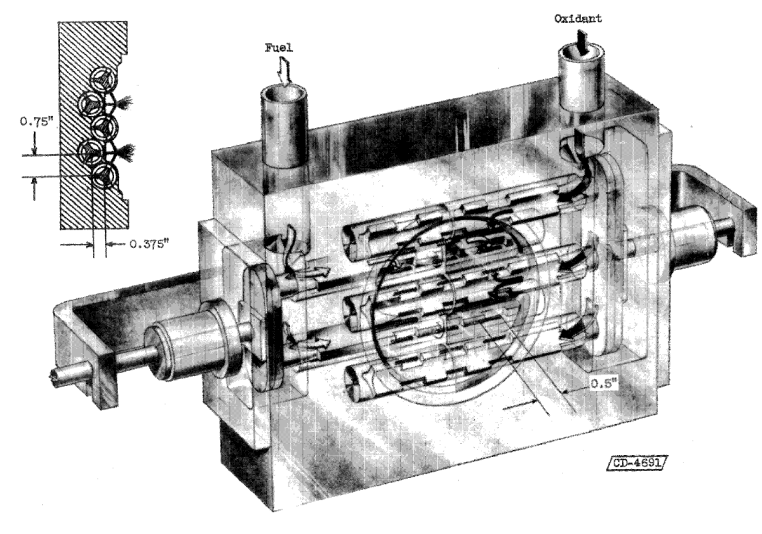

Figure 22. Triplet Impinging-Jet Variable Area Injector

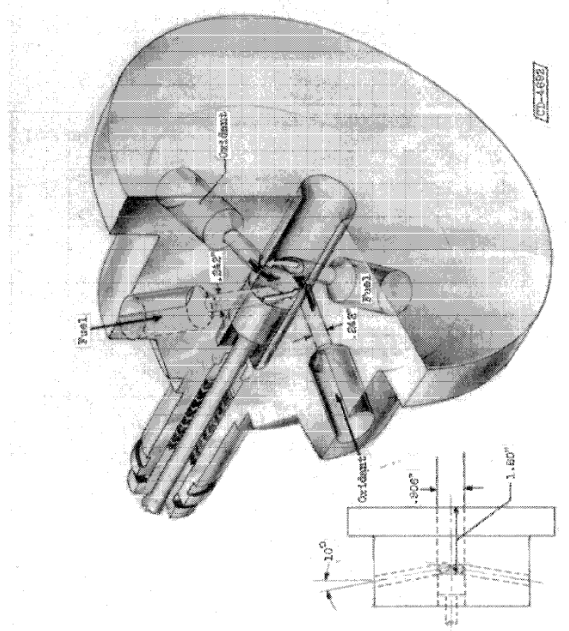

Figure 23. Swirl-Cup Variable Area Injector

The triplet impinging-jet injector was tested over a thrust range of 12-to-1 and the swirl cup injector was tested over a thrust range of 18.5-to- 1 . The triplet injector had $96 \%$ efficiency at full thrust, which steadily decreased until $20 \%$ thrust where it decreased sharply. The swirl cup injector had $90 \%$ efficiency at full thrust which also decreased sharply below $20 \%$. Figure 24 compares combustion efficiency for the two injectors.

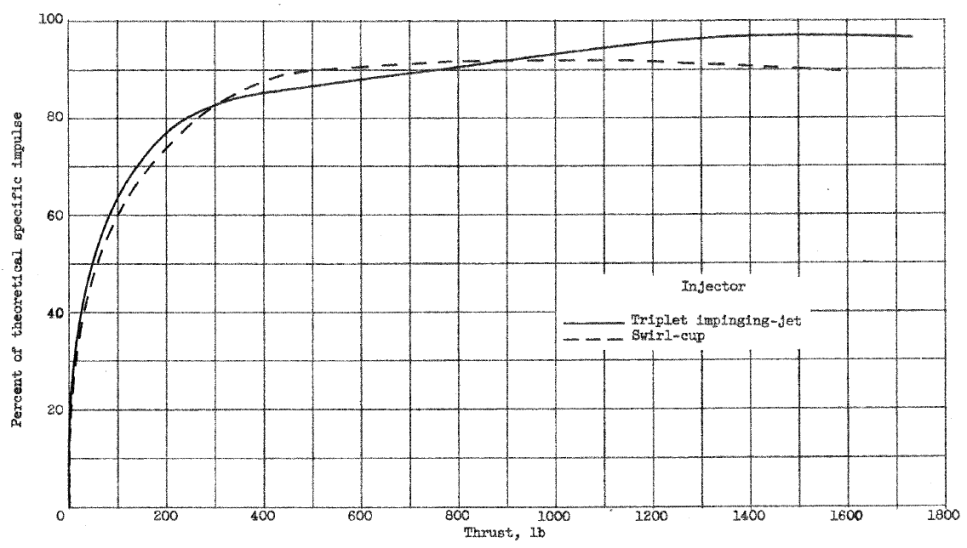

Figure 24. Theoretical Specific Impulse for Triplet Impinging-Jet Variable Area Injector

One difficulty in this setup was leakage around the pistons, which degraded the spray pattern and altered the mixture ratio. The performance drop in the triplet injectors was attributed to this leakage and poor mixture ratio control. The performance drop in the swirl-cup injector was attributed to poor mixing at low thrusts as was demonstrated in water flow tests.

\section{Lunar Module Descent Engine Program (1963)}

The most well known throttleable engine in the United States is certainly the Lunar Module Descent Engine (LMDE). Engine development began in 1963 and man-rated qualification was completed in 1967. The engine was first used on Apollo 5 in an unmanned configuration in January 1968, and then on Apollo 9 for a manned flight in March 1969. On Apollo 11, the engine landed astronauts Neil Armstrong and Buzz Aldrin on the surface of the moon. The engine was also used to return the astronauts of Apollo 13 to an earth orbit from a lunar orbit after an oxygen tank failure damaged the service module.

The operating requirements of the LMDE included a 10-to-1 throttling capability. The nominal LMDE duty cycle included a 33-second orbit injection burn, an hour on-orbit coast, and a 784-second descent burn, as shown in Fig. 25. Both engine burns started to $10 \%$ while the vehicle was stabilized. The descent firing included a full thrust 
braking phase and a $60 \%$ thrust braking phase, followed by a slow reduction to $40 \%$ thrust during vehicle flare-out, and reduction to near $25 \%$ during the hovering phase.

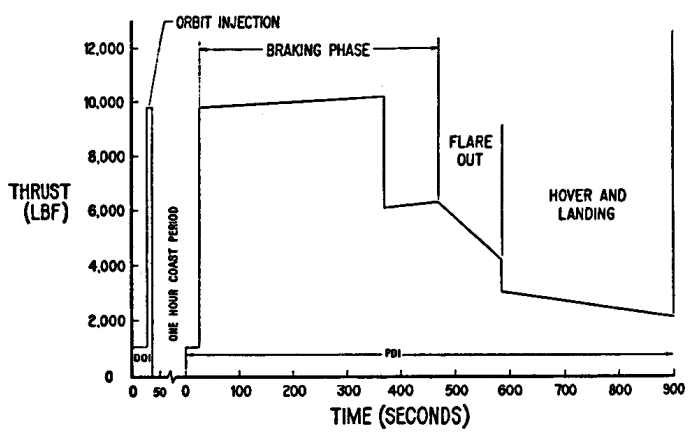

Figure 25. LMDE Nominal Duty Cycle

The engine schematic is illustrated in Fig. 26. Fuel cooled the injector faceplate and flowed into the combustion chamber out of the annular orifice of the pintle injector element. The annular orifice was created by an extension of the injector face and a moveable sleeve. A small portion of the fuel was injected along the side of the chamber wall through thirty-six tubes. The oxidizer flowed through the center of the pintle and was injected radially near the tip through thirty-six holes. Movement of the fuel sleeve varied the injection area of both the fuel and oxidizer.

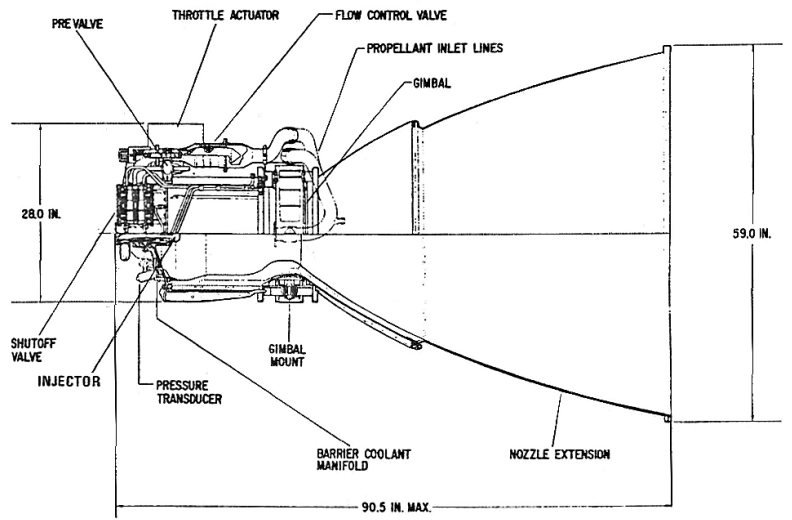

Figure 26. LMDE Engine Layout

Three fundamental requirements for the descent engine system were 1) accurate mixture ratio control over the entire thrust range, 2) controlled injection for performance and combustion stability over the entire thrust range, and 3 ) simplicity of moving parts. Two solutions were employed to solve these requirements. First, the propellant flow control was separated from the propellant injection functions, which allowed optimization of each without one compromising the other. Second, an injector with a centrally located single element pintle contained a single moving part to vary both the oxidizer and fuel orifice areas. This solution provided the greatest design simplicity.

One disadvantage with variable area injectors is the inability to control mixture ratio, since as the injector orifice area changes, the mixture ratio can change as well. The method used to control the mixture ratio in LMDE was to incorporate variable area cavitating venturis in the propellant lines in addition to the variable area injection orifices, which ensured that the propellant flow rates would be insensitive to variations in downstream pressures that resulted from injector orifice area changes. Provided the manifold pressure stayed below the pressure required for cavitating flow, the flow rate would remain constant. The cavitation regime was active only below $70 \%$ thrust; otherwise the propellant flow was controlled by the pressure drop of the entire system, which eliminated the large pressure loss penalties associated with high cavitating flows.

Combustion instability was addressed by positioning the single element injector in a region that minimized coupling with tangential acoustic modes of the chamber. A centrally located injector element would be most stable for a tangential acoustic mode, which has a pressure node line through the center of the chamber and is most resistant to a driving combustion forcing function at this location. On the other hand, a centralized element injector would be susceptible to a radial acoustic mode, which has an antinode in the center of the chamber. However, 
neither radial nor tangential modes were detected from over 2800 tests including 31 bomb tests. The reason the first radial mode was not excited may have been due to the reaction zone being annular rather than concentrated exactly in the center of the chamber. Low frequency pressure oscillations were present during throttling transition with 20 psi peak-to-peak in the 10 to 100 psi chamber pressure range.

Performance remained relatively high over the throttling range, as shown in Fig. 27.

SPECIFIC MAPUSE PERFORMANCE (PRIOR TO TMROAT EROSION)

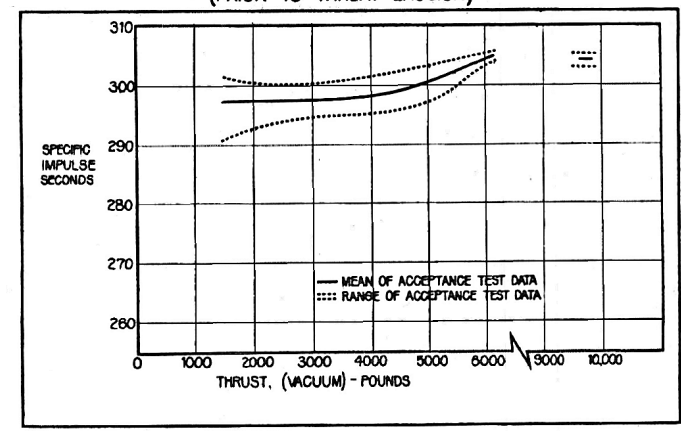

Figure 27. LMDE Engine Specific Impulse Prior to Throat Erosion

\section{TRW Inc. Studies - MIRA 150A (1965) $)^{102-105}$}

The MIRA 150A variable thrust rocket engine was designed for attitude control on the Surveyor spacecraft. The engine was ablatively cooled because of the incompatibility of available coolant flow over the entire 5-to- 1 thrust range. The injector was a single element coaxial tube pintle. A single moving sleeve provided variable area control to the annular propellant orifices. Propellant flows were also controlled by variable area cavitating venturis upstream of the injector orifices. The NASA MSFC later selected MIRA 150A as one of two engines to be evaluated for a lunar exploration flying system. The injection velocities were re-optimized for a new propellant combination. A total of 84 starts with 4 engine configurations demonstrated deep throttling (6.8-to-1), chamber durability, ballistic performance, and dynamic response.

\section{Gaseous Propellant Throttling Rocket Engine Study $(1965)^{106-110}$}

Several gas injection rocket engine experiments were performed at a rocket engine test facility at the Air Force Institute of Technology (AFIT) located on Wright-Patterson Air Force Base in Ohio. Although this study does not use LREs, the features of this mode of throttling are very similar. The variable area injector throttling method was selected since it was most suitable for the design requirements and was compatible with the test facility at AFIT. A small engine was designed for 10-to-1 throttling based on a constant thrust engine design by Ow. ${ }^{110}$ The modified throttleable engine incorporated a new injector plate and 3 movable pintles. Movement of the central pintle regulated the oxidizer flow while movement of the other two pintles regulated the fuel flow. Ethylene propylene rubber seals were used between the movable pintles and the injector front cover plate. The engine assembly schematic is shown in Fig. 28. Fuel was injected radially through the side walls of the entire chamber and acted also as film coolant. The two fuel variable area orifices were located upstream of the film coolant manifold. The self impinging oxidizer was injected through a central orifice that was controlled by the central pintle.

The injector was later redesigned to a twin orifice showerhead injector which solved facility issues. There was one orifice in the chamber for fuel and one orifice for oxidizer on the opposite side. Two plates slid over each propellant orifice to define the basic throttling mechanism. The engine was throttled 4.1-to-1, and no combustion instabilities were observed. Combustion efficiency increased at lower thrust levels.

Another modified variable thrust rocket engine incorporated a variable area injector using gaseous propellants. The propellant lines included separate orifices, one for each propellant, and again plates slid over each propellant orifice. The impinging injector face contained one central hole for the oxidizer and ten surrounding holes for the fuel, angled so that impingement occurred roughly two inches from the injector face. Throttling over 7-to-1 was achieved. Steady state set-point tests demonstrated the overall performance to remain nearly constant, with a very slight drop-off of specific impulse. The $\mathrm{c}^{*}$ performance was highest at the low throttle conditions and was attributed to the longer gas molecule chamber residence time. There was no indication of combustion instabilities. 
A hydraulic control system was later implemented that actuated the throttling mechanism and examined the engine response to transient throttling over a thrust range of 5-to-1. Impulse throttling showed that the decreasing percent throttle tests required more time than increasing percent throttle tests to return to steady state performance values. This was attributed to flow pressures in the manifold and resulting friction forces. There was no indication of combustion instabilities.

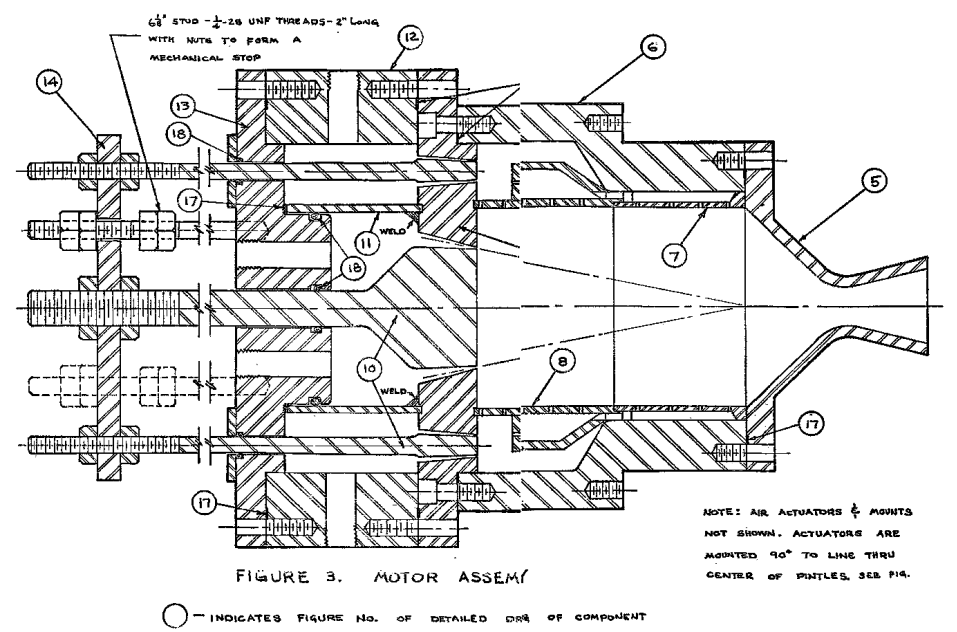

Figure 28. Gaseous Propellant Variable Area Injector Engine Schematic

\section{Deep Throttling TR202 (2005) ${ }^{111-113}$}

Northrop Grumman Space Technology (NGST) is developing the TR202 engine, a closed expander cycle engine with independent turbopumps and a variable area pintle injector, for technology development of a cryogenic propellant applicable to the lunar descent engine. The independent turbomachinery and variable area pintle would enable full control over mixture ratio and thrust. Injector tests have been performed at NASA Marshall Space Flight Center. Stable combustion performance was demonstrated with a pintle injector at several setpoints over a 10-to-1 throttling range with $\mathrm{LO}_{2}$ and $\mathrm{GH}_{2}$ propellants.

The pintle injector would control the core and wall mixture ratios and maintain acceptable injection propellant pressure drops, which should provide high combustion efficiency and combustion stability over the entire throttling range. An illustration of the pintle concept is shown in Fig. 29. NGST lists several technology challenges, most relating to behavior during deep throttling, including acceptable injector performance, continuous and deep throttling with cryogenic propellants, stable combustion, acceptable cooling, balancing injector stiffness with pump performance and pump exit pressures during throttling, maintaining mixture ratio at desired levels, avoiding pump stall at low flow conditions, and developing deep throttling turbopump technology. Most of these issues are general concerns for any deep throttling technology.

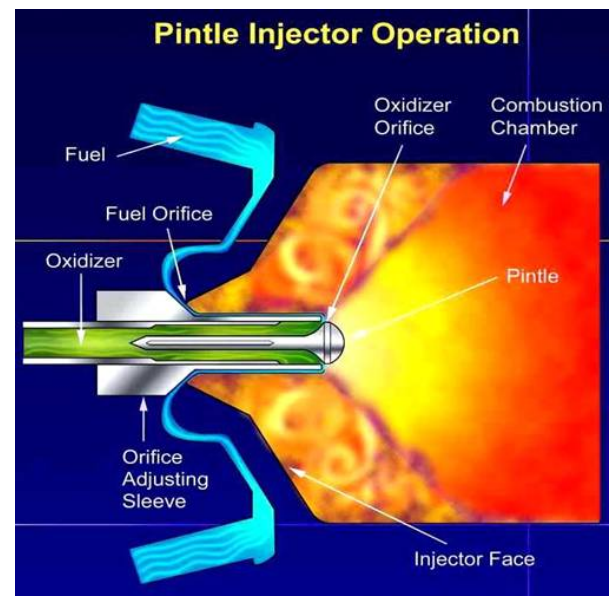

Figure 29. Pintle Injector Operation Illustration 
The injector would be developed to a 10-to- 1 throttling range and the data used to update the engine design based on program throttling needs. As the engine throttles, the fuel stiffness will increase because the density is a strong function of temperature. The oxidizer stiffness will also increase because the variable area injector orifices are sized for a specific pressure drop. The stiffness would range from $20 \%$ at full thrust to $106 \%$ at minimum thrust. This has no effect on the cycle balance because there is more power margin at lower throttle settings. The ability to control mixture ratio over the throttling range provides the ability to maximize propellant utilization, and the ability to control stiffness eliminates the possibility of chug or high oxidizer pump exit pressures at high thrust.

\section{H. Hydrodynamically Dissipative Injector}

Hydrodynamically dissipative injectors use fluid dynamic methods to create adequate impedance across the injector. Methods to do this include use of capillary tubes which create a high pressure drop by means of viscous losses, or long element features to create added fluid mass or inertance as additional impedance. The most common method, and widely used in Russia, ${ }^{114}$ is to use swirling vortex tubes to effectively alter the discharge coefficient over a throttling range in combination with propellant throttling. ${ }^{4,15,116}$ A dual-manifold approach is used in combination with this technique. These methods ensure that the injector is free of moving parts, however in some cases additional valving is necessary. Hydrodynamically dissipative injector methods are usually subsets of other methodologies such as high-pressure-drop injectors or dual-manifold injectors.

\section{Demonstration of Throttleable LOX/GH $\mathrm{H}_{2}$ Injector Concepts (2001) 117,118}

A swirl injector with a two-channel liquid oxidizer system was designed and successfully tested at the Pennsylvania State University with expert advising from visiting professor Vladimir Bazarov. The tangential-entry dual-inlet swirl injector is a common Russian design and is sometimes categorized in this section. It is effectively a dual-manifold injector design and throttling is performed by independently controlling flow through the two channels. Throttling behavior is quantified not only by mass flow variation, but also by variations in injector discharge coefficient. A vortex tube is formed inside the injector element by considering element design and managing pre-injection swirl flow. The theory shows how controlling the hydraulics inside the injector element influences the discharge coefficient. Single throttle point experiments were conducted over a 10-to-1 throttle range, and continuously throttling experiments were conducted by continuously varying propellant flow rates over a wide operating range during a single run.

Chug ( $45 \mathrm{~Hz}$ with harmonics) was observed at the lowest chamber pressure while the dual-element injector was in single-channel operating mode. This instability, attributed to very long $(33 \mathrm{ft})$ feedlines and inadequate pressure drops, degraded performance at this operating point. The chug oscillation also appeared occasionally during transient runs and also occurred at the transition between two-channel operation and single-channel operation, but that could have been attributed to the closure of the LOX valve.

Performance efficiencies were reduced during chug instabilities but also at high throttling conditions. The performance degradation at high throttling was shown possibly due to poor mixing caused from a fuel-oxidizer momentum imbalance. Much better performance was obtained when the straight shearing gaseous fuel injection plate was replaced with the swirling injector plate giving an adequately sized swirl jet.

\section{Combined Methods}

Some throttling methods inherently combine techniques to utilize advantages from each particular method and provide even deeper throttling, such as variable area injectors or hydrodynamically dissipative injectors. Variable area injectors commonly use valves in the propellant lines for additional flow control. Hydrodynamically dissipative injectors combine propellant throttling, dual-manifold injectors, and variable discharge coefficients. Dual-manifold throttling requires propellant throttling. Pulse modulation by Bell Aerospace combines highpressure-drop injectors for 12-to-1 throttling and pulsing methods to increase throttling to 100 -to-1. Generally most methods require propellant throttling to some extent. Other throttling technology combinations are also possible.

\section{Advanced Throttling Concepts Study (1964) ${ }^{43,73}$}

A combination constant area injector and variable area injector, as contradictory as it sounds, was investigated in the Advanced Throttling Concept Study by Pratt \& Whitney Aircraft in 1964. The intent of this study was to evaluate injector systems that provide high combustion performance during deep throttling (specified down to 50-to1). The injector called the BIProportional Area Spring (BIPAS) was operated in two distinct modes. At low thrust levels it acted as a variable area injector to maintain a constant pressure drop, and at high thrust levels it had the characteristics of a constant area injector with variable pressure drop. This allowed for a reasonable injector 
pressure drop over a wide thrust range while providing enough stiffness at high thrust to prevent low frequency instabilities. Spring rate of the poppet valves and the location of a physical stop restricting the poppet valves could be changed based on the stability characteristics of the engine. This injector design was not selected for demonstration testing although it appeared superior to the variable area injector.

\section{Summary and Conclusions}

LREs are generally designed for fixed thrust operation with small variations about the design point for throttling. However, there are many applications where variable thrust is required, including planetary entry and descent, space rendezvous, orbital maneuvering including orientation and stabilization in space, and hovering and hazard avoidance during planetary landing. This paper reviewed the methods identified since the pioneering work for throttling LREs. The following paragraphs briefly summarize the important characteristics of each method.

\section{Summary - High-Pressure-Drop Injectors}

Project Thumper, one of the first extensive deep throttling investigations, touched on many of the issues related to throttling with a fixed-geometry injector. Performance was reduced at low power levels due to poor combustion at low chamber pressures, mainly because there was insufficient injector pressure drop to sustain good atomization and mixing of the propellants. Instabilities were discovered at lower chamber pressures including whistling (high frequency combustion instability), motorboating (chug), and hydraulic instability. The instabilities increased the heat transfer rates several times greater than expected without instability. Studies showed that the fuel in a regeneratively cooled chamber would vaporize at low pressures, and in general, cooling ability was decreased at lower thrusts.

Similar characteristics were observed in other fixed-geometry injectors from other programs, including the sequence of instabilities as chamber pressure was reduced and the increase in heat transfer during instability. Highpressure-drop injectors have performed better than low-pressure-drop injectors in terms of stability and performance during throttling. Several other solutions were proposed to improve stability, including reducing the injector area if pump head rise was available, providing heat transfer to increase the amount of vapor in the manifolds and thus increasing resistance, and providing gas injection into the liquid manifolds having the same increasing resistance effect. Low frequency system instabilities occurred when coolant flow vaporized inside the coolant jacket.

Rapid transients over the throttling range were also investigated. In a pump-fed system, throttling from high thrust to low thrust could stall the fuel pump. Other pump-related concerns during throttling included rotordynamic stability, running at shaft critical speeds, high pressure fuel turbopump thrust bearing lift off, hydrostatic bearing of the high pressure oxidizer turbopump running in the stall region, freezing turbine gas, sustaining a satisfactory axial thrust balance, bi-stability of the high pressure oxidizer turbopump boost pump, and performance of the turbopumps at low flow-to-speed ratios. Nozzle sideloads during the start and shutdown from low thrust were also concerns.

\section{Summary-Dual-Manifold Injector}

There are several common themes that occur in dual-manifold injector systems. In general, higher performance efficiency can be achieved at low thrust levels because the injector can be designed with high injection velocities at low thrust so performance is acceptable, and high injector resistance so stability is acceptable. Typically the oxidizer side or liquid side contains the dual manifold because that circuit is generally the driving mechanism for combustion instability. Complexity is increased over high-pressure-drop injectors because of the additional control valves.

There are combustion stability and operational concerns at the transition point. Instability at the transition point has occurred as well as at low thrust where only one manifold operates. In one case, chug was attributed to liquid flowing into the secondary manifold and compressing the trapped gas inside. The chug was eliminated by bleeding the secondary manifold to remove the gas. In another case, instability was incited by two-phase flow entering the secondary injector orifices and becoming trapped after the secondary injector control valve was closed, and again was eliminated by releasing the trapped injector purge gases in the secondary manifold. The selection of the transition point is a compromise to obtain adequate injector velocity from the secondary injector for good propellant mixing and conformance to limiting system pressures as well as providing adequate stability margin. Complete closure of the secondary manifold can cause overheating of the secondary manifold, depletion of propellant from the secondary manifolds, and contamination of the unprimed secondary manifold with combustion products. Low thrust over a long period of time can deplete the secondary manifold propellant and cause a significant time delay and lower thrust for diversion of primary flow to re-prime the secondary manifold. 
Other design challenges include the transient system response when flowing from low thrust to high thrust because of the necessity to prime the secondary manifold. The proposed method to obtain a fast response during the transition is to continuously flow fluid through the secondary manifold either by a bleed flow through the secondary valve or a bleed flow from the primary fluid flow. Injector volume is typically minimized to generally ensure adequate flow response during throttling.

Stability and performance can be optimized by optimizing the flow splits between the primary and secondary manifold. In one example the secondary injector flow was not pumped evenly from the injector causing an uneven mixture ratio distribution in the chamber.

The throttling heat transfer results indicate that the existence of a transitional and/or a laminar boundary layer in the nozzle region may be encountered at some point over the throttling range. This transition would likely occur if the ejector system could not replicate vacuum conditions adequately. The total chamber heat load fits over the entire throttling range generally with the classical heat transfer correlation of $\mathrm{p}_{\mathrm{c}}{ }^{0.8}$.

\section{Summary - Gas Injection}

The primary advantage of the gas injection method for large thrust engines is to maintain a high injector pressure drop over a wide throttling range by a lowering of the propellant bulk density. This method has been shown to eliminate instabilities by increasing injector resistance, and is generally only necessary when operating at low thrust. For very small thrust engines the additional flow can increase thrust. Additionally, performance is not reduced during throttling, and in fact may increase, due to the increased pressure drop as well as increased mixing from an aerated propellant. In most cases, however, the added weight and complexity for gas injection hardware including valving, piping and control systems will reduce the payload gain from any performance increase. As a minimum the gas should be tapped off another system such as the tank pressurant. The gas injection flow rate can be optimized for both performance and stability but the flow rates required are generally less than $1 \%$ of the propellant flow.

The gas injection device must be designed so that smooth homogeneous gas injection occurs. In one water flow test, feed system instability was created by the surging gas into the injector manifold. Another concern expressed was maldistribution or nonuniformity of the aerated propellant, which could cause mixture ratio variations and local hot and cold regions in the combustion chamber. And lastly, one interesting technique used combustion in the propellant lines to lower the density produced stable and repeatable results, but had obvious concerns of trying to control reaction rates in the propellant lines.

\section{Summary-Multiple Chambers}

The primary advantage of throttling with multiple chambers is that a deeper throttling can be achieved by controlling the thrust of each chamber independently. Multiple chambers are commonly used in Russia for reasons not specific to throttling, primarily for combustion stability and manufacturing advantages. The obvious disadvantages include the feed system complexity and less than optimum weight. Aerospike engines can take advantage of using multiple chambers. Multiple small chambers make up banks that can be independently throttled in the aerospike engine.

\section{Summary - Pulse Modulation}

The objective of pulse modulation is to obtain a thrust profile by utilizing pulses of various thrust levels and durations. Two typical modes of operation include obtaining a thrust profile by using pulse modulation of a constant width but varying the thrust level, and obtaining a thrust profile by pulse modulation of a constant thrust for each pulse but with varying pulse width. A fast response valve is essential to providing pulses of propellants into the combustion chamber. A small manifold provides maximum pulse response and pulse performance.

The performance from a pulsed thrust operating point is usually lower than that of an unpulsed or continuous operating point due to the effect of including the transient as a significant portion of the duration in the overall impulse. The poorer mixing and atomization during the transients lower the average performance of the pulse. Disadvantages also include shock loading on the vehicle, heat soak in the chamber head end, inefficient use of propellant due to chamber cooling channel and injector dribble volume losses between pulses. Ignition of each pulse can be a concern depending on the pulse rate.

Having the ability to pulse can provide extreme throttling capability. Combining pulsing with continuous operation has provided throttling to $1 \%$ of maximum thrust, but due to performance degradation while in pulse mode, most of the time in the mission should occur at high thrust during continuous operation. 


\section{Summary - Throat Throttling}

The throat throttling method is unique in that it provides the highest performance and chamber pressure at low thrust. However there are many disadvantages with this method, including cooling the throat pintle and preventing excessive vibrations of the pintle. An uncooled throat pintle was historically not an option because of material limitations, but there are higher temperature materials or thermal coatings available now. The pintle could also be regeneratively cooled.

Performance losses were attributed to gas separation in the nozzle cone because of the location of the pintle, which was verified visually with exhaust gas directed at steeper angles during throttling. An optimized pintle device shape would be important to obtain maximum performance. The effect of pintle design on nozzle coefficient should be investigated to obtain the best performance during throttling. Additionally, for a constant pressure propellant system, it would be impossible to obtain optimized atomization and mixing with this method because there is not an adequate pressure drop across the injector over the full range. A compromise must be made in chamber size because there are large variations in $\mathrm{L}^{*}$ due to the varying throat area. At low thrust, the $\mathrm{L}^{*}$ is much higher and allows for more complete combustion which improves efficiency. Combustion instabilities are a concern at low thrust even with the high chamber pressure because the injector pressure drop is small at low thrust. A high rate of thrust change can be designed by incorporating a good hydraulic system for the pintle device.

Finally, throat throttling by means of gas injection into the nozzle throat does not immediately seem practical. The major drawback is the required high temperature needed for the injected gas. In the ideal configuration, the secondary gas injected would have a low specific heat ratio, a low molecular weight, and a high temperature, and be injected at the throat.

\section{Summary - Variable Area Injection}

The variable area injector methodology is the most familiar throttling method because of the legacy of the LMDE. The major advantages of variable area injectors are the relative simplicity and the few incidences of high frequency combustion instability. The resistance to high frequency combustion instabilities probably occurs because the location of energy release from the center-mounted pintle injector minimizes coupling with the tangential and first radial acoustic modes.

Disadvantages include the requirement for a propellant control system and heat transfer to a pintle injector element. Major concerns in early experiments included optimization of flow control and injector design, integration of the variable area injector with the thrust control system, leakage around the pintle injector, and maintaining a specific mixture ratio for a particular thrust. Most of the problems were rectified by incorporating flow control valves in the propellant lines. In this way, both an appropriate injection pressure drop and a controlled mixture ratio were possible. Performance efficiency may not be as high as with a multi-element injector.

\section{Summary - Hydrodynamically Dissipative Injector}

The hydrodynamically dissipative injector uses fluid dynamics to improve the impedance across the injector. Swirling vortex tubes are the most common method and enables deep throttling by altering the discharge coefficient. The major advantage of this method is that the system remains simple because there are no moving parts in the injector. Although there is limited work in this area, an analytical framework allows the design of a two-channel hydrodynamically dissipative injector, more specifically, a tangential-entry dual-inlet swirl injector. Throttling behavior is quantified not only by mass flow variation, but also by variations in injector discharge coefficient. A vortex tube is formed inside an injector element by considering element design and managing pre-injection swirl flow. The theory shows how controlling the hydraulics inside the injector element influences the discharge coefficient.

\section{Acknowledgments}

The authors greatly acknowledge the assistance of Dianne Moore and the librarians from the Redstone Scientific Information Center (RSIC) and also Amy High from the Air Force Institute of Technology (AFIT) academic library.

\section{References}

\footnotetext{
${ }^{1}$ "The Vision for Space Exploration," NASA, NASA NP-2004-01-334-HQ, Washington, DC.

2"NASA Authorization Act of 2005," Senate and House of Representatives, Washington, DC, 16 Dec. 2005.

${ }^{3}$ Sutton, G. P., History of Liquid Propellant Rocket Engines, AIAA, Reston, VA, 2006.
} 
${ }^{4}$ Bazarov, V. G., "Throttleable Liquid Propellant Engines Swirl Injectors for Deep Smooth Thrust Variations," 30th AIAA/ASME/SAE/ASEE Joint Propulsion Conference, AIAA Paper 94-2978, 1994.

${ }^{5}$ Sutton, G. P., Rocket Propulsion Elements An Introduction to the Engineering of Rockets, 5th ed., John Wiley \& Sons, New York, NY, 1986.

${ }^{6}$ Huzel, D. K. and Huang, D. H., Seebass, A. R. (ed.) Modern Engineering for Design of Liquid-Propellant Rocket Engines, Progress in Astronautics and Aeronautics, Vol. 147, AIAA, Washington, DC, 1992.

${ }^{7}$ Welton, D. E., Bensky, S. M., and Hiland, J. R., "Toward the Variable-Thrust Liquid-Rocket Engine," Astronautics and Aerospace Engineering, Vol. 1, No. 11, 1963, pp. 77.

${ }^{8}$ Welton, D. E., Bensky, M. S., and Hiland, J., "Variable-Thrust Liquid Propellant Rocket Engines," AIAA Summer Meeting, AIAA Paper 63-268, 1963.

${ }^{9}$ Sutton, G. P., "History of Liquid Propellant Rocket Engines in the United States," Journal of Propulsion and Power, Vol. 19, No. 6, 2003, pp. 978-1007.

${ }^{10}$ Dornberger, W., $V$-2, The Viking Press, Inc., New York, 1954

${ }^{11}$ Perry, R. L., "The Antecedents of the X-1," AIAA Second Annual Meeting, AIAA Paper 65-453, 1965.

${ }^{12}$ Walter, H., "Report on Rocket Power Plants based on T-Substance," NACA, NACA TM 1170, Washington, DC.

${ }^{13}$ Rusek, J. J., "New Decomposition Catalysts and Characterization Techniques for Rocket-Grade Hydrogen Peroxide," Journal of Propulsion and Power, Vol. 12, No. 3, 1996, pp. 574-579.

${ }^{14}$ Andrews, D., "Advantages of Hydrogen Peroxide as a Rocket Oxidant," Journal of the British Interplanetary Society, Vol. 43, 1990, pp. 319-328.

${ }^{15}$ Walter, H., "Experience with the Application of Hydrogen Peroxide for Production of Power," Jet Propulsion, 1954, pp. 166171.

${ }^{16}$ Clark, J. D., Ignition! An Informal History of Liquid Rocket Propellants, Rutgers University Press, New Brunswick, NJ, 1972.

${ }^{17}$ Smith, J. R., Kay, A. L., and Creek, E. J., German Aircraft of the Second World War, Putman \& Company Limited, London, 1972.

${ }^{18}$ Myhra, D., Secret Aircraft Designs of the Third Reich, Schiffer Publishing Ltd., Atglen, PA, 1998.

${ }^{19}$ Dressler, G. A., "Summary of Deep Throttling Rocket Engines with Emphasis on Apollo LMDE," 42nd AIAA/ASME/SAE/ASEE Joint Propulsion Conference \& Exhibit, AIAA Paper 2006-5220, 2006.

${ }^{20}$ Rutkowski, E. V., "Variable-Thrust Rocket Engines," Astronautics, Vol. 4, No. 10, 1959, pp. 40.

${ }^{21}$ Amneus, J. S., "First Progress Report on Rocket Motor Throttling," Willow Run Research Center Engineering Research Institute University of Michigan, UMM-71, Dec. 1950.

${ }^{22}$ Harrje, D. T. and Reardon, F. H., "Liquid Propellant Rocket Combustion Instability," NASA, NASA SP-194, Washington, DC, 1972.

${ }^{23}$ Gill, G. S. and Nurick, W. H., "Liquid Rocket Engine Injectors," NASA, NASA SP-8089, Washington, DC, Mar. 1976.

${ }^{24}$ Zweig, F., Tuteur, F. B., Cunningham, W. J., and Bower, J. L., "The Dynamics of Throttling Hydraulic Systems," Yale University, Report 8252-R, New Haven, CT, Jun. 1950.

${ }^{25}$ Merritt, F. and Dumont, L., "Supplemental Report - Wide Range Flow Control Program," Air Force, AFRPL-TR-69-141, Edwards Air Force Base, CA, May 1969.

${ }^{26}$ Relyea, L. K., "Thumper Project: Rocket Motor Throttling Tests," General Electric Company, R49A0410, Schenectady, NY, 10 Jun. 1949.

${ }^{27}$ Papp, D. S., "From Project Thumper to SDI - The Role of Ballistic Missile Defense in US Security Policy," Air \& Space Power Journal, Vol. I, No. 3, 1987.

${ }^{28}$ Wanhainen, J. P., Antl, R. J., Hannum, N. P., and Mansour, A. H., "Throttling Characteristics of a Hydrogen-Oxygen, Regeneratively Cooled, Pump-Fed Rocket Engine," NASA, NASA TM X-1043, Washington, DC, Dec. 1964.

${ }^{29}$ "Advanced Injector Concepts Investigation Final Report," Aerojet Liquid Rocket Company: A Division of Aerojet General, Report 21052-3F, 30 Apr. 1971.

30"Advanced Injector Concepts Investigation Final Summary Report," Aerojet Liquid Rocket Company: A Division of Aerojet General, Report 21052-3FS, 30 Apr. 1971.

${ }^{31}$ Andrus, S. R., Bishop, H. L., Duckering, R. E., Gibb, J. A., Nelson, A. W., and Ransom, V. H., "Throttling and Scaling Study for Advanced Storable Engine: Part 1 of Two Parts," Air Force Rocket Propulsion Laboratory, AFRPL-TR-68-2, Part 1, Sacramento, CA, Jan. 1968.

${ }^{32}$ Andrus, S. R., Bishop, H. L., Gibb, J. A., and Nelson, A. W., "Throttling and Scaling Study for Advanced Storable Engine: Part 2 of Two Parts," Air Force Rocket Propulsion Laboratory, AFRPL-TR-68-2, Part 2, Sacramento, CA, Jan. 1968.

${ }^{33}$ Addoms, J. F., Jr., Cordova, R., and McGough, C. B., Method of Making Composite Ultra-Thin Metal Platelet having Precisely Controlled Pattern of Flow Passages Therein, Patent No. 3,413,704, filed 26 Nov. 1965.

${ }^{34}$ Wilcoxen, M. L., "RL10A-5: An Assessment of Reusability Demonstrated during the SSRT Program," 32nd AIAA/ASME/SAE/ASEE Joint Propulsion Conference, AIAA Paper 96-3110, 1996.

${ }^{35}$ Rachuk, V. S., Shostak, A. V., Dmitrenko, A. I., Goncharov, G. I., Hernandez, R., Starle, R. G., and Hulka, J., "Benchmark Testing of an Enhanced Operability LO2/LH2 RD-0120 Engine," 32nd AIAA/ASME/SAE/ASEE Joint Propulsion Conference, AIAA Paper 96-2609, 1996.

${ }^{36}$ Bradley, M. A., "SSME Off-Nominal Low Power Level Operation," 33rd AIAA/ASME/SAE/ASEE Joint Propulsion Conference and Exhibit, AIAA Paper 1997-2685, 1997. 
${ }^{37}$ Anderson, B., Bradley, M. A., and Ives, J., "SSME Key Operations Demonstration," 33rd AIAA/ASME/SAE/ASEE Joint Propulsion Conference and Exhibit, AIAA Paper 1997-2686, 1997.

${ }^{38}$ Giuliano, V. J., Leonard, T. G., Adamski, W. M., and Kim, T. S., "CECE: A Deep Throttling Demonstrator Cryogenic Engine for NASA's Lunar Lander," 43rd AIAA/ASME/SAE/ASEE Joint Propulsion Conference \& Exhibit, AIAA 2007-5480, 2007.

${ }^{39}$ Giuliano, V. J., Leonard, T. G., and Kim, T. S., "Development Status of the CECE Cryogenic Deep Throttling Demonstrator Engine," Space Propulsion 2008, 2nd International Symposium on Propulsion for Space Transportation, 2008.

${ }^{40}$ Kenny, R. J., "Influence of Variable Thrust Parameters on Swirl Injector Fluid Mechanics," Doctor of Philosophy University of Alabama in Huntsville, Huntsville, AL, 2008.

${ }^{41}$ Conrad, W., Hannum, N. P., and Bloomer, H. E., "Photographic Study of Liquid-Oxygen Boiling and Gas Injection in the Injector of a Chugging Rocket Engine," NASA, NASA TM X-948, Washington, DC, Dec. 1964.

${ }^{42}$ Lefebvre, A. H., Chigier, N. (ed.) Atomization and Sprays, Combustion: An International Series, Taylor \& Francis, 1989.

${ }^{43}$ Mitchell, J. P., "Technical Report No. 2 of Advanced Throttling Concepts Study," Pratt \& Whitney Aircraft, Florida Research and Development Center, PWA FR-1045, West Palm Beach, FL, 25 Jul. 1964.

${ }^{44}$ Mitchell, J. P., "Technical Report No. 3 of Advanced Throttling Concepts Study," Pratt \& Whitney Aircraft, Florida Research and Development Center, PWA FR-1108, West Palm Beach, FL, 15 Sep. 1964.

${ }^{45}$ Mitchell, J. P., "Technical Report No. 4 of Advanced Throttling Concepts Study," Pratt \& Whitney Aircraft, Florida Research and Development Center, PWA FR-1231, West Palm Beach, FL, 15 Dec. 1964.

${ }^{46}$ Zettle, E. V., Riebling, R. W., and Clapp, S. D., "Chamber Technology for Space-Storable Propellants," AIAA Joint Propulsion Specialists Conference, 1965.

${ }^{47}$ Nagai, C. K., Bartlett, R. C., Knight, R. M., and Clapp, S. D., "Chamber Technology for the Space Storable OF 2 - MMH Propellant Combination," AIAA Second Propulsion Joint Specialist Conference, AIAA Paper 66-623, 1966.

48"Final Report, Chamber Technology for Space Storable Propellants," NASA, NASA CR-110644, Canoga Park, Sep. 1969.

${ }^{49}$ Burry, R. V. and Pauckert, R. P., "Engine System Designs for Space Storable Propellants," AIAA 4th Propulsion Joint Specialist Conference, AIAA Paper 68-615, 1968.

${ }^{50}$ Ingebo, R. D., "Drop-Size Distributions for Impinging-Jet Breakup in Airstreams Simulating the Velocity Conditions in Rocket Combustors," NACA, NACA TN 4222, Washington, Mar. 1958.

${ }^{51}$ Rupe, J. H., "The Liquid-Phase Mixing of a Pair of Impinging Streams," Jet Propulsion Laboratory, California Institute of Technology, JPL-PR-20-195, 6 Aug. 1953.

${ }^{52}$ Atherton, R. R., "Advanced Cryogenic Rocket Engine Program Staged Combustion Concept, Final Report, Vol I," AFRPLTR-67-298-VOL I, Dec. 1967.

${ }^{53}$ Atherton, R. R., "Advanced Cryogenic Rocket Engine Program Staged Combustion Concept, Final Report, Vol II," AFRPLTR-67-298-VOL II, Dec. 1967.

${ }^{54}$ Atherton, R. R., "Advanced Cryogenic Rocket Engine Program Staged Combustion Concept, Final Report, Vol III," AFRPLTR-67-298-VOL III, Dec. 1967.

${ }^{55}$ Atherton, R. R., "Air Force Reusable Rocket Engine Program XLR129-P-1 First Annual Report, Vol I," U. S. Air Force, AFRPL-TR-69-3-Vol I, Edwards, CA, Jan. 1969.

${ }^{56}$ Atherton, R. R., "Air Force Reusable Rocket Engine Program XLR129-P-1 First Annual Report, Vol II," U. S. Air Force, AFRPL-TR-69-3-Vol II, Edwards, CA, Jan. 1969.

${ }^{57}$ Atherton, R. R., "Air Force Reusable Rocket Engine Program XLR129-P-1 First Annual Report, Vol III," U. S. Air Force, AFRPL-TR-69-3-Vol III, Edwards, CA, Jan. 1969.

${ }^{58}$ Atherton, R. R., "Air Force Reusable Rocket Engine Program XLR129-P-1 Engine Performance," U. S. Air Force, AFRPLTR-69-19, Edwards, CA, Apr. 1969.

${ }^{59}$ Atherton, R. R., "Air Force Reusable Rocket Engine Program XLR129-P-1 Demonstrator Engine Design, Vol 1," U. S. Air Force, AFRPL-TR-70-6 Vol 1, Edwards, CA, Apr. 1970.

${ }^{60}$ Atherton, R. R., "Air Force Reusable Rocket Engine Program XLR129-P-1 Demonstrator Engine Design, Vol 3," U. S. Air Force, AFRPL-TR-70-6 Vol 3, Edwards, CA, Apr. 1970.

${ }^{61}$ Atherton, R. R., "Air Force Reusable Rocket Engine Program XLR129-P-1 Final Report, Vol I," U. S. Air Force, AFRPLTR-71-1-Vol I, Edwards, CA, Jan. 1971.

${ }^{62}$ Atherton, R. R., "Air Force Reusable Rocket Engine Program XLR129-P-1 Final Report, Vol II," U. S. Air Force, AFRPLTR-71-1-Vol II, Edwards, CA, Jan. 1971.

${ }^{63}$ Atherton, R. R., "Air Force Reusable Rocket Engine Program XLR129-P-1 Final Report, Vol III," U. S. Air Force, AFRPLTR-71-1-Vol III, Edwards, CA, Jan. 1971.

${ }^{64}$ Hankins, R. A. and Yankovich, M., "Throttlable [sic] Primary Injector for Staged Combustion Engine," U. S. Air Force, AFRL-TR-70-40, Edwards.

${ }^{65}$ Masters, A., "Advanced Expander Test Bed Program," AIAA Space Programs and Technologies Conference, AIAA Paper 90-3708, 1990.

${ }^{66}$ Masters, A. I. and Mitchell, J. C., "Advanced Expander Test Bed Program: Final Annual Technical Progress Report," NASA, NASA CR 187082, West Palm Beach, FL, Apr. 1991.

${ }^{67}$ Masters, A. I. and Mitchell, J. C., "Advanced Expander Test Bed Program: Preliminary Design Review Report," NASA, NASA CR 187081, West Palm Beach, FL, May 1991. 
${ }^{68}$ Masters, A. I. and Tabata, W. K., "Design of an Advanced Expander Test Bed," AIAA/NASA/OAI Conference on Advanced SEI Technologies, AIAA Paper 91-3437, 1991.

${ }^{69}$ Riccardi, D. P. and Mitchell, J. P., "Advanced Expander Test Bed Program: Second Annual Technical Progress Report," NASA, NASA CR 189130, West Palm Beach, FL, Mar. 1992.

${ }^{70}$ Mitchell, J. C. and Tabata, W. K., "Design of an Advanced Expander Test Bed," AIAA/SAE/ASME/ASEE 29th Joint Propulsion Conference and Exhibit, AIAA Paper 93-2133, 1993.

${ }^{71}$ Riccardi, D. P. and Mitchell, J. C., "Advanced Expander Test Bed Program: Annual Technical Progress Report for 1992," NASA, NASA CR 191049, Jan. 1993.

${ }^{72}$ Morrell, G., "Rocket Thrust Variation with Foamed Liquid Propellants," NACA, NACA-RM-E56K27, Washington, DC, 26 Feb. 1957.

${ }^{73}$ Mitchell, J. P., "Final Report of Advanced Throttling Concepts Study," Pratt \& Whitney Aircraft, Florida Research and Development Center, PWA FR-1279, West Palm Beach, FL, 19 Mar. 1965.

${ }^{74}$ Rivard, J. G., "New Techniques for Throttleable Bipropellant Rocket Engines," AIAA Joint Propulsion Specialists Conference, AIAA Paper No. 65-560, 1965.

75"CPIA/M5 Liquid Propellant Engine Manual," CPIA, CPIA M5, Columbia, MD.

${ }^{76}$ Hammock, W. R., Jr., Currie, E. C., and Fisher, A. E., "Apollo Experience Report - Descent Propulsion System," NASA, NASA TN D-7143, Washington, DC, Mar. 1973.

${ }^{77}$ Ruddock, S. and McCrea, J., "Feasibility Study and Performance Modeling of a Throttleable Attitude Control Thruster," Bachelor of Engineering with Honors University of Bristol, Bristol, United Kingdom, 1991.

${ }^{78}$ Sutton, G. P., "History of Liquid Propellant Rocket Engines in Russia, Formerly Soviet Union," Journal of Propulsion and Power, Vol. 19, No. 6, 2003, pp. 1008-1037.

${ }^{79}$ Diem, H. G., "Advanced Thrust Chamber for Space Maneuvering Propulsion Third Quarterly Report," U. S. Air Force, AFRPL-TR-67-78, Edwards Air Force Base, CA, Mar. 1967.

${ }^{80}$ Wiswell, R. L., "Advanced Maneuvering Propulsion Technology Program (Second Quarterly Progress Report)," Air Force Rocket Propulsion Laboratory, AFRPL-TR-68-20, Canoga Park, CA, May 1968.

${ }^{81}$ Wiswell, R. L., "Advanced Maneuvering Propulsion Technology Program (Third Quarterly Progress Report)," Air Force Rocket Propulsion Laboratory, AFRPL-TR-68-154, Canoga Park, CA, Sep. 1968.

${ }^{82}$ Wiswell, R. L., "Advanced Maneuvering Propulsion Technology Program (Fourth Quarterly Progress Report)," Air Force Rocket Propulsion Laboratory, AFRPL-TR-68-221, Canoga Park, CA, Dec. 1968.

${ }^{83}$ Wiswell, R. L., "Advanced Maneuvering Propulsion Technology Program (Fifth Quarterly Progress Report)," Air Force Rocket Propulsion Laboratory, AFRPL-TR-69-47, Canoga Park, CA, Mar. 1969.

${ }^{84}$ Wiswell, R. L., "Advanced Maneuvering Propulsion Technology Program (Seventh Quarterly Progress Report)," Air Force Rocket Propulsion Laboratory, AFRPL-TR-69-189, Canoga Park, CA, Sep. 1969.

${ }^{85}$ Gunston, B., World Encyclopedia of Aero Engines: from the Pioneers to the Present Day, 1992.

${ }^{86}$ Werrell, K. P., "The Evolution of the Cruise Missile," Air University, Maxwell Air Force Base, AL, Sep. 1985.

${ }^{87}$ Brunk, W. E. and Flaherty, R. J., "Methods and Velocity Requirements for the Rendezvous of Satellites in Circumplanetary Orbits," NASA, NASA TN D-81, Washington, DC, Oct. 1959.

${ }^{88}$ Hord, R. A. and Durling, B. J., "Analysis of a Linear System for Variable-Thrust Control in the Terminal Phase of Rendezvous," NASA, NASA TN D-953, Washington, DC, Sep. 1961.

${ }^{89}$ Carey, L., "Dual-Mode, 100:1 Thrust Modulation Rocket Engine," Journal of Spacecraft and Rockets, Vol. 5, No. 2, 1968, pp. 168-172.

${ }^{90}$ Lawrence Jr., L., Nesbitt, M. W., Huse, A. K., and Olson, D., "Interim Engineering Report on 2000 Pound Acid Aniline Variable Thrust Liquid Propellant Rocket Engine," Reaction Motors, Inc., RMI-205N-2, Dover, NJ, 22 Aug. 1947.

${ }^{91}$ Gunter, F. L. and Fahrenholz, F. E., "Final Report on a Study of Rocket Thrust Control by Gas Injection," Massachusetts Institute of Technology Naval Supersonic Laboratory, Technical Report 448, Cambridge, MA, May 1961.

${ }^{92}$ Martin, A. I., "The Aerodynamic Variable Nozzle," Journal of the Aeronautical Sciences, Vol. 24, No. 5, 1957, pp. 357.

${ }^{93}$ "F-1 Thrust Vector Control Study," Rocketdyne Engineering, R-1717, 28 Oct. 1959.

${ }^{94}$ Riviere, R. R., "An Analytical Study on Efficiency of Variable Thrust Liquid Rocket Engines," U.S. Army, RP-TM-61-1, Huntsville, AL, 12 Sep. 1961.

95"Proposed 5,000 Pound Variable Thrust Engine Development Program," Reaction Motors, Inc., 24, Oct. 1950.

${ }^{96}$ Fredrickson, H., Rice, P. J., and Amneus, J. S., "Second Progress Report on Rocket Motor Throttling," Willow Run Research Center Engineering Research Institute University of Michigan, UMM-89, Jan. 1952.

${ }^{97}$ Tomazic, W. A., "Rocket-Engine Throttling," NACA, NACA RM E55J20, Cleveland, OH.

${ }^{98}$ Elverum Jr., G., Staudhammer, P., Miller, J., and Hoffman, A., "The Descent Engine for the Lunar Module," AIAA 3rd Propulsion Joint Specialist Conference, AIAA Paper 67-521, 1967.

${ }^{99}$ Gilroy, R. and Sackheim, R., "The Lunar Module Descent Engine - A Historical Summary," AIAA/ASME/ASME/ASEE 25th Joint Propulsion Conference, AIAA Paper 89-2385, 1989.

${ }^{100}$ Dressler, G. A., "The Deep Throttling Pintle Injector: History, Technology and Application to Near-Term Programs," 53rd JANNAF Propulsion Meeting, 2005.

${ }^{101}$ Bennett, F. V., "Apollo Experience Report - Mission Planning for Lunar Module Descent and Ascent," National Aeronautics and Space Administration, NASA TN D-6846, Washington, DC, Jun. 1972. 
${ }^{102}$ Johnson, R. J., Boyd, B. R., and Smith, T. H., "Application of the MIRA 150A Variable Thrust Rocket Engine to Manned Lunar Exploration Flying Systems," AIAA 3rd Propulsion Joint Specialist Conference, AIAA Paper 67-505, 1967.

${ }^{103}$ Johnson, R. J., Boyd, B. R., and Smith, T. H., "Application of the MIRA 150A Variable-Thrust Engine to Manned Lunar Flying Systems," Journal of Spacecraft and Rockets, Vol. 5, No. 7, 1968, pp. 849-851.

${ }^{104}$ Shieber, H. and Rupert, R. C., "Assurance of Service Life of the MIRA 150A Variable Thrust Rocket Engine," AIAA Joint Propulsion Specialists Conference, AIAA 65-608, 1965.

${ }^{105}$ Shieber, H. and Rupert, R. C., "Assurance of Service Life of the MIRA 150A Variable Thrust Rocket Engine," Journal of Spacecraft and Rockets, Vol. 3, No. 7, 1966, pp. 1034-1038.

${ }^{106}$ Watkins 1st Lt. USAF, F. E., "A Design for Throttling a Gaseous Propellant, Film Cooled, Rocket Motor by Injector Area Variation," Master of Science Air Force Institute of Technology Air University, Wright-Patterson Air Force Base, OH, 1965.

${ }^{107}$ Smith III 1st Lt. USAF, C. D., "The Design, Construction, and Test of a Throttling System for a Gaseous Propellant Rocket Motor," Master of Science Air Force Institute of Technology Air University, Wright-Patterson Air Force Base, OH, 1966.

${ }^{108}$ De Groot 1st Lt. USAF, F. J., "Thrust Variation of a Gaseous Propellant Rocket Engine," Master of Science Air Force Institute of Technology Air University, Wright-Patterson Air Force Base, OH, 1967.

${ }^{109}$ Wernle II 1st Lt. USAF, C. F., "Throttling Rocket Engine," Master of Science Air Force Institute of Technology Air University, Wright-Patterson Air Force Base, OH, 1968.

${ }^{110}$ Ow, G. Y. W., "An Evaluation of Film Cooled Gaseous Hydrogen and Oxygen Rocket Engine of 100 Pounds Thrust," Master of Science Air Force Institute of Technology Air University, Wright-Patterson Air Force Base, OH, 1960.

${ }^{111}$ Chianese, S. G., Majamaki, A. N., and Gavitt, K. R., "NGST TR202 Throttling Lunar Descent Pintle Engine," 54th JANNAF Propulsion Meeting, 2007.

${ }^{112}$ Majamaki, A. N., Chianese, S. G., and Kim, T. S., "TR202 Deep Throttling Lunar Descent Engine Pintle Injector Technology Development Status," JANNAF 6th MSS / 4th LPS / 3rd SPS Joint Meeting, 2008.

${ }^{113}$ Majamaki, A. N. and Chianese, S. G., "TR202 Variable Thrust Pintle Descent/Ascent Engine (Cumulative Through Phase II, Option I)," Northrop Grumman Space Technology, NASA CR-2008-215472, Sep. 2008.

${ }^{114}$ Mikhaylov, V. V. and Bazarov, V. G., "Throttled Liquid Propellant Rocket Engines (from Russian - Drosseliruyemyye Zhidkostnyye Raketnyye Dvigateli)," Report FTD-1D(RS)T-0960-86 Machine Translation, Wright-Patterson Air Force Base, OH (Original - Moscow), 15 Dec. 1986 (Original - 1985).

${ }^{115}$ Bazarov, V., Yang, V., and Puri, P., "Design and Dynamics of Jet and Swirl Injectors," Vol. 200 American Institute of Aeronautics and Astronautics, Inc., Reston, VA, 2004, pp. 19-103.

116"Liquid Rocket Thrust Chambers: Aspects of Modeling, Analysis, and Design," Vol. 200 AIAA, Reston, VA, 2004.

${ }^{117}$ Santoro, R. J., "Demonstration of Throttleable LOX/GH ${ }_{2}$ Injector Concepts Final Technical Report," The Pennsylvania State University, Dec. 2001.

${ }^{118}$ Greene, C., Woodward, R., Pal, S., and Santoro, R., "Design and Study of a LOX/GH $\mathrm{G}_{2}$ Throttleable Swirl Injector for Rocket Applications," 38th JANNAF Combustion Subcommittee Meeting, CPIA-Publ-712-Vol-1, 2002. 


\section{Liquid-Propellant Rocket Engine Throttling: A Comprehensive Review}

Matt Casiano - NASA Marshall Space Flight Center

Jim Hulka - Jacobs Engineering, ESTS Group

Vigor Yang - Georgia Institute of Technology 


\section{Objective}

The Vision for Space Exploration outlined in the NASA Authorization Act of 2005 brought a renewed interest to throttleable liquid rocket engines (LREs).

- Throttling LREs can continuously follow the most economical thrust curve and are applicable to

- Planetary entry and descent

- Space rendezvous

- Orbital maneuvering (orientation and stabilization in space)

- Hovering / hazard avoidance

- Aircraft rocket engine control

- Ballistic missile defense trajectory control

- The primary objective is to review LRE throttling techniques and to examine the concerns and issues as well as compare the advantages and shortcomings. 


\section{Outline}

- LRE Throttling Background

- LRE Throttling Methods and Discussion of Selected Programs

- High-pressure-drop systems

- Dual-manifold injectors

- Gas injection

- Multiple chambers

- Pulse modulation

- Throat throttling

- Variable area injectors

- Hydrodynamically dissipative injectors

- Combined methods

- Summary 


\section{Throttling Background}

- Throttling - the nomenclature is used in variable thrust rocket engines primarily because one of the most common ways of thrust control is to regulate propellant flow using control valves

- Throttling ranges are mission dependent with higher throttling ratios for more precise trajectory control

- Thrust equation

$$
F_{T}=\dot{m} \cdot v_{e}+\left(p_{e}-p_{a}\right) \cdot A_{e}
$$

- Controllable physical parameters

- Propellant flow rates

- Propellant types and composition

- Nozzle exit area

- Nozzle throat area 


\section{Throttling Background (cont.)}

- Throttleable LREs originally developed in Germany in late 1930s

- Experiments and research led by Major-General Dr. Walter Dornberger (then Major) and Hellmuth Walter

- November, 1937 a Heinkel He 112 flew at Neuhardenberg, Germany and was the $1^{\text {st }}$ aircraft powered by a manually throttleable rocket engine

- Hellmuth Walter TP-1 rocket engine - 220 lbs rated thrust using a monopropellant hydrogen peroxide solution

- Throttling Critical Issues

- Combustion and system instabilities

- Performance degradation

- Excessive heat transfer

- Pump dynamics 


\section{High-pressure-drop Systems}

- Single, fixed-geometry injectors can generally throttle 2:1 to $3: 1$ with a nominal injector configuration and a typical injector pressure drop

- A higher-than-usual injector pressure drop is necessary to maintain a minimum injector pressure drop at minimum thrust for deep throttling

- Injector stiffness varies linearly with flowrate for liquid propellants

- $5 \% \Delta \mathrm{p} / \mathrm{p}_{\mathrm{c}}$ at $10 \%$ thrust requires $50 \% \Delta \mathrm{p} / \mathrm{p}_{\mathrm{c}}$ at $100 \%$ thrust

- Project Thumper - 1948, a General Electric program sponsored by the US Army to develop high-altitude antiaircraft ballistic missile defense against the German V-2 rockets

- One of the $1^{\text {st }}$ extensive deep throttling investigations

- High frequency combustion instability, chug, and hydraulic instabilities were present in the operational map as thrust was reduced

- Other well known engines/programs using high-pressure-drop systems

- DC-X and DC-XA, 1991

- RD-0120, 1996

- SSME, 1997

- CECE, 2005 


\section{High-pressure-drop Systems (cont.)}

- SSME, rated thrust $-470,000 \mathrm{lbs}, 1997$

- Throttled to $17 \%$ of rated thrust

- No issues, only a minor ox boost pump bistability at $50 \%$

- Concerns were mostly pump-related

- Rotordynamic stability

- Running at shaft critical speeds

- HPFTP thrust bearing to lift off

- Pump stall

- Ox boost pump bi-stability

- Pump performance

- $\quad$ CECE, rated thrust - 13,700 lbs, 2005

- Throttled to $8 \%$ of rated thrust

- Early onset of chug from oxygen boiling

- Insulated injector decreased the onset of chug to a lower power level

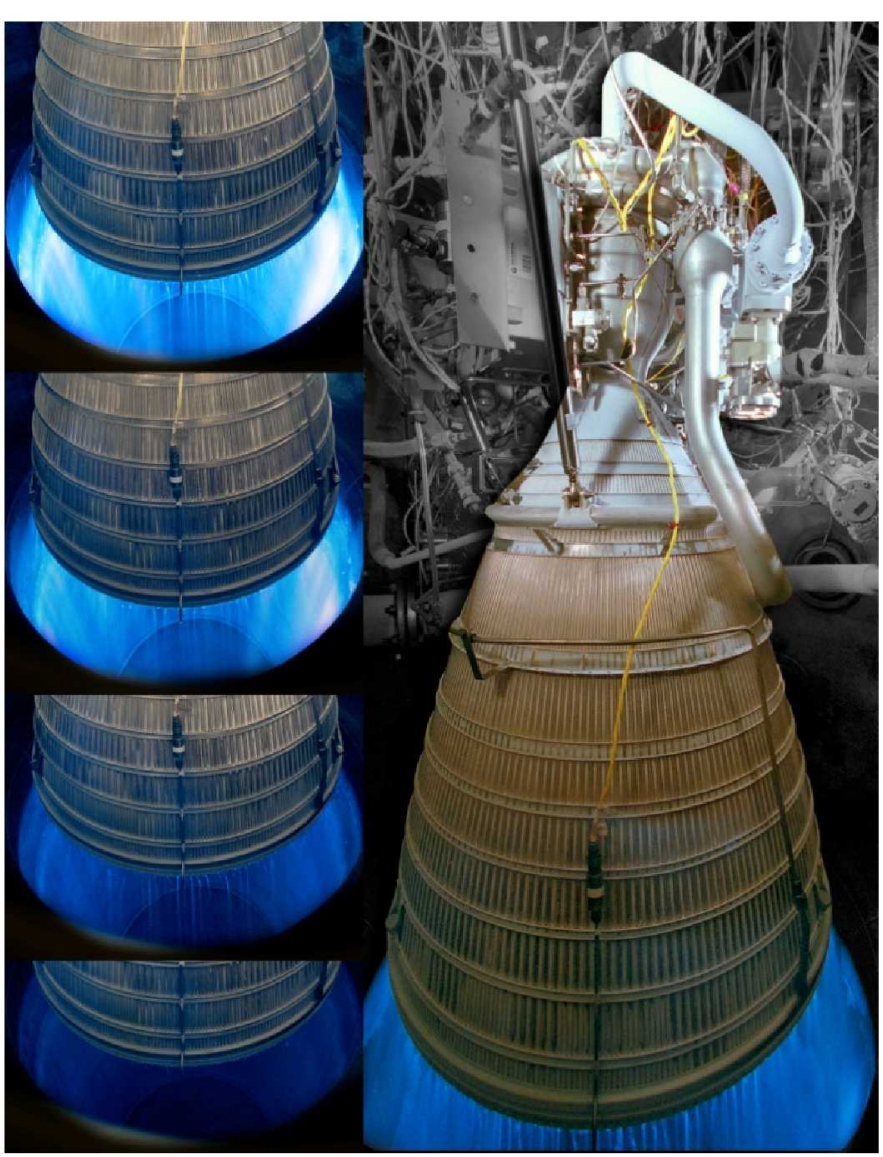

Common Extensible Cryogenic Engine (CECE) at Varying Thrust (2005) 


\section{Dual-manifold Injectors}

- Dual-manifold, two-stage, dual-element, dual-circuit, dual-orifice injector

- Dual-manifold injector is designed to maintain satisfactory injector pressure drop at low thrust while not requiring excessive pressure drop at full thrust

- Combines two fixed-area injectors into a common structure

- Independent flow control to each injector manifold

- Deep throttling is achieved by proceeding from two-manifold operation at high thrust to single-manifold operation at low thrust, thus changing the effective injection area

- All the flow transitions to the primary manifold at the predetermined transition point

- Transition point historically ranged between $20 \%$ and $50 \%$ of full flow

- Operating parameters must be optimized and still conform to system pressures

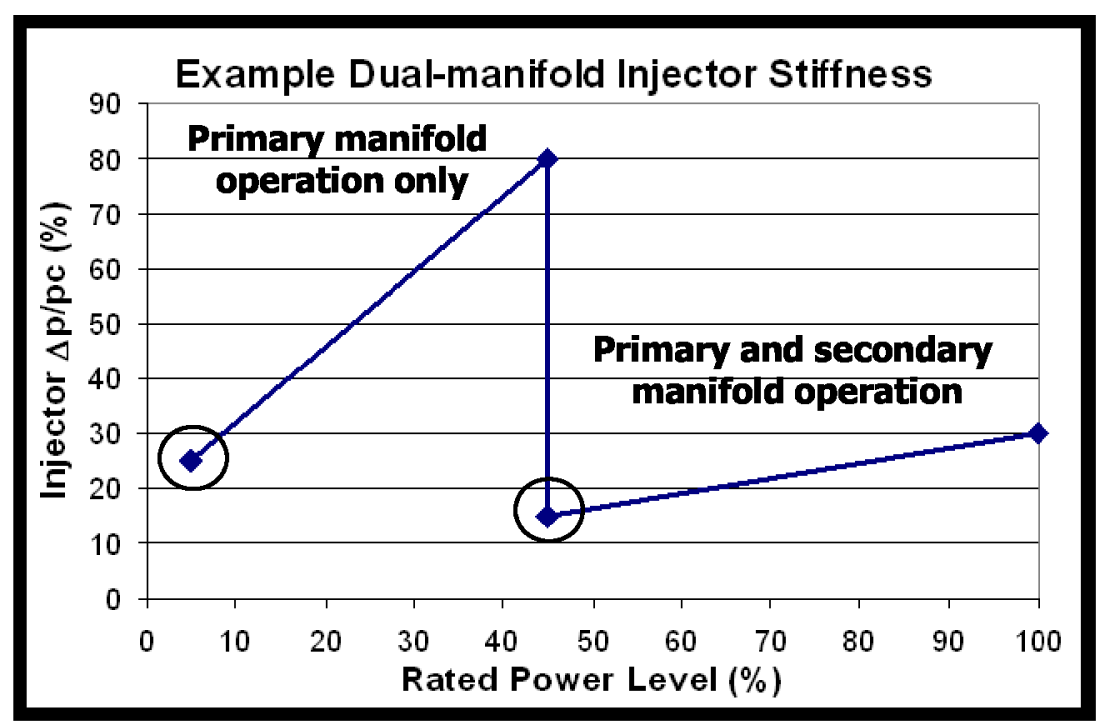

Example Dual-manifold Injector Stiffness 


\section{Dual-manifold Injectors (cont.)}

- Usually on the oxidizer side only

- The high injector pressure drop at low thrust provides better performance and improved stability margin

- No moving parts, additional control valves
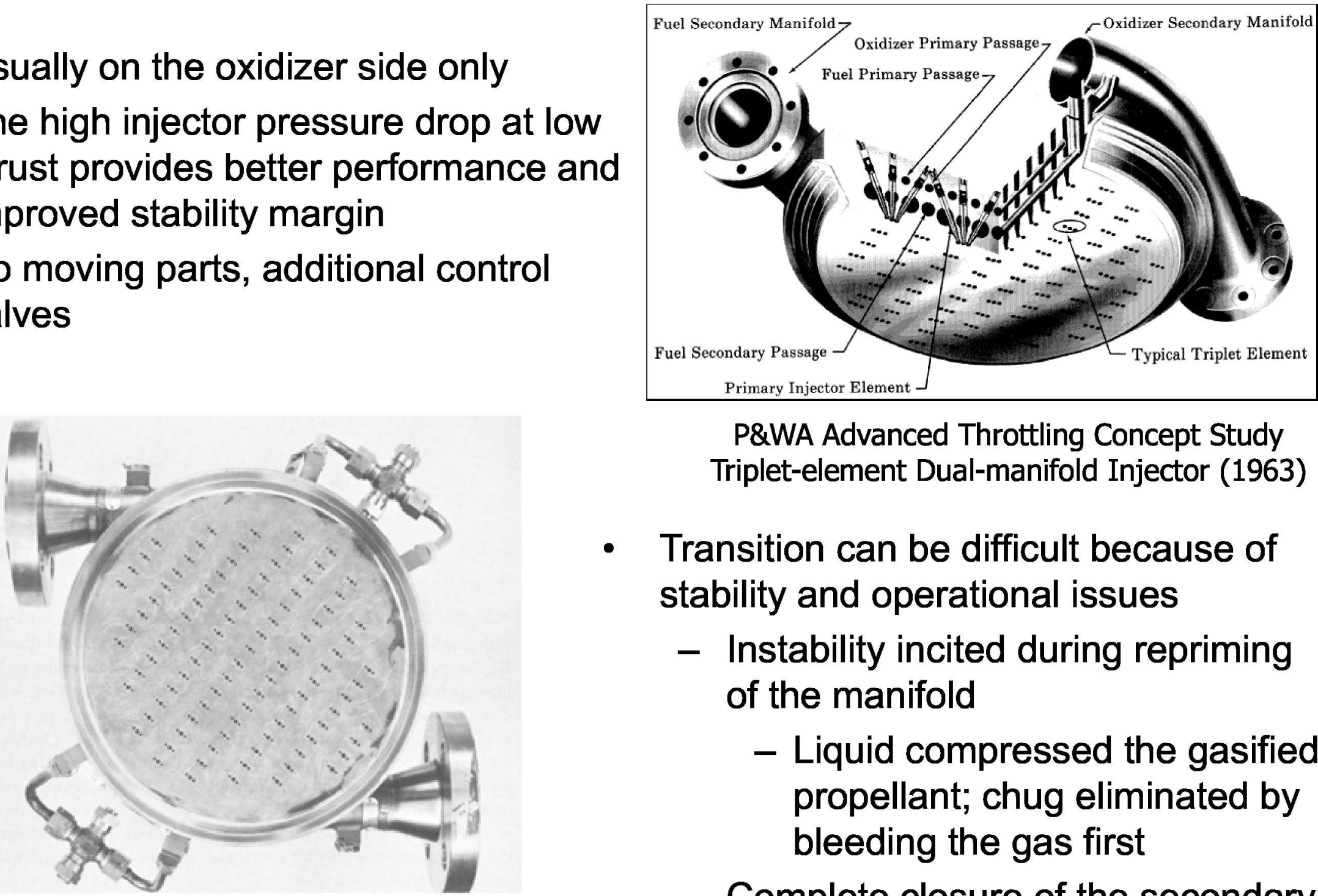

P\&WA Advanced Throttling Concept Study Triplet-element Dual-manifold Injector (1963)

- Transition can be difficult because of stability and operational issues

- Instability incited during repriming of the manifold

- Liquid compressed the gasified propellant; chug eliminated by bleeding the gas first

Triplet-element Dual-manifold Injector Hardware (1963)

- Complete closure of the secondary manifold can cause overheating and contamination with comb. gas 


\section{Dual-manifold Injectors (cont.)}

- Chamber Technology for Space Storable Propellants, rated thrust - 1000 lbs, 1964

- Rocketdyne research engine

- Thrust varied from $15 \%$ to $150 \%$ rated thrust with FLOX / storable fuel

- Transition at $49 \%$ thrust

- Peak performance at secondary manifold flow cutoff, high injection velocity

- System response delay occurred when throttling up due to the need to reprime the secondary manifold; continuous flow through secondary manifold proposed to reduce response time

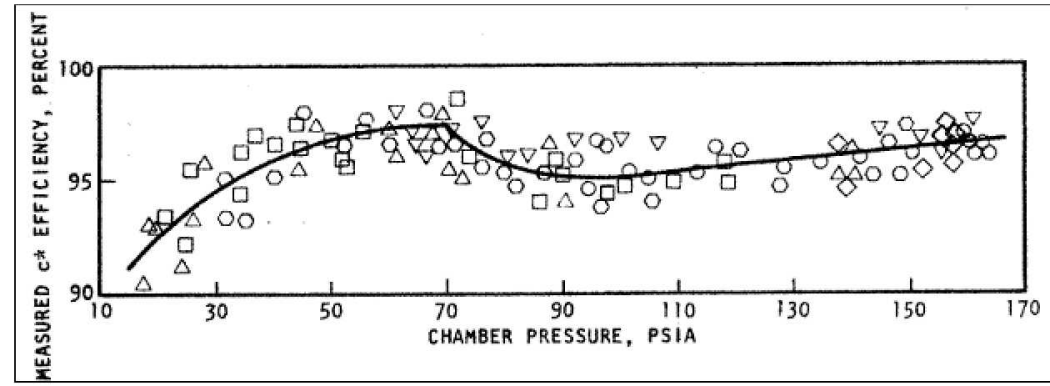

Dual-manifold throttling performance in Rocketdyne research engine, FLOX / MMH

- Other well-known programs

- XLR-129, 1967

- AETB, 1990 


\section{Gas Injection}

- Gas Injection, foamed flow, propellant aeration

- Gas injected into liquid propellant reduces the bulk density, and thus increases the injector pressure drop (while flow rate is essentially unchanged), and subsequently increases injector stiffness

$$
\dot{m}=C_{D} \cdot A_{j} \cdot \sqrt{2 \cdot \rho \cdot \Delta p}
$$

- Gas Injection comments

- Improves performance at low thrust by improving atomization

- Improves chug stability margin

- Usually this requires a weight penalty for the equipment

- Homogeneous gas injection to prevent low frequency instabilities

- Other well-known programs

- SE-10, 1963

- CECE, 2005 


\section{Multiple Chambers}

- Multiple chamber throttling is performed by stopping flow through one or more chambers or varying thrust of each chamber independently

- Can provide a deeper throttling by independently varying each chamber by a small amount

- Used on aerospike engines by coordinating banks of chambers

- Russians used multiple chambers for reasons other than throttling

- Manufacturability

- Combustion stability

- Engine-out reliability

- Multiple chambers do not provide optimum engine weight

- Other well-known engines

- RD-170, 1976-1986

- RD-180, 1992-1999

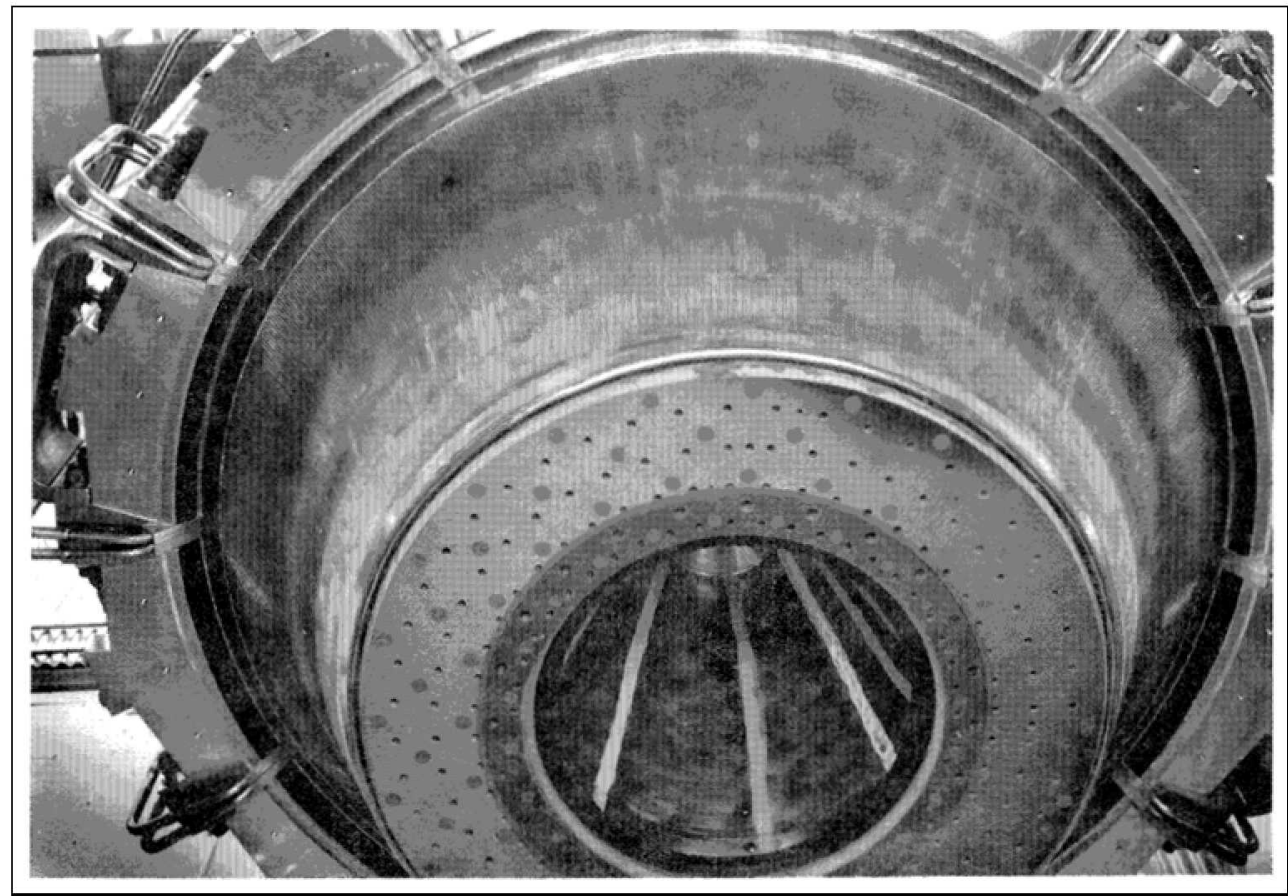

Rocketdyne Advanced Development Engine (1965) 


\section{Pulse Modulation}

- Pulse-width modulation is on-off cycling that provides quasi-steady state average thrust

- Predominantly used in monopropellant engines

- V-1 buzz bomb pulses at $100 \mathrm{~Hz}$

- Pulse detonation engines (PDEs) are a similar more recent technology

- Oxidizer and fuel mixture is supersonic at detonation

- Process is more efficient, but difficulties converting energy into efficient thrust

- Pulsing concerns and disadvantages

- Need fast response valving

- Performance is low due to transients

- Shock loading and heat soak into chamber head end

- Pulsing techniques

- Thrust interval is fixed, thrust magnitude is variable

- Thrust interval is variable, thrust magnitude is fixed

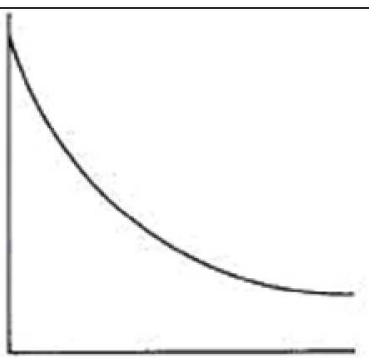

Thrust Program for a System

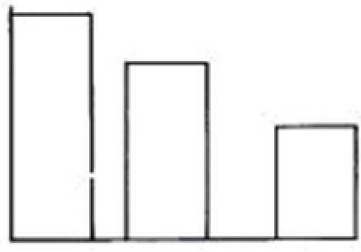

Approximation for which Thrust Interval is Fixed and Thrust is Variable

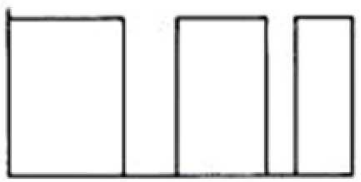

Approximation for which Thrust Magnitude is Fixed, but Duration is Variable 


\section{Pulse Modulation (cont.)}

- Bell Aerospace Lunar Flying Vehicle Study, rated thrust - 1000 lbs, 1964

- This engine pulses to obtain a range from $12 \%$ to $1 \%$ thrust

- Number of elements need to be optimized

- High enough performance

- Small enough manifold volume

- Performance is lower for a comparable steady state operating point

- Shorter duration

- Transient effects

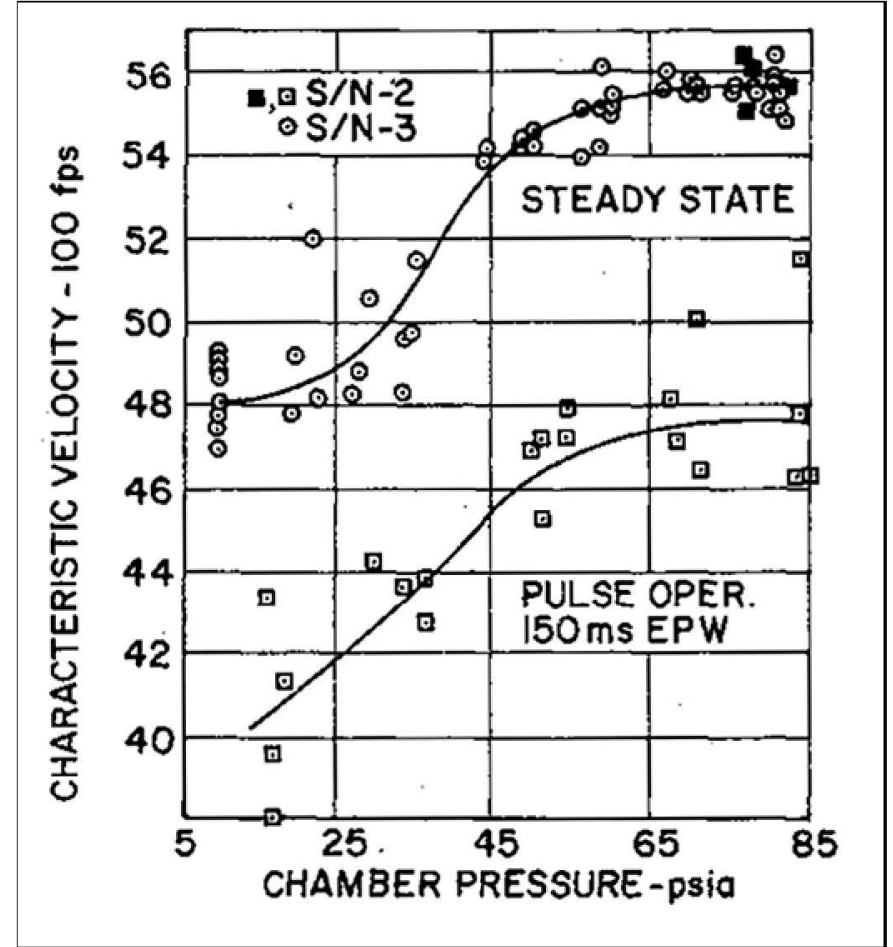

Bell model 8414

Throttleable Maneuvering Engine 


\section{Throat Throttling}

- Throat throttling achieved by two techniques

- Cooled mechanical pintle inserted and retracted through the nozzle throat region

- Gas injected into the throat

- At constant propellant pressures, the throat restriction increases the chamber pressure, which decreases the injector pressure drop and subsequently reduces propellant flow rates and thrust

- Chamber pressure increases as thrust is decreased

- Maximum theoretical performance occurs at lower thrust

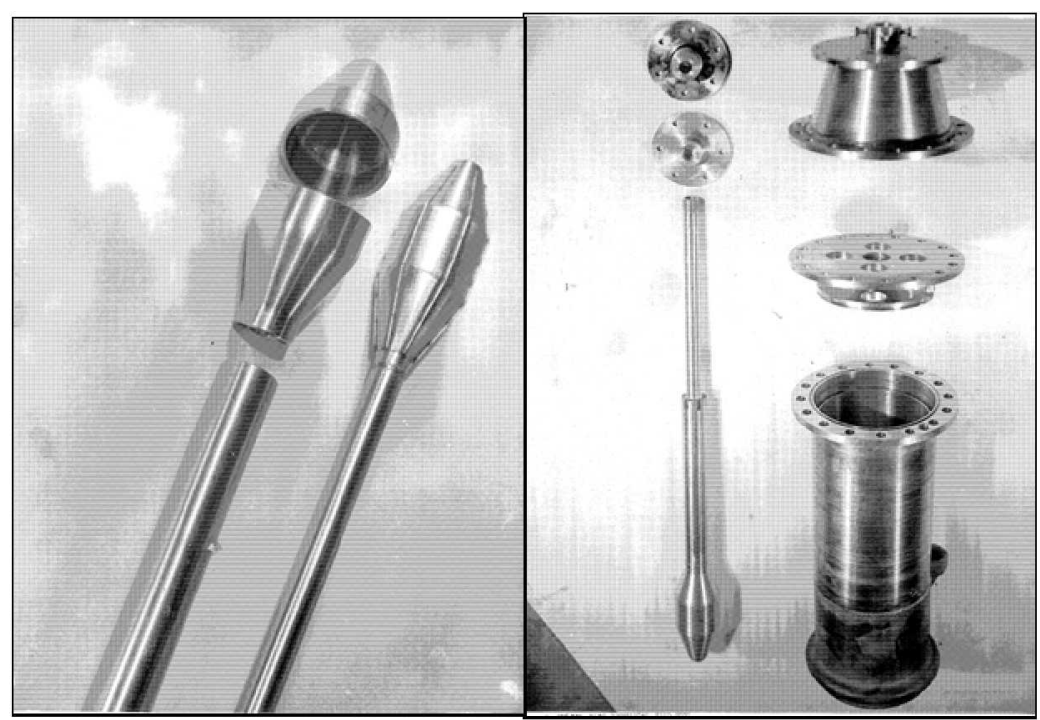

Reaction Motors, Inc. Restrictor Device 


\section{Throat Throttling (cont.)}

- General Concerns

- Combustion performance must be optimized since this method is characterized by a variable $L^{*}$

- Excessive heat transfer to the pintle device

- Excessive vibrations

- Need to optimize pintle shape - attributed to nozzle separation performance loss

- Injector design must provide high injection pressure drops at max thrust to maintain a minimum injector pressure drop at low thrust

- Gas injection into the throat is impractical for throttling

- Effectiveness dependent on stagnation temperature of injected gas, needs to be high temperature 


\section{Variable Area Injectors}

- Most well-known throttleable engine is the Apollo Lunar Module Descent Engine (LMDE)

- Maximum thrust occurs when the injection orifices are fully open; as the injection area is reduced using a movable injector component, the chamber pressure and thrust is reduced, and pressure drop is increased

- Majority of variable area injectors contain a single central pintle feature

- Generally there is a need for flow control valves in conjunction with the variable area injector for complete mixture ratio and throttling control

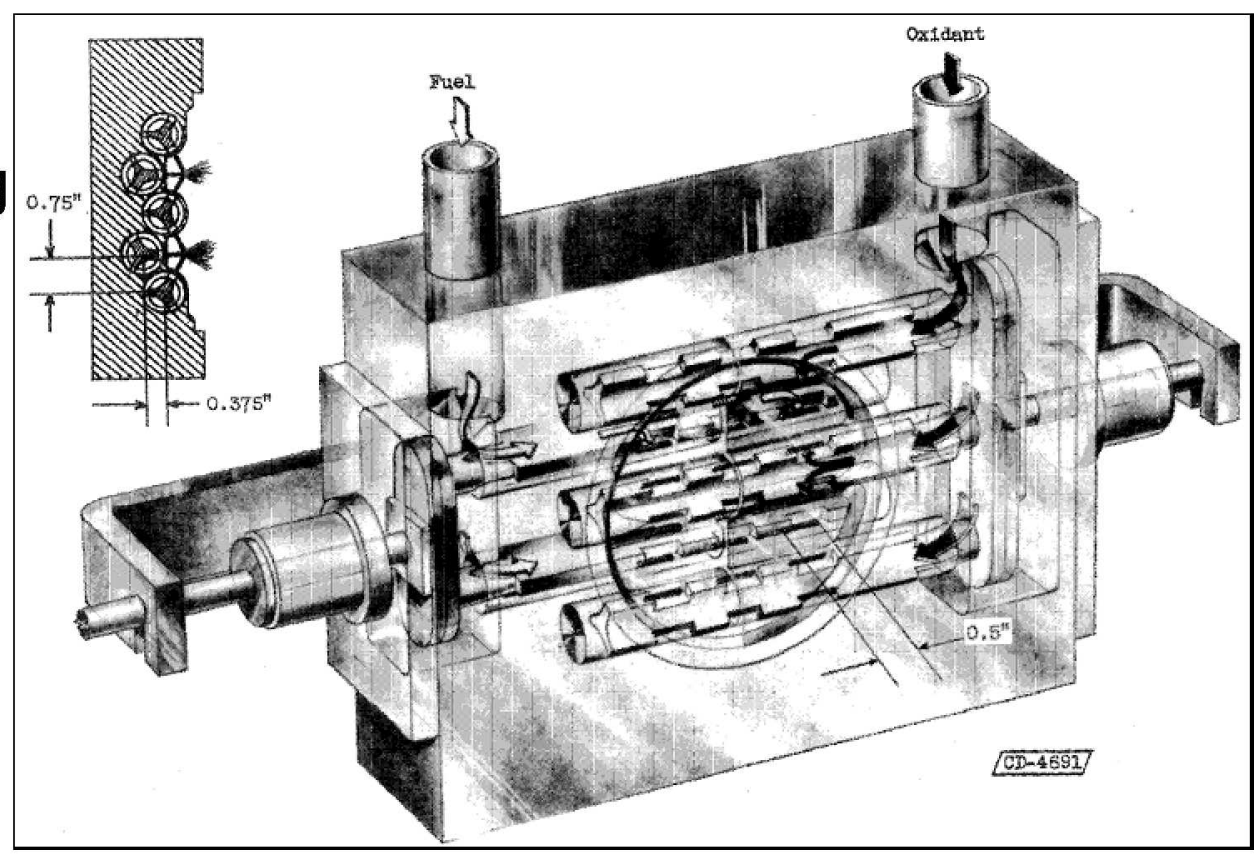

NACA Triplet Impinging Jet Variable Area Injector 


\section{Variable Area Injectors (cont.)}

- Variable area injector comments

- Design simplicity with some complexity in the actuating and guiding elements

- Leakage is one concern

- Higher injector pressure drop at lower thrust providing better atomization and stability margin at lower thrust

- Requires an optimization between performance and throttling since the better atomization occurs at lower thrust

- High frequency combustion stability is uncommon because of the central location of the injector element

- First tangential acoustic mode has a central nodal line; annular reaction zone helps with radial instability

- Encountered in an early study

- Other well-known engines

- LMDE, 1963

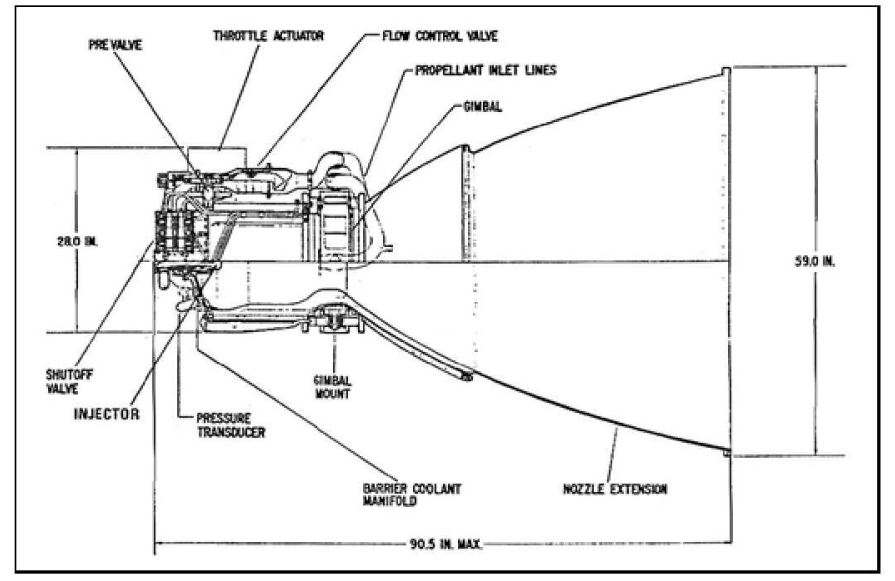

LMDE Schematic

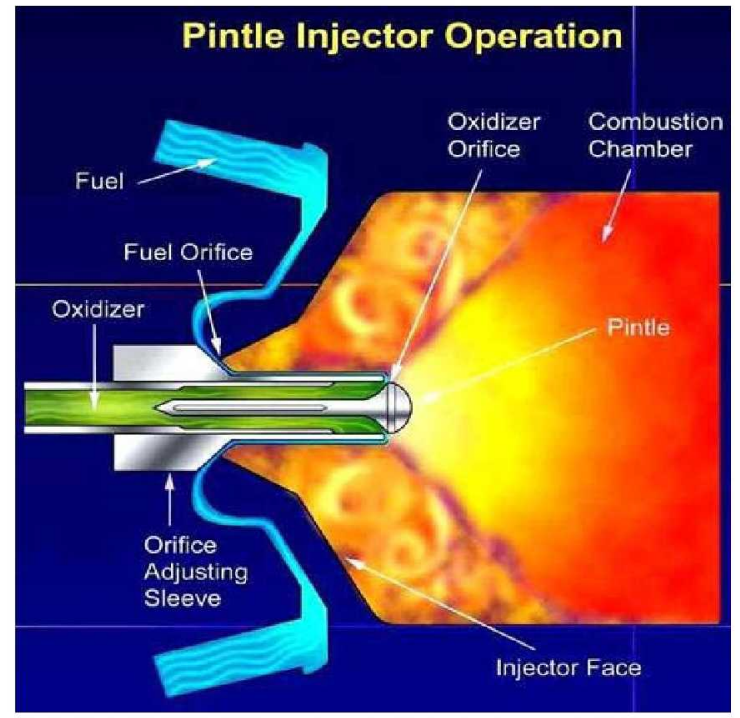

Pintle Injector Operation

- TR202, 2005 


\section{Variable Area Injectors (cont.)}

- LMDE

- Engine development began in 1963; man-rated by 1967

- Used first in Apollo 5 in unmanned configuration in Jan. 1968

- Used to return the astronauts of Apollo 13 to an earth orbit after an oxygen tank failure damaged the service module

- Starts to $10 \%$ during vehicle stabilization

- No high frequency combustion instabilities attributed to central location of the pintle element

- Low frequency instability with 20 psi peak-to-peak

- Fuel sleeve movement varied the injection area of both the fuel and oxidizer

- Cavitating throttling valves were incorporated to maintain flowrate belov ${ }_{(\mathrm{IBF})}^{\text {THRisT }}$ $70 \%$ thrust

- Injector orifice changes did not affect mixture ratio

- Eliminated large pressure loss penalties at higher thrust that would be present with high cavitating flow

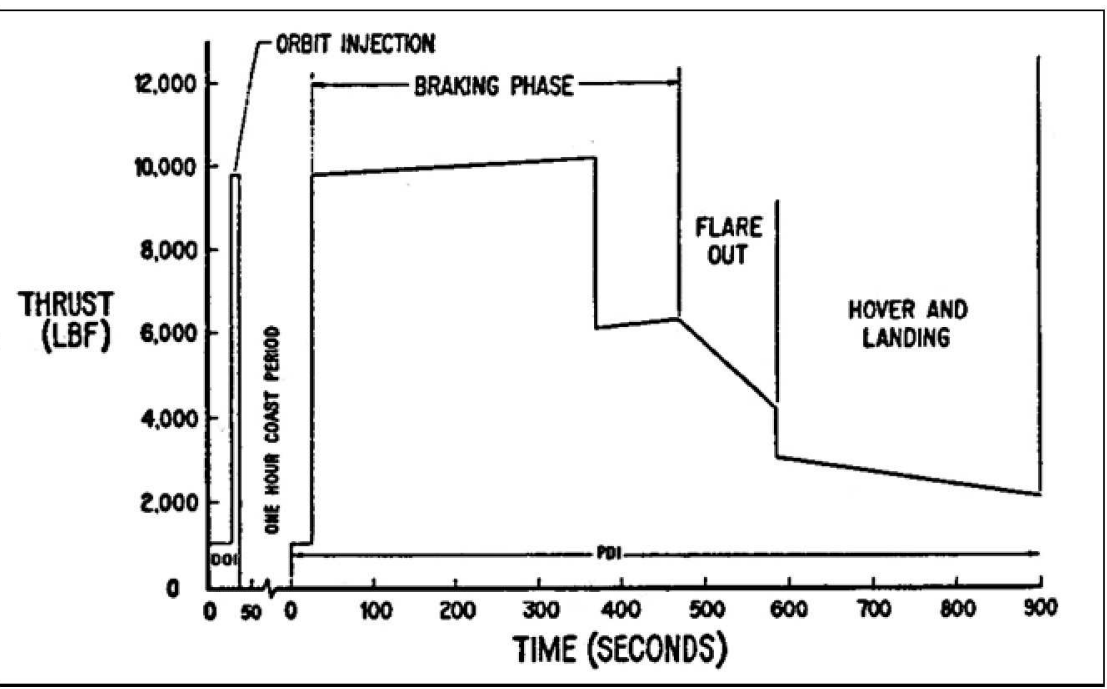

LMDE Nominal Duty Cycle 


\section{Hydrodynamically Dissipative Injectors}

- Use fluid dynamics to obtain adequate impedance across the injector

- Increased inertance by lengthening the elements

- Increased resistance by using capillary tube elements

- Effective control of the resistance by varying element hydraulics: variable discharge coefficient

- Usually a subset of other methodologies such as high-pressure-drop injectors or dual-manifold injectors

- Usually a simple design, but there is limited work in this area

- Professor Bazarov has applied classic swirl theory to dual-channel tangential orifice injectors

- Tangential-entry dual-inlet swirl injectors throttle by means of varying hydraulic conditions

- Using a dual-channel injector element: the pre-injection swirl flow can be managed such that a vortex forms inside the injector passages

- With the variation of flow to each inlet independently, the vortex and orifice conditions are affected - thus controlling the discharge coefficient

- Penn State has experimented with Bazarov's injectors over a 10:1 throttling range 


\section{Combined Methods}

- Combined methods allow an even deeper throttling by combining throttling methods

- Carry the advantages of two or more methods

- Usually adds complexity

- Generally all methods need flow control to some extent

- Some methods inherently are combined methods

- Variable area injector

- Dual-manifold injector

- Hydrodynamically dissipative injectors

- Bell Aerospace had combined high-pressure-drop injector with pulsing

- 100-to-1 throttling achieved

- Pratt \& Whitney Aircraft combined a constant area injector with a variable area injector

- At low thrust, a variable area injector maintained enough pressure drop

- At higher thrust, a constant area injector allowed increasing pressure drop

- Reasonable pressure drop over a wide range while providing enough stiffness at high thrust to prevent low frequency instabilities 


\section{Summary}

- Throttling critical issues

- Combustion and system instabilities

- Performance degradation

- Excessive heat transfer

- Pump dynamics

- Throttling Methods

- High-pressure-drop systems

- Dual-manifold injectors

- Gas injection

- Multiple chambers

- Pulse modulation

- Throat throttling

- Variable area injectors

- Hydrodynamically dissipative injectors

- Combined methods 